\title{
SUBSTRATE CURVATURE MEASUREMENT SYSTEM
}

\author{
Ben Groenewald
}

Supervisor : Dr J Tapson

\section{Department of Electrical Engineering University of Cape Town}

A dissertation submitted to the University of Cape Town in partial fulfilment of the requirements of the degree of Master of Science (MSc) in Electrical Engineering, Cape TownJune 1999. 
The copyright of this thesis vests in the author. No quotation from it or information derived from it is to be published without full acknowledgement of the source. The thesis is to be used for private study or noncommercial research purposes only.

Published by the University of Cape Town (UCT) in terms of the non-exclusive license granted to UCT by the author. 
Various techniques of curvature measurement have been developed and employed in the past. Most of these techniques provided fairly accurate and reliable results, but all suffered certain drawbacks and limitations. One of the major drawbacks of the techniques employed are the possible errors that could be induced due to the use of a moving furnace or hot stage construction. In cases where this drawback was eliminated it resulted in techniques where the optical scan system moved. This solution shifted the focus of possible errors from the moving furnace to the optical scan system. Similar possible errors were still experienced, but now it was transferred to the optical scan path. None of these techniques utilized a 2-dimensional scanning technique with an error feedback loop to minimize possible system induced errors.

It is with these drawbacks, and possible improvements in mind that we set out to develop an electro-optical system for measuring the curvature of coated wafer substrates. The system will embody the successful principles of previous systems while incorporating capabilities that will provide improved stability with the minimum number of moving components while performing in situ measurements. Further aims are to provide a 2-dimensional scan of any surface under test, while maintaining a high data collection and scan speed. Ultimately the system should be capable of producing positional accuracies in radius of curvature (ROC) in excess of $10 \mathrm{~km}$ through the application of a system error feedback loop. 


\section{ABSTRACT}

Industry often requires, in a variety of processes, the measurement of deformation induced in a solid object by mechanical stress. One such process is during the manufacture of very large scale integrated circuits (VLSI). During this process a substrate is coated with a thin film to protect the micro circuitry formed on the substrate. Due to the differences in thermal expansions between film and substrate, mechanical stresses can develop which may lead to deformation of the substrate surface. Any deformation of the substrate surface will result in mechanical stress in the interconnections of the circuitry, which could result in severe damage to the operation of the circuit.

Different measurement techniques are available to measure the spherical deformation of substrates, with the latest known technique being a combination of a laser beam deflection and light scattering techniques. Many of the existing techniques reveal shortcomings, one of which is a 2-dimensional scanning capability with a minimum of moving components. Another shortcoming is the incapability of previous techniques to calculate the relative error which the measuring technique induces into the results. The aim of this study has been to develop an electro-optical system embodying the successful principles of these techniques in a system which will eliminate the shortcomings and produce results in excess of those previously recorded.

In this work, we have concentrated on discussing the development of a system which will produce in situ real time monitoring of mechanical stresses in a solid. The system includes the minimization of system induced errors through the calculation of error voltage gains, and the introduction of a 2-dimensional scanning capability to determine the true position of the laser beam without prior knowledge of the initial substrate curvature. A four-quadrant position sensitive detector (PSD) with relevant LabView software and programs were also introduced into the system. 
This project has investigated the capabilities of a 2-dimensional substrate measurement scanning system with a system error feedback loop. Factors affecting the design of this system were examined and a theoretical analysis of aspects of its operation has been performed. Various applications for this system have been identified; the measurement of mechanical stress in a solid object being the primary concern. In all the test runs performed this system has shown advantages over previous systems. Experimental results have revealed a high degree of system sensitivity, well below $1 \mu \mathrm{m}$. Results also showed that positional inaccuracy can be reduced through the calculation of error voltages; this can be achieved before measurement if the system is pre-calibrated. Results proved that the accuracy of the system is not limited by the $1 \mu \mathrm{m}$ stage position resolution, as long as the sub-micron error can be determined from the PSD error. 
This thesis is dedicated to my wife

Gillian and my two children, Chantal and Jonathan

for all their support, understanding and love.

\section{ACKNOWLEDGEMENTS}

The author would like to thank Dr J. Tapson for his helpful and inspirational supervision, his belief in his fellow man and his unquestionable integrity. Dr B.J.P. Mortimer is acknowledged for his advice and input on laser technology. Mr Q. Smit is thanked for his continuous support, technical advice, Mr A.B. Hoosain and Mr I. Khan for their help with the hardware construction, and the School of Mechanical Engineering, Cape Technikon for the manufacture of the clamps and jigs during the experimental stages. Many thanks to all staff and students at The School of Electrical Engineering, Cape Technikon who all contributed to an enjoyable working environment.

This project formed part of a co-operative program between the Instrumentation Research group at University of Cape Town and the Department of Materials Science and Engineering at the Johns Hopkins University, Baltimore, USA. The help and co-operation of Dr A.B. Mann and Professor Tim Weihs is gratefully acknowledged. Financial support was received from the US Air Force Office of Scientific Research. 


\section{TABLE OF CONTENTS}

CHAPTER 1: $\ldots \ldots \ldots \ldots \ldots \ldots \ldots \ldots \ldots \ldots \ldots \ldots \ldots \ldots \ldots \ldots \ldots$

INTRODUCTION $\ldots \ldots \ldots \ldots \ldots \ldots \ldots \ldots \ldots \ldots \ldots \ldots \ldots \ldots \ldots \ldots$

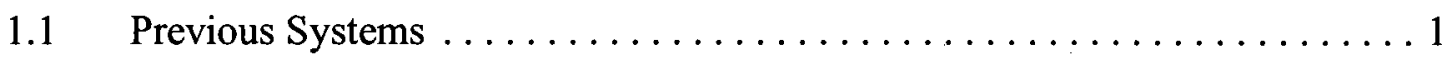

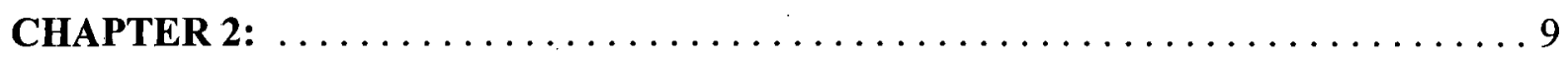

PRINCIPLES OF THE CURRENT WORK $\ldots \ldots \ldots \ldots \ldots \ldots \ldots \ldots$

$2.1 \quad$ Position Sensing Detector (PSD) $\ldots \ldots \ldots \ldots \ldots \ldots \ldots \ldots \ldots \ldots \ldots$

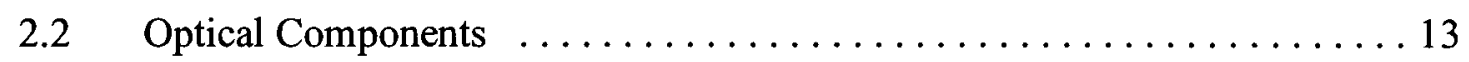

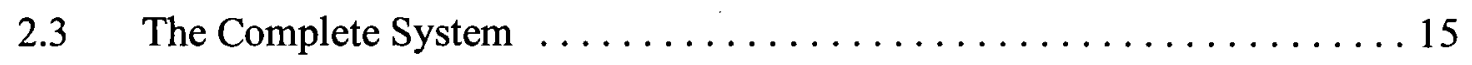

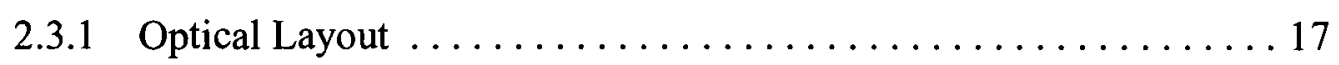

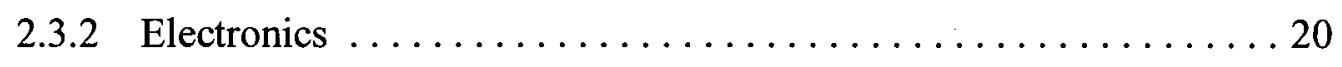

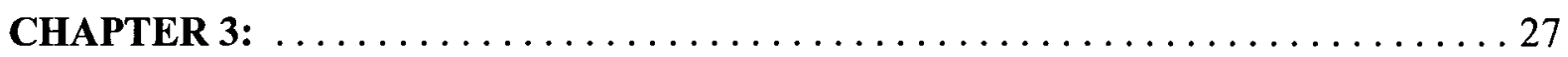

SYSTEM SOFTWARE AND OPERATION $\ldots \ldots \ldots \ldots \ldots \ldots \ldots \ldots \ldots$

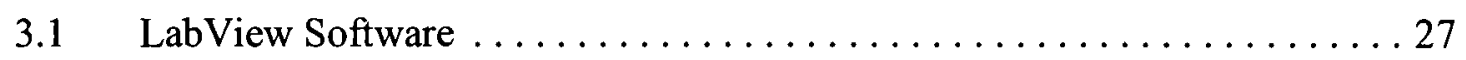

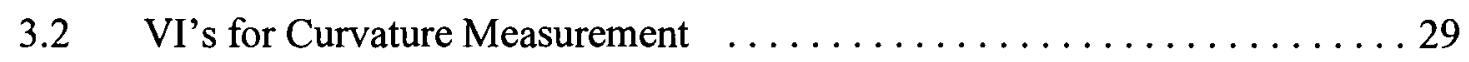

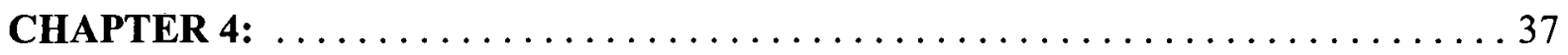

SYSTEM EVALUATION AND EXPERIMENTAL RESULTS . . . . . . . . . 37

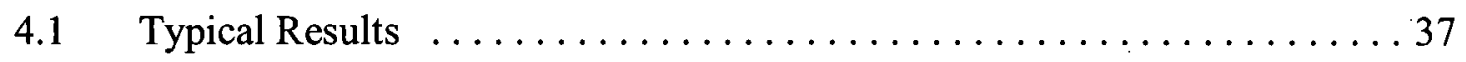

4.1 .1 System Evaluation $\ldots \ldots \ldots \ldots \ldots \ldots \ldots \ldots \ldots \ldots \ldots \ldots \ldots \ldots \ldots \ldots$

4.1 .2 Experimental Results $\ldots \ldots \ldots \ldots \ldots \ldots \ldots \ldots \ldots \ldots \ldots \ldots \ldots$ 
4.2 Reduction of Position Inaccuracy using Error Voltage $\ldots \ldots \ldots \ldots \ldots 4$

4.2.1 Error voltage scan procedure . . . . . . . . . . . . 44

4.2 .2 Mirror Calibration Scan . . . . . . . . . . . . . 45

4.2 .3 Calculating Error Voltage Gain . . . . . . . . . . . 48

4.2.4 Chamber Window Calibration . . . . . . . . . . . . . . . 49

4.2.5 Substrate Calibration Scan $\ldots \ldots \ldots \ldots \ldots \ldots \ldots \ldots \ldots \ldots \ldots \ldots \ldots \ldots$

4.3 Analysis of Results using Error Voltage $\ldots \ldots \ldots \ldots \ldots \ldots \ldots \ldots \ldots \ldots \ldots \ldots$

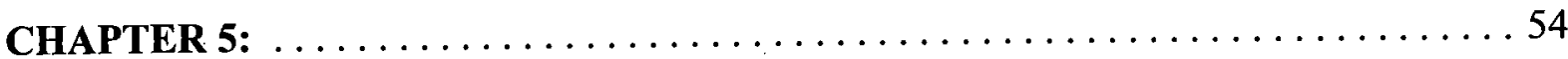

CONCLUSIONS AND RECOMMENDATIONS $\ldots \ldots \ldots \ldots \ldots \ldots \ldots \ldots$

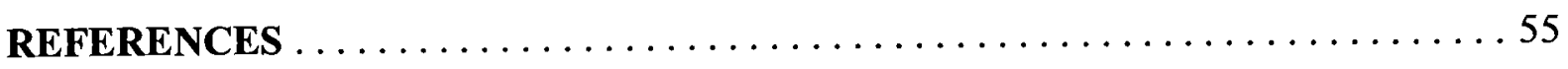

\section{APPENDICES}

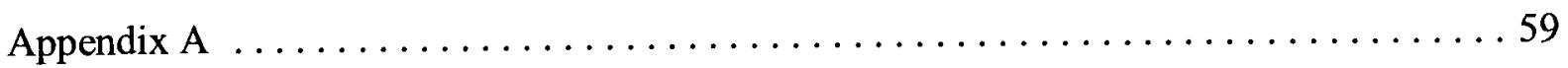

Overall system construction

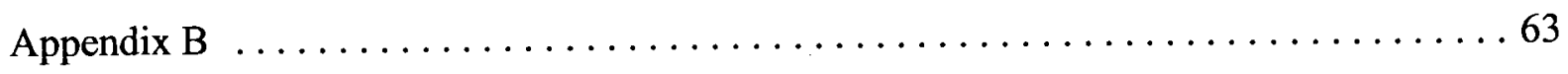

System interconnections

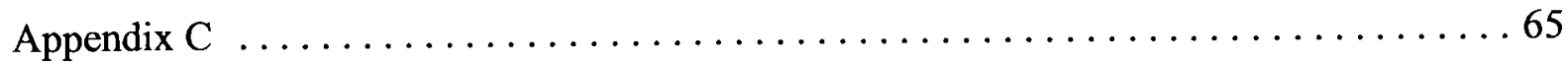

DC motor characteristics

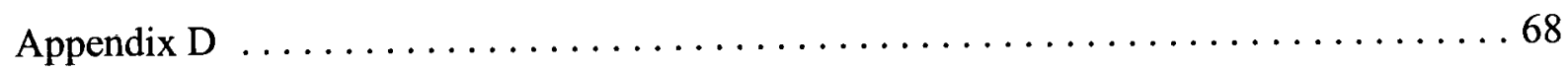

PSD data sheets

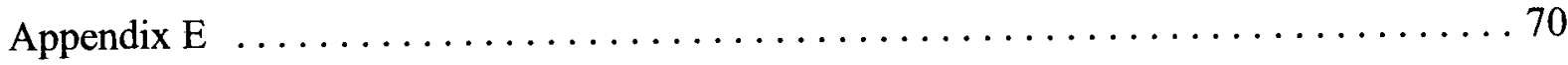

Mathematical proof of flux distribution 
Appendix F

Subcurve VI - Front panel and Block diagrams 


\section{SUBSTRATE CURVATURE MEASUREMENT SYSTEM}

\section{CHAPTER 1:}

\section{INTRODUCTION}

Measurement of the deformation induced in a solid object by mechanical stress is a basic requirement in many processes. An example of such a situation is during the manufacture of very large scale integrated circuits (VLSI) where it is important that the substrate surface retain its original form. Any deformation of the substrate surface will result in mechanical stress in the interconnections of the circuitry, which could result in malfunction in the operation of the circuit. These deformations can cause short circuits due to hillocks and open circuits from metal cracking and voiding. Various techniques have been employed to measure deformities in substrates, all with certain drawbacks ' ${ }^{1}$. M. E. Thomas et al. ${ }^{1} 1988$, refers to the many techniques tabulated in L. I. Maissel and R. Glang's "Handbook of Thin Film Technology" 2 Subsequent research on this topic is reflected in the papers of G.J. Leusink et al. ${ }^{3}$, JoonWon Choe et al. ${ }^{4}$, and Carina Kylner and Lars Mattson ${ }^{5}$. In the research of Leusink et al. ${ }^{3}$ and JoonWon Choe et al. ${ }^{4}$ measurements on the curvature of substrates were obtained through the use of dual beam systems. These systems are fairly complex and require intricate set-up procedures.

In this dissertation we strive to produce a substrate curvature measurement system that will combine the technologies used in the past to reduce the majority of drawbacks and at the same time provide a system which is flexible, easy to set up and to provide accuracy which is in excess of previous results.

\subsection{Previous Systems}

In this section, previous systems for measuring curvature of substrates are described. In many cases, these systems facilitate temperature cycling under ultra-high vacuum, which is also a 
requirement in the present case. The system used by A. K. Sinha et al. $1978^{6}$, an optical lever deflection technique, is shown in Figure 1. The film stress in this research was deduced from the change in curvature induced in the Si substrate due to the deposited film. The wafer was placed on a horizontal hot stage $\left(25-500^{\circ} \mathrm{C}\right)$ enclosed in a housing to minimize the convection currents. The substrate temperature was calibrated against the apparent value displayed by the controlling thermocouple, using a thermocouple glued to the test wafer.

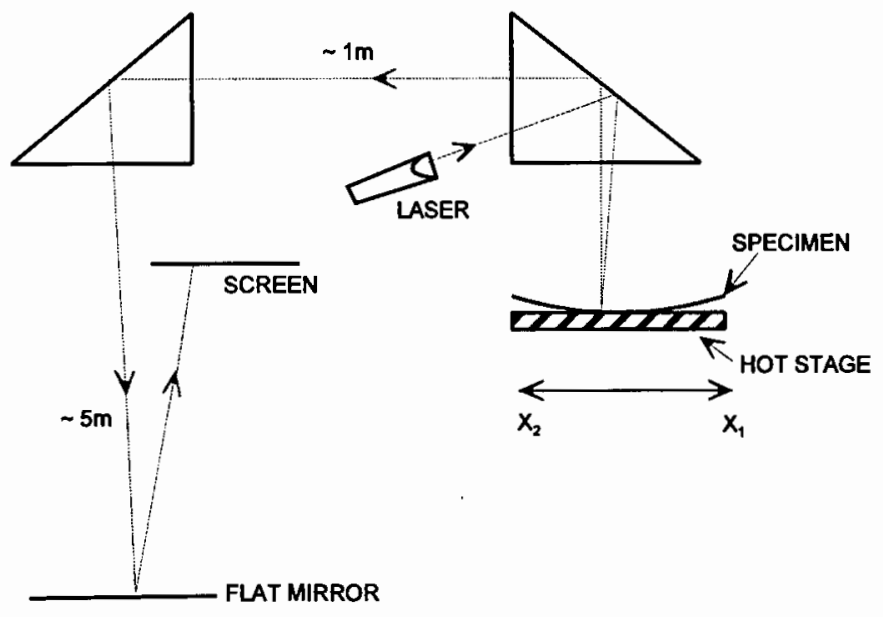

Figure 1: Schematic of apparatus for wafer curvature measurements $\left(25-500^{\circ} \mathrm{C}\right)^{6}$.

The radius of curvature, $\mathrm{R}$ of the wafer, was calculated using the following equation

$$
R=2 L(\Delta x / \Delta d)
$$

were $\Delta x$ is the translation of the specimen, $\Delta d$ is the resulting translation of the reflected beam, and $L$ was confirmed by curvature measurements on standard mirrors. No detail regarding the measurements of the travel distance (L) of the reflected beam, the translation $\Delta x$ of the specimen or the translation $\Delta d$ of the reflected beam was stated. No mention of the accuracies obtained during this research is made. It is also not clear how the hot stage is moved across the laser beam path, and whether the laser beam is fixed or not. The apparent disadvantages of this system are the relatively long optical path needed to carry out the measurements to determine the radius of curvature, the fact that it is not an automatic process and the omission of the accuracies with which the change in curvature were measured. 
In 1984 J. T. Pan and Ilan Blech ${ }^{7}$ used a system manufactured by United Detector Technology in Culver City, California to do in situ stress measurements of refractory metal silicides during sintering. They constructed an experimental apparatus (Figure 1) to measure thin film stress in situ in a controlled gas at temperatures above $900{ }^{\circ} \mathrm{C}$. This equipment was used to measure silicide film stress during heating in an inert gas from room temperature to greater than $900{ }^{\circ} \mathrm{C}$ and during cooling to room temperature. The wafer was placed in a vertical quartz furnace tube in a resistively heated furnace. The He-Ne laser beam and positioning sensing device are both

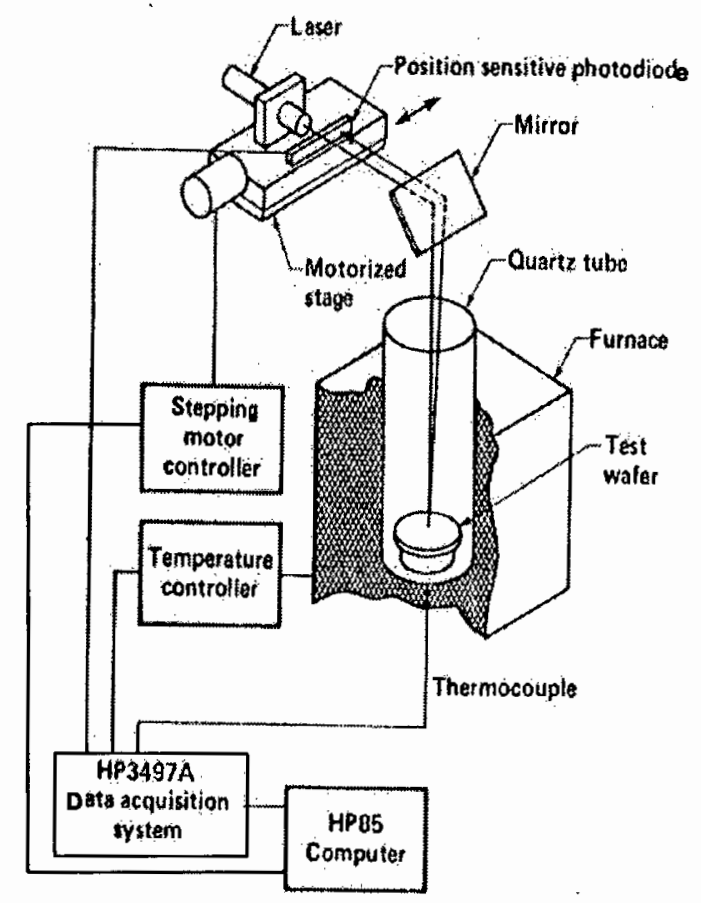

Figure 2: Schematic of the stress measurement apparatus used by Pan and Blech ${ }^{7}$.

mounted on a motorized stage. The laser beam was reflected from a mirror down to the wafer surface in the quartz furnace tube through a tube cover fitted with an optical flat top. The beam reflected from the wafer surface was reflected from the same mirror into the position sensing device. The sensing device they used was a silicon photo detector with simultaneous signal outputs for the light intensity of the beam, and the beam position of the reflected laser beam. An HP85 computer was used to control the furnace temperature and the motorized stage, and record the reflected beam position, the light intensity, and the furnace temperature (measured 
by a thermocouple inside the quartz tube). The film stress was measured by moving the laser beam for a $50 \mathrm{~mm}$ span across the wafer surface while the computer recorded readings on the light intensity and the beam position at $5 \mathrm{~mm}$ intervals. The wafer curvature and film stress were then calculated from the change of the reflected beam position as a function of the beam position on the wafer surface. They then compared their results with studies done by Retajczyk and Sinha ${ }^{8}$ on "Elastic Stiffness and Thermal Expansion Coefficients of Various Refractory Silicides and Silicon Nitride Films". The results obtained by Pan and Blech ${ }^{7}$ on the $\mathrm{TaSi}_{2}$ stress measurements did not compare too well to those of Retajczyk and Sinha ${ }^{8}$ due to slope differences on the substrates. Similar results were however obtained to those of Retajczyk and Sinha ${ }^{8}$ during the stress measurements done on the $\mathrm{TiSi}_{2}$ film. An apparent disadvantage of this system is that the whole optical scan system moved, which could reduce stability, and it only produced a one dimensional scan of the surface.

In 1987 Paul A. Flinn et al. ${ }^{9}$ produced a curvature measurement system based on laser scanning of the surface under test by means of a rotating mirror. This system, shown in Figure 3, had the advantage that the majority of the components were fixed. The only moving object is the galvanometer-driven mirror which produced a forward and backward scan of the surface under test. The galvanometer-driven mirror provides a rapid scan in angle; it is directed by the long focal length lens into a linear scan across the wafer. The position of the reflected beam in the focal plane of the lens depends only on the angle of the reflected light relative to the optical axis. The change in displacement of the reflected beam is proportional to the change in the angle between the incident laser beam and the wafer surface; it is therefore a derivative measuring device. If a perfectly flat wafer is scanned, the reflected spot at the detector is stationary. The motion of the reflected spot in the focal plane of the lens is measured with a position sensitive photodiode. This may be considered as a sheet of uniform resistivity with a current source at the position of the light spot. The current is thus divided between the connections at the edges of the detector inversely as the distances from the spot to the edges. The position of the spot is then calculated as the ratio of the difference of these two currents to their sum; variations in light intensity affect numerator and denominator equally and do not change the result. P. A Flinn et al. ${ }^{9}$ record that for the actual measurement, the currents are amplified, converted to digital form, and entered into the computer. The precision of the 


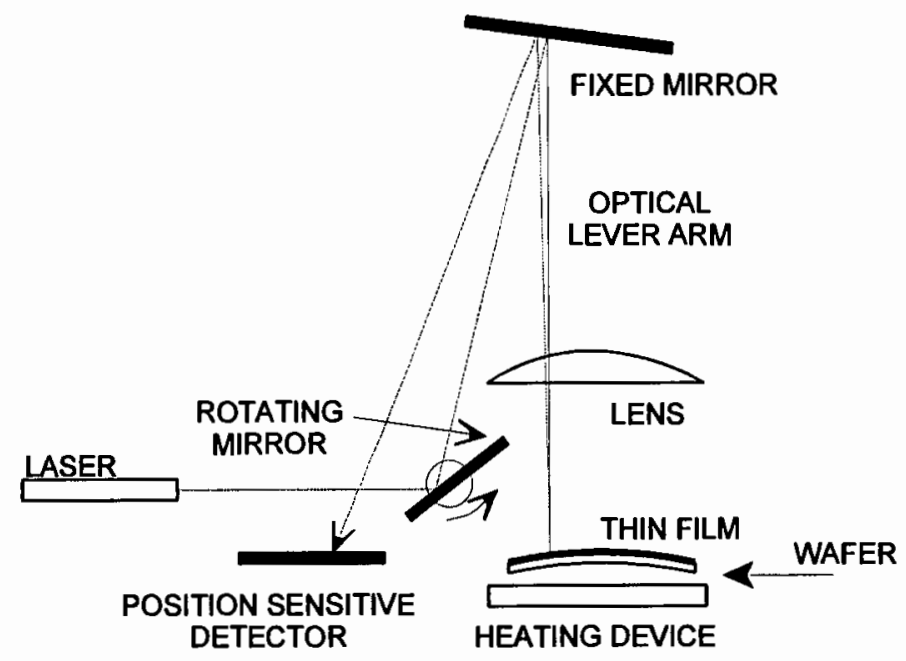

Figure 3: Diagram of stress measuring apparatus used by P. A. Flinn et al. ${ }^{9}$.

current measurement, determined by the resolution of the digital to analog converter, is 1 part in $2^{12}$; after the arithmetic, the precision is about 1 part in $2^{11}$. Since the width is $\pm 1 \mathrm{~cm}$, the position sensitivity is about $5 \mu \mathrm{m}$. For a sample of $100 \mathrm{~mm}$ diameter they achieved a radius of curvature of $40 \mathrm{~km}$. The disadvantages of this system are that it is one dimensional and has a relatively long optical path to provide for the focal length of the lens $( \pm 1 \mathrm{~m})$.

In 1992 G. J. Leusink et al. ${ }^{3}$ published in their paper an improved version of Flinn's rotating mirror concept. Using their dual parallel laser beam technique, (Figures 4 and 5) they achieved a sensitivity of $6.5 \mathrm{~km}^{-1}$ compared to $150 \mathrm{~m}^{-1}$ achieved by Flinn et al. ${ }^{8}$. During their research, based on the work done by Flinn et al. ${ }^{9}$ and Teal and Murarka ${ }^{10}$, Leusink et al. ${ }^{3}$ incorporated a hollow mirror in the light path of the laser beams between wafer and detector. The parallel laser beams are aimed at the wafer in such a way that the beams are reflected at positions on the wafer equidistant from the centre of the wafer. Due to the curvature of the wafer, which was assumed to be spherical, the laser beams are deflected at an angle $\gamma$. The stress was now determined by measuring the angle $\gamma$. Leusink et al. ${ }^{3}$ reported that the insertion of the hollow mirror caused the laser beams to cover several times the focal length of the hollow mirror making it possible to measure the curvature of the wafer with a high sensitivity, because the displacement of the laser spots on the detector has become more sensitive to the curvature of 


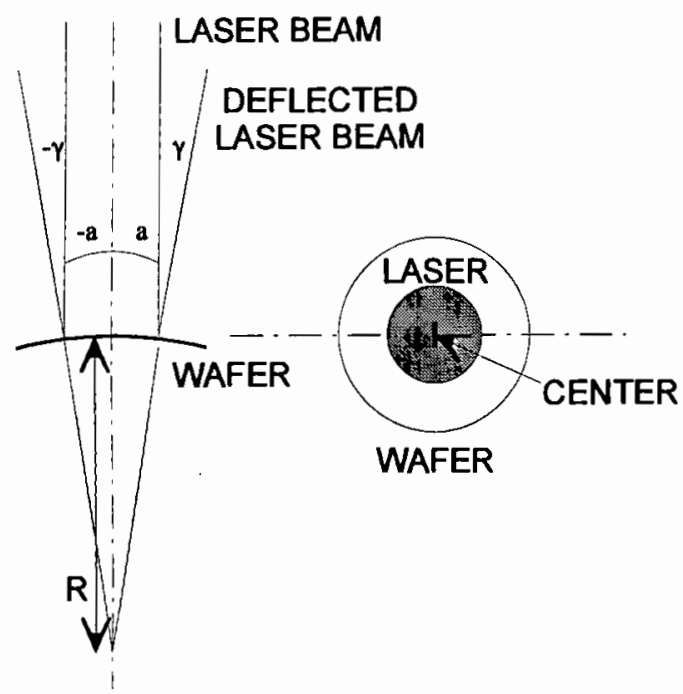

Figure 4: Positions on which the laser beams are reflected and the centre of the wafer are on a line. The angle of deflection as a function of distance between the laser beams and radius of curvature of wafer. G. J. Leusink et al. ${ }^{3}$.

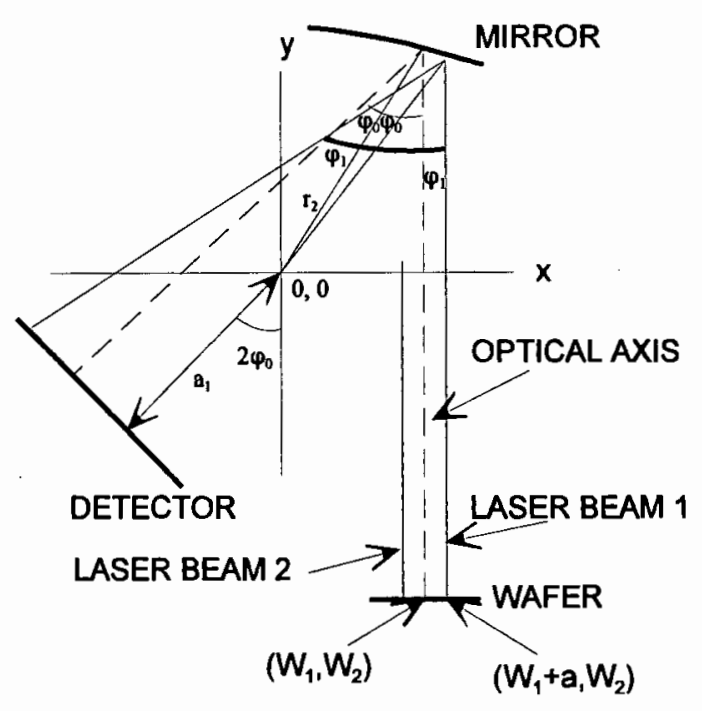

Figure 5: General view of the optical components in the coordinate system used to calculate the spot displacement as a function of wafer curvature. $G$. J. Leusink et al. ${ }^{3}$.

the wafer. Each laser spot is detected by a spot follower consisting of two photocells. Each spot follower was then mounted on one of the carriers of a chart recorder. The position of the carriers are controlled by the applied voltage. The spot follower moves in the direction of the photocell with the higher signal, and remains in position when both photocells are illuminated with equal intensity. The distance between the spot followers is determined from the difference between the voltages necessary to keep the two carriers in position. This voltage was monitored by a computer. The carriers are allowed to travel $\sim 300 \mathrm{~mm}$; the distance was then measured to an accuracy of $0.16 \mathrm{~mm}$. The data were then expressed as a function of the angle of deflection, using a coordinate system whose origins coincide with the centre of curvature of the hollow mirror (see Figure 5). Their calculations suggested a sensitivity of $6.5 \mathrm{~km}^{-1}$ (or a maximum radius of curvature of $6.5 \mathrm{~km}$ ). Leusink et al. ${ }^{3}$ make no mention of whether they manage to minimize or eliminate the factors that influenced the accuracy of the experiment experienced by Teal and Murarka ${ }^{10}$ during their work on "Stresses in $\mathrm{TaSi}_{\mathrm{x}}$ films sputter deposited on polycrystalline silicon". Their experiment still had the disadvantage that it had a long optical path and produced a one dimensional scan.

During $1994 \mathrm{~J}$. Choe et al..$^{4}$ studied the constrained-film sintering of a gold circuit paste used 
in microelectronic packaging applications. During these studies they developed optical techniques to determine the stresses generated during sintering in the constrained films. Their system (Figure 6) has the advantage that all the optical path components are stationary. They attached the hot stage to a linear translation stage and placed a constrained sample on top of a fused quartz disk, with the film facing down. As the stage moved, a He-Ne laser beam was used to scan the length of the polished silicon substrate. The reflected laser beam was detected by a position sensitive detector. During the runs they recorded the stage position and the detected signal by a computer at specified intervals. A simple geometrical analysis showed that the bending curvature is directly proportional to the slope of a detected signal vs. stage position plot.

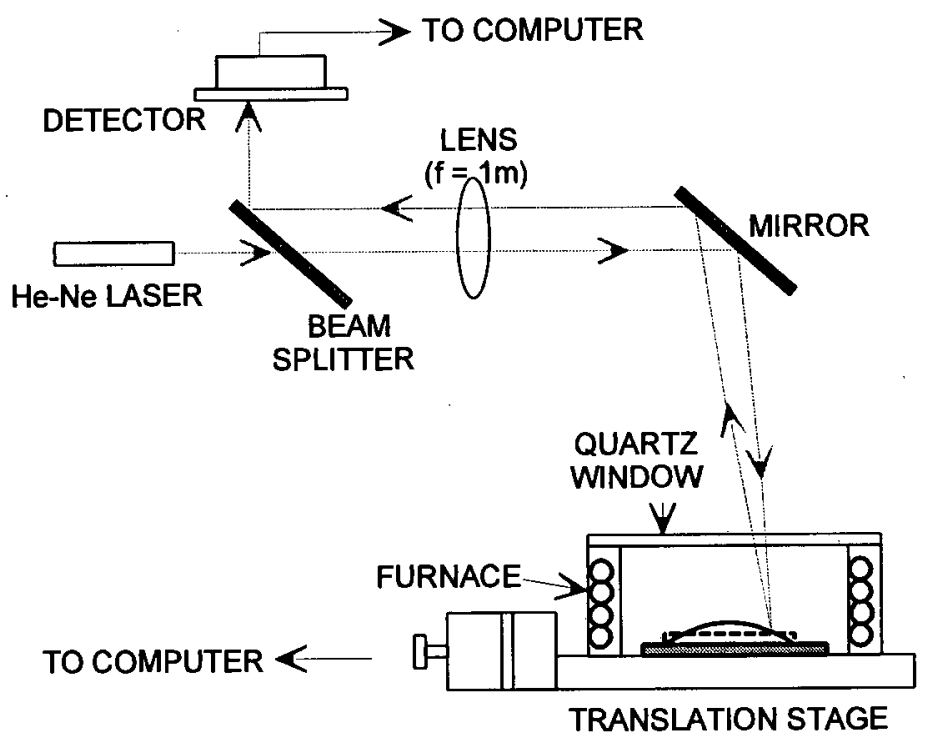

Figure 6: A schematic of the optical system for in situ measurements of curvature developed during constrained sintering of gold films by J. Choe et al. ${ }^{4}$.

The in-plane stress $(\sigma)$ was then estimated from the curvature $(\kappa)$ using the Stoney formula:

$$
\sigma=\left[\frac{k E_{s} d_{s}^{2}}{6\left(1-v_{s}\right) d_{0}}\right]
$$

where $E_{s}$ and $v_{s}$ are the elastic modulus and Poisson's ratio of the silicon, $130 \mathrm{GPa}$ and 0.279 , 
respectively, $d_{s}$ is the substrate thickness, and where $d_{0}$ is the initial film thickness $(25 \mu \mathrm{m})$. The disadvantages are again the fact that this system provides a one dimensional scan and that the complete furnace is moved to produce the scan.

During 1997 Carina Kylner et al. ${ }^{5}$ published a paper concentrating on overall stress during heating and the scattering caused by local stress relaxation. They recorded substrate curvature changes with accuracies up to $3.5 \times 10^{-5} \mathrm{~m}^{-1}$ or an equivalent radius of curvature of $40 \mathrm{~km}$, without prior knowledge of the initial substrate curvature. 


\section{CHAPTER 2:}

\section{PRINCIPLES OF THE CURRENT WORK}

The aims of this work were as follows:

- To improve the existing substrate curvature measurement systems so that more accurate research results can be produced.

- To provide a system that is very stable during operation, with the minimum number of moving components.

- To produce a 2-dimensional scan of any surface under test, because with a 2dimensional scan it is possible to determine any alignment error and then rectify this error to find an absolute value for ROC.

- To produce a compact optical system by folding the optical beam path, but still provide positional accuracies in ROC of $10 \mathrm{~km}$ or more.

- To resolve the limiting factors of past systems, such as the speed at which scanning data was collected, and the limitations of photodetector width.

Further requirements, specific to the experimental programme for which this system was required, were:

- The substrate must be placed in an ultra high vacuum environment (UHV) with provision for heating from room temperature to at least $1000^{\circ} \mathrm{C}$.

- The substrate curvature must be monitored during this process with an accuracy in radius of curvature (ROC) of $10 \mathrm{~km}$.

- Specific requirements of this system were that there be no movement of the furnace in which the surface under test will be located, and a personal computer (PC) is used to monitor the furnace temperature and record all positional data.

The particular focus in this work is on the curvature measuring system. It was decided to develop an electro-optical system embodying the successful principles of previous systems, 
while eliminating the drawbacks. This system requires the following elements:

- A stable furnace set-up: because stability is of paramount importance the furnace was mounted in a fixed position while the laser beam is moved across the surface under test via a prism mounted on a motorized stage. The furnace top door has a quartz window, allowing optical access.

- Detection of the laser beam movement: the movement of the beam is detected by a fourquadrant position sensitive device.

- Positional data recording: the positional information is recorded by a computer which translates the data and then feeds it back to the system.

Figure 7(a) provides a schematic diagram of the components required for curvature measurement. The components for the optical portion of the system consist of a four-quadrant photodetector, a low-power He-Ne laser ( $1 \mathrm{~mW})$, a mirror, a lens and a highly polished $90^{\circ}$ prism. Figure 7 (b) shows the geometry, with respect to the radius of curvature $R$ of the specimen under test.

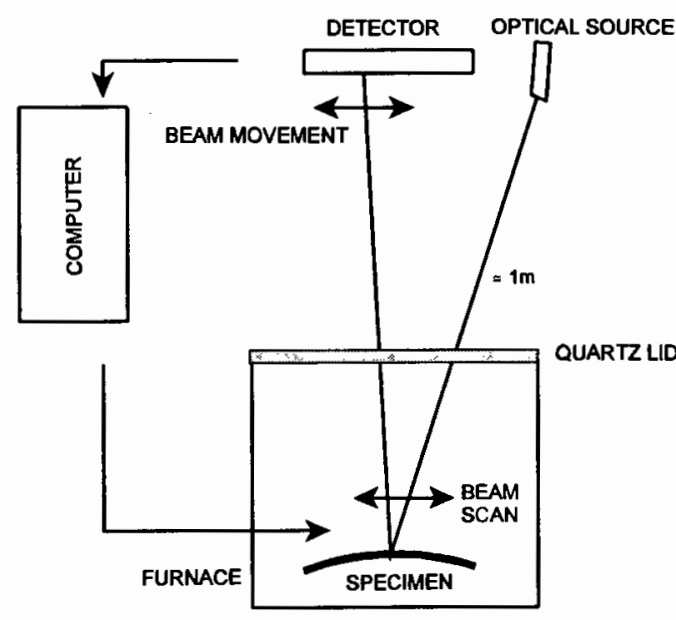

(a)

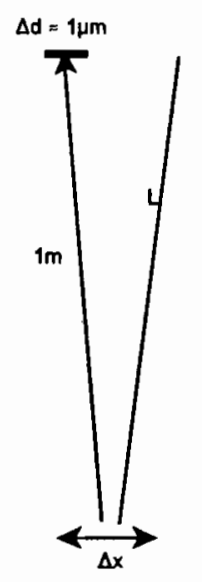

(b)

Figure 7: Figure 7(a) displays a schematic of the components required for curvature measurements. Variables used in calculating the radius of curvature are shown in figure (7b). It should be noted that the system envisaged and eventually produced made provision for detector movement in two axes: the one shown, and also on the axis projecting into the page. 
From equation (1) a $1 \mu \mathrm{m}$ beam movement on the detector will result in a ROC of

$$
\begin{aligned}
\mathrm{R} & =2 \mathrm{~L}(\Delta x / \Delta d) \\
& =\frac{2 \times 1\left(10 \times 10^{-3}\right)}{1 \times 10^{-6}} \\
& =20 \times 10^{3} \\
& =20 \mathrm{~km}
\end{aligned}
$$

A general discussion of the components follows below.

\subsection{Position Sensing Detector (PSD)}

Silicon photodetectors are commonly used for light intensity measurements in a wide range of applications. For this application the photodetector will be utilised as an optical position sensor, widely referred to as a Position Sensing Detector or simply PSD. Application of these devices in ultra-fast auto focussing schemes is widely recognised. They are capable of detecting a beam position with sub-micron accuracy. A standard option is a four segment (quadrant) photodetector, which is a common substrate photodiode divided into four segments (for twodimensional measurements), separated by a gap or dead region (see Figure 8 ). When a symmetrical optical beam is focussed onto the segments it generates equal photocurrents in all segments, if positioned at the centre of the detector. The relative position may be inferred by measuring the output current of each segment. In the present system the, photocurrent from each segment is fed to an amplifier with a gain of $-10000 \mathrm{~V} / \mathrm{A}$. The signal from each quadrant
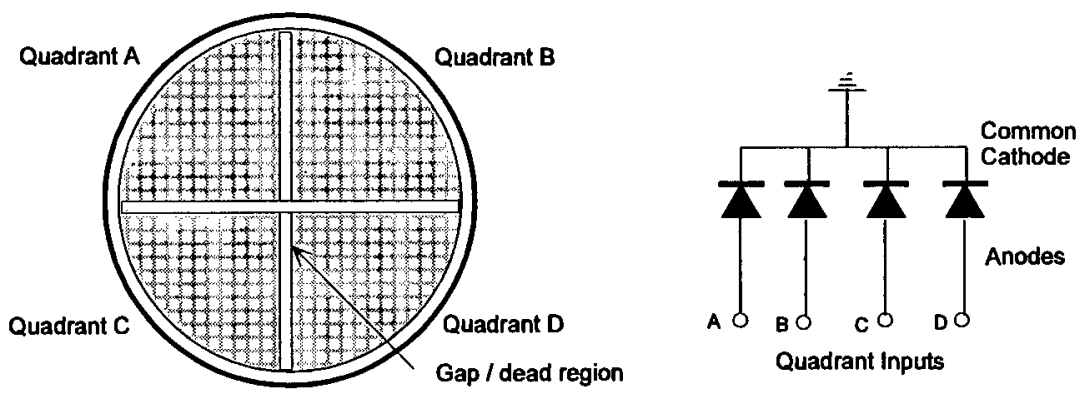

Figure 8: Diagram of the four segment PSD and the equivalent circuit of each segment. Note the gap/dead region between segments. 
( $A, B, C, D)$ is added to two others to get $A+B(=$ top), $A+C$ (=left), C+D (= bottom), and B+D (= right). The difference between top and bottom is found using one differential amplifier, and left and right using another. These differencing amps have a gain of 1000 (see Figure 20). This circuit is attached directly to an analogue-to-digital (ADC) card in the PC. The actual circuits used in this work are discussed in detail in a later section. The segmented PSD produces position resolutions in the order of $0.1 \mu \mathrm{m}$ and a very high accuracy due to the excellent responsivity match between the elements (Figure 9). Very low light level detection is thus possible, which makes the use of a low-powered laser beam possible. The responsivity of the silicon photodiode is a measure of the sensitivity to light, and it is defined as the ratio of photocurrent $I_{p}$ to the incident light power $P$ at a given wavelength ${ }^{11}$ :

$$
\mathrm{R} \lambda=\frac{\mathrm{I}}{\mathrm{P}}
$$

In other words, it is a measure of the effectiveness of the conversion of the light power into

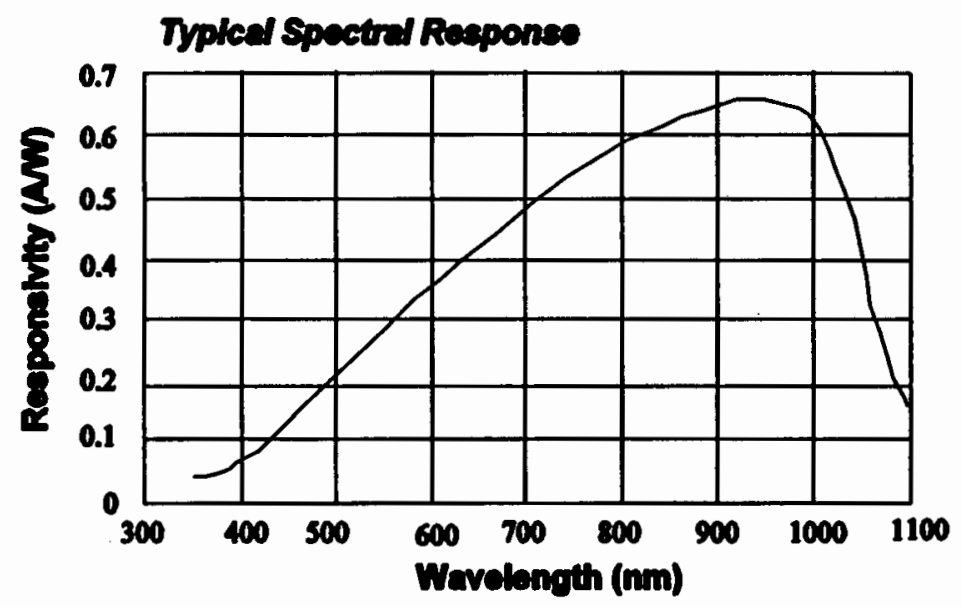

Figure 9: Spectral response of the detector used in the system, from [12].

electrical current. It varies with the wavelength of the incident light. Another factor to be considered is the independence of the PSD on the signal-to-noise ratio $(\mathrm{S} / \mathrm{N})$ of the system. Because the PSD is mounted in close proximity to a furnace it provides excellent stability over time and temperature with fast response times for high speed operations, making it ideal for this application. A drawback of this PSD however is that for linear operation the light spot has to 


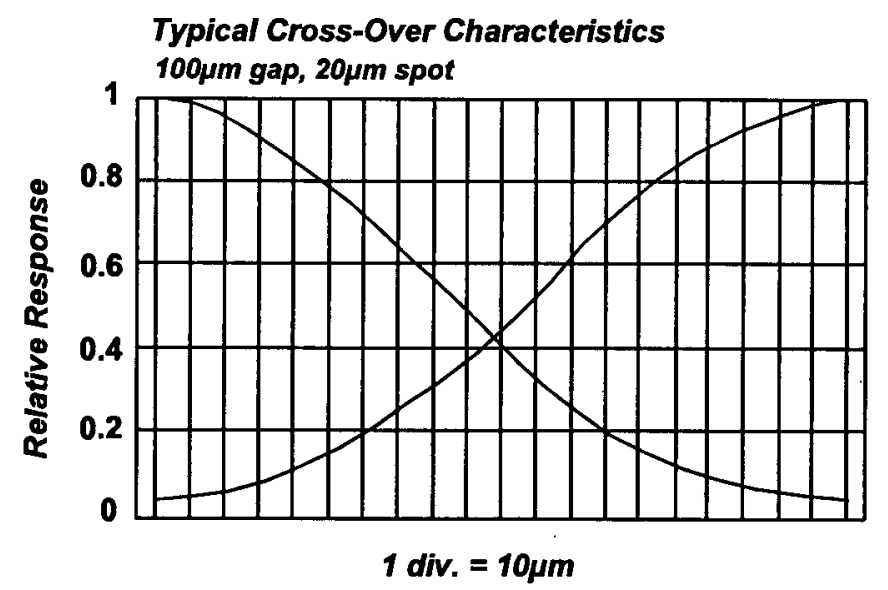

Figure 10: The curves show the response uniformity between adjacent elements which makes very accurate nulling or centring possible, from [12].

overlap all segments at all times and it cannot be smaller than the gap between the segments. This drawback is easily overcome by the use of a focusable laser. The PSD produces a very uniform intensity distribution (see Figure 10) of the light spot which makes correct measurements favourable especially for applications like nulling and beam centring.

\subsection{Optical Components}

With the selection of the optical components the criteria of minimum components and compatibility is essential. The intensity distribution and responsivity of the PSD therefore plays a big part in the selection of the laser and the accompanying components. Based on Figure 9 the laser was selected to operate on the linear part of the spectral response curve. Some characteristics of the optical system are as follows:

- The wavelength of the He-Ne laser is in the $670 \mathrm{~nm}$ region with an output power of $0.95 \mathrm{~mW} \pm 4 \%$. The laser contains a non-intrusive focussing mechanism which is kept in position through a locking knurled outer ring. The beam diverges at a rate of $0.35 \mathrm{mrad}$ with an original maximum beam size of $3.0 \mathrm{~mm}$ dia. at the aperture. This extremely small divergence angle of the beam makes it suitable for use over long distances. The nominal focussed spot size of the laser is $55 \mu \mathrm{m}$ at $1 / \mathrm{e}^{2}$, or 0.135 of the 
centre value which is within the requirements as indicated in Figure 10. The focus range of the laser is from $\pm 62.5 \mathrm{~mm}$ from the module, to past collimation, while the waist diameter of the laser can be calculated as follows;

$$
\begin{aligned}
\mathrm{d}_{0} & =4 \lambda / \pi \theta \\
& =2.437 \mu \mathrm{m}
\end{aligned}
$$

where $d_{0}$ is the waist diameter $(\mathrm{m}), \lambda$ the wavelength of the radiation $(\mathrm{m})$ and $\theta$ the divergence angle ( $\mathrm{rad})$.

- The prism is a right angle prism with a width of $35 \mathrm{~mm}$ and a length of $50 \mathrm{~mm}$ used to refract the optical beam through $180^{\circ}$.

- The mirror which is used to direct the optical beam into the furnace and onto the surface under test is a $50 \mathrm{~mm} \times 50 \mathrm{~mm}$ front surface aluminium dielectric-enhanced mirror with a reflectance $\mathrm{R}>90 \%$ average over the $400-700 \mathrm{~nm}$ wavelength band. A round Pyrex front surface mirror with a diameter of $12.7 \mathrm{~mm}$ is used to direct the optical beam onto the PSD.

- A convex focussing lens is used to concentrate the optical beam onto the PSD.

A detailed description of the complete system layout and operation follows below. 


\subsection{The Complete System}

The complete system can be broken down into four stages: the chamber/furnace, the optical system, the motorized stages, and the PC with its peripherals. The chamber in which the specimen will be located basically consists of four major components (see Figure 11). The first component is the chamber outer shell which contains a door with a glass viewport. The object

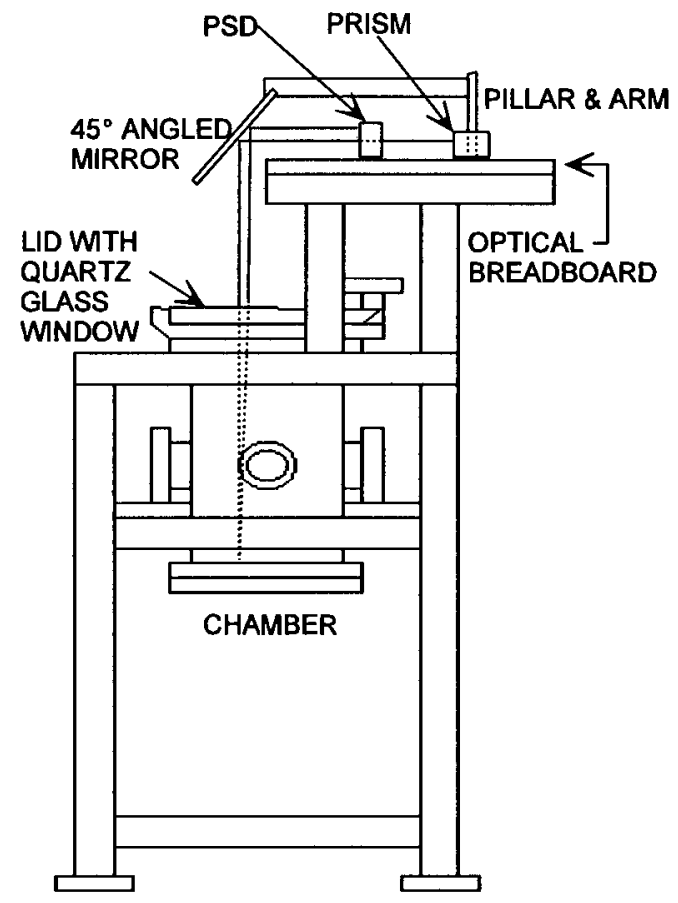

Figure 11: Side view of the chamber mounted inside a workbench showing the position of the optical breadboard and the $45^{\circ}$ angle mirror arrangement. The beam path from prism to PSD is also shown. The construction is very solid to provide stability to the furnace.

of the glass viewport is that the laser beam can penetrate the chamber to reach the specimen inside the furnace. In addition to the glass viewport door the chamber makes provision for a pump vacuum system to be attached to it (see Figure 12). The third component is a multiport 


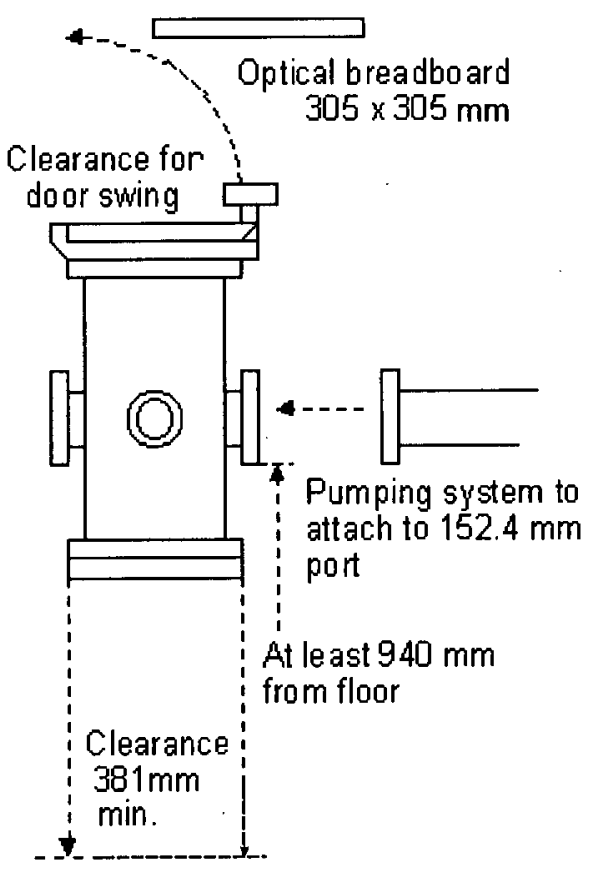

Figure 12: Diagram of the chamber showing provision for the vacuum system, the clearance for the quartz glass lid and the mounting position of the optical system.

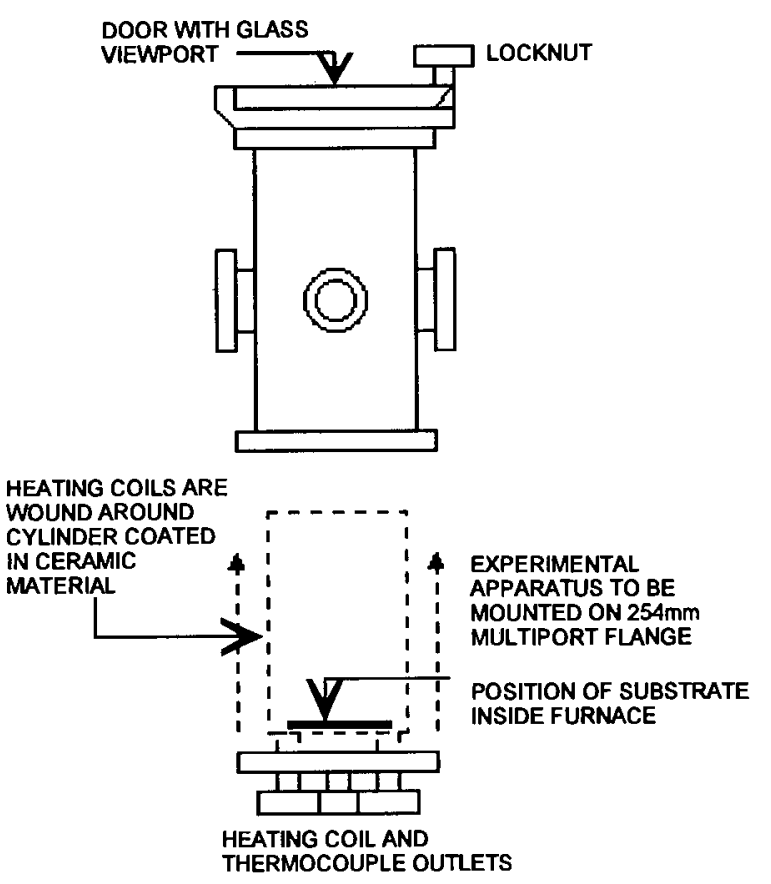

Figure 13: The chamber is mounted onto the multiport flange, which has electrical feed throughs for the heating coils. 
flange on which a stainless steel cylinder is mounted (see Figure 13). The stainless steel cylinder which will act as the furnace is covered on the outside with a ceramic material (alumina). Heating coils are wound around the ceramic coated stainless steel cylinder, and the terminals are taken out through one of the feed throughs in the multiport flange. Figure 13 indicates the position of the substrate inside the furnace. For repeatable measurements, a repeatable mounting system for the substrates is required; this however was not part of the current research. A thermocouple is mounted inside the chamber to control the temperature of the furnace. Temperatures of up to $900{ }^{\circ} \mathrm{C}$ are possible. The last component is the optical breadboard, which is mounted above the glass viewport (see Figure 11). See Appendix A for further details on system components.

\subsubsection{Optical Layout}

Before discussion on the layout of the optical system can start, it is essential to get an overview of the mechanical arrangement of the components on the optical breadboard. Figure 14 clearly shows the three motorized stages in relation to the laser beam and the mirrors. A discussion on the layout and the operation of the optical system, in a flat plane, follows below.

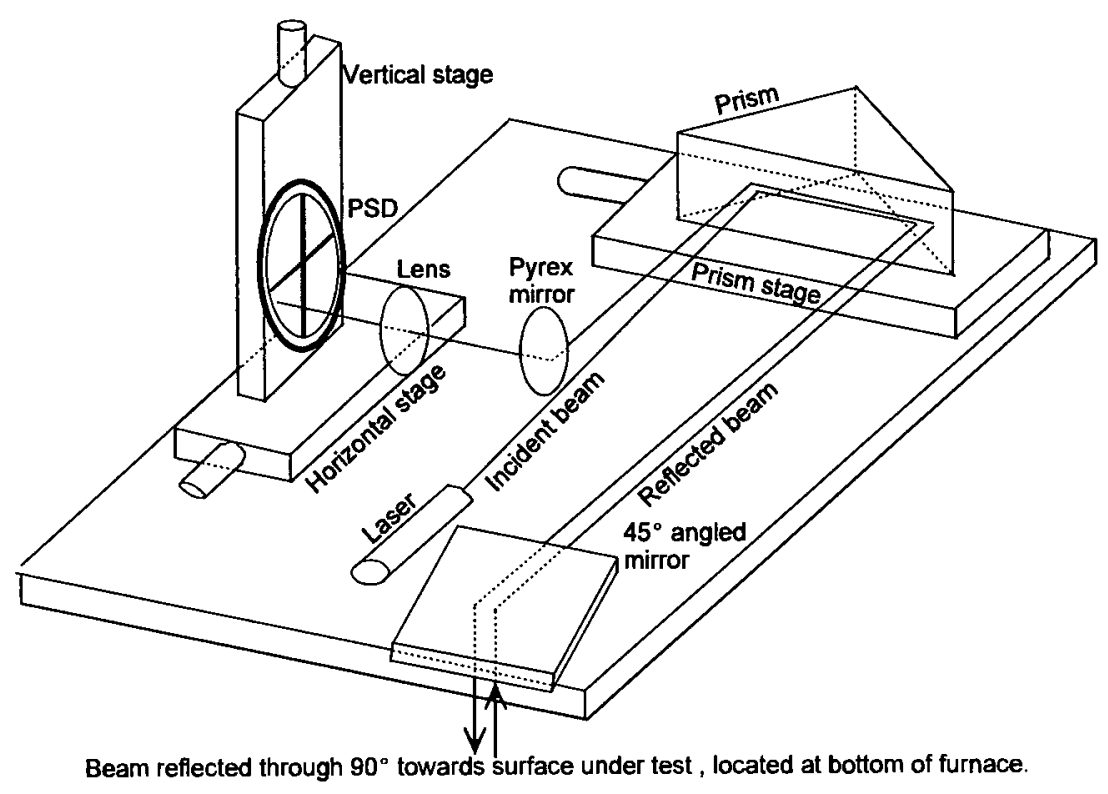

Figure 14: This diagram shows the mechanical arrangement of the components on the optical breadboard. Notice the position of the laser in relation to the prism and how the incident beam is refracted by the prism towards the $45^{\circ}$ angled mirror which in turn reflects the beam through $90^{\circ}$ towards the surface under test, located at the bottom of the furnace. 
The optical system layout shown in Figure 15 is mounted above the vacuum chamber shown in Figure 11. Figure 15 shows that the He-Ne laser is mounted directly in line with the stage containing the glass prism. The $1 \mathrm{~mW}$ optical beam generated by the $\mathrm{He}-\mathrm{Ne}$ laser is projected towards the prism (the primary incident beam). This primary incident beam will be refracted through $180^{\circ}$ by the prism. From Figure 15 it can be seen that the reflected primary beam is directed towards the $45^{\circ}$ angle mirror which is situated directly in line with the prism and directly above the glass viewport in the chamber. The mirror is suspended in the optical path by means of a pillar and arm construction. The primary beam is then reflected from the $45^{\circ}$ angle mirror onto the specimen under test. Any angular deflection from the specimen will be translated back to the $45^{\circ}$ angled mirror and back towards the prism. This secondary incident beam will now be refracted through $180^{\circ}$ onto the round pyrex mirror which will reflect the secondary beam onto the PSD (see Figure 15) which is mounted on Motorized stages 2 and 3.

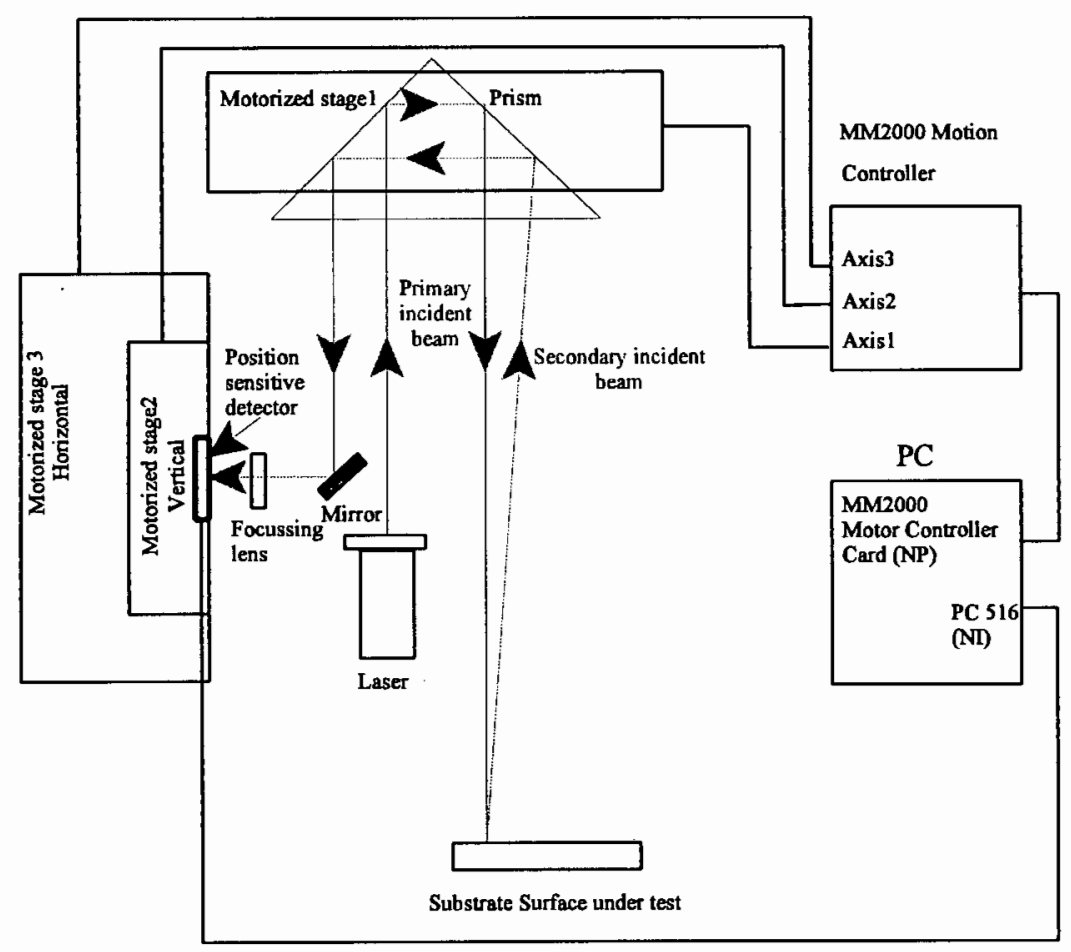

Figure 15: This schematic shows the optical system used to measure the curvature of surfaces under mechanical stress. The optical path is clearly illustrated in this diagram. Notice however that the surface under test is shown in a flat plane, which was only the case during the initial experimental stage. During the actual process the surface under test is mounted inside the furnace and the optical beam is reflected via a $45^{\circ}$ angled mirror onto the surface. The links between the PC, the PSD and the motorized stages are also illustrated. 
All three motorized stages use identical DC motors which drive a fine-threaded lead screw for stage positioning. The stages can be positioned with approximately $1 \mu \mathrm{m}$ accuracy and their position measured with $0.055 \mu \mathrm{m}$ resolution (see Appendix C). These high resolution motors control the movement of the optical beam. The motorized stages are named as axis 1 to 3 . Motorized stage 1 contains the $35 \mathrm{~mm} \times 50 \mathrm{~mm}$ right angled prism which is locked into position by a locking device containing rubber rings to protect the prism against possible damage (see photograph in Figure 16). The physical mass of the prism is small enough that it has no effect on the "on axis load capacity" of the motor. This ensures that the pitch, given as $200 \mu \mathrm{rad}$ maximum, and the yaw, given as $100 \mu \mathrm{rad}$ maximum, are not affected when the stage is in motion. Any controlled movement of motorized stage 1 will result in a corresponding movement across the surface of the specimen under test (see Figure 17).

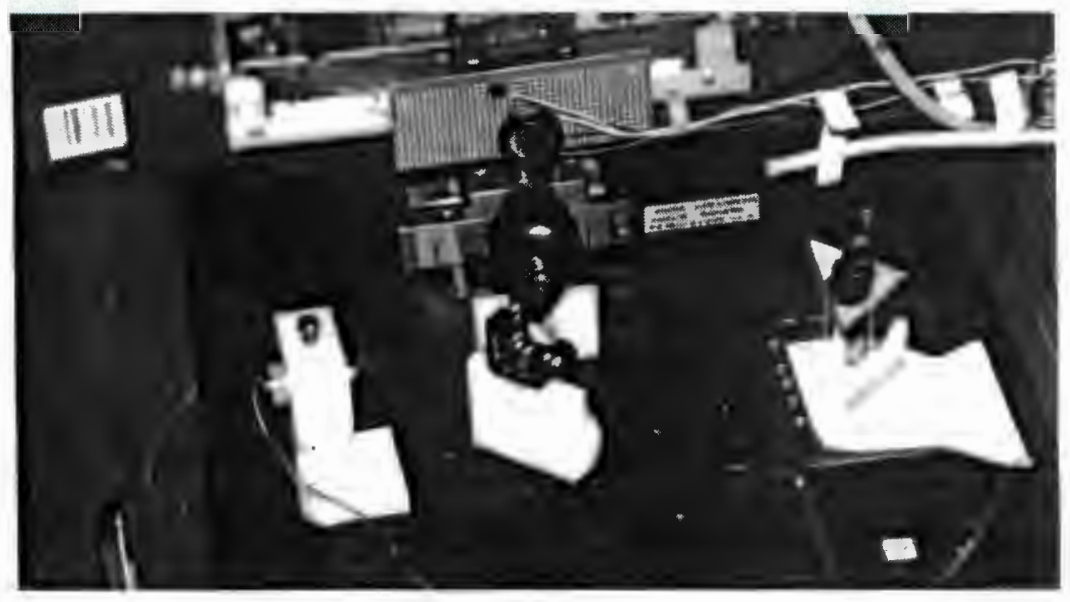

Figure 16: Photograph of complete set-up during experimental stage. The prism with its locking device is clearly visible in the photograph.

Motorized stages 2 and 3 are combined into a horizontal ( $\mathrm{x}$-axis) and vertical (y-axis) movement stage ( motorized stage 2 is bolted vertically on top of motorized stage 3 ). The four quadrant positioning sensitive detector (PSD) is fixed to motorized stage 2, providing the PSD with horizontal and vertical movement. This enables the PSD through the necessary software to centre itself and thus provide an absolute position for the laser beam. All these motorized stages are linked to an MM2000 Motionmaster interface box via a 15/19 pin cable (see Appendix B). The MM2000 interface box is linked to the MM2000 controller card, located in the PC, via a 68 pin interconnect cable, all of which are manufactured by NewPort industries. This provides a channel for communication of instructions and data between the stage controller and the PC. The data relates to the movement of the prism (motorized stage 1) 


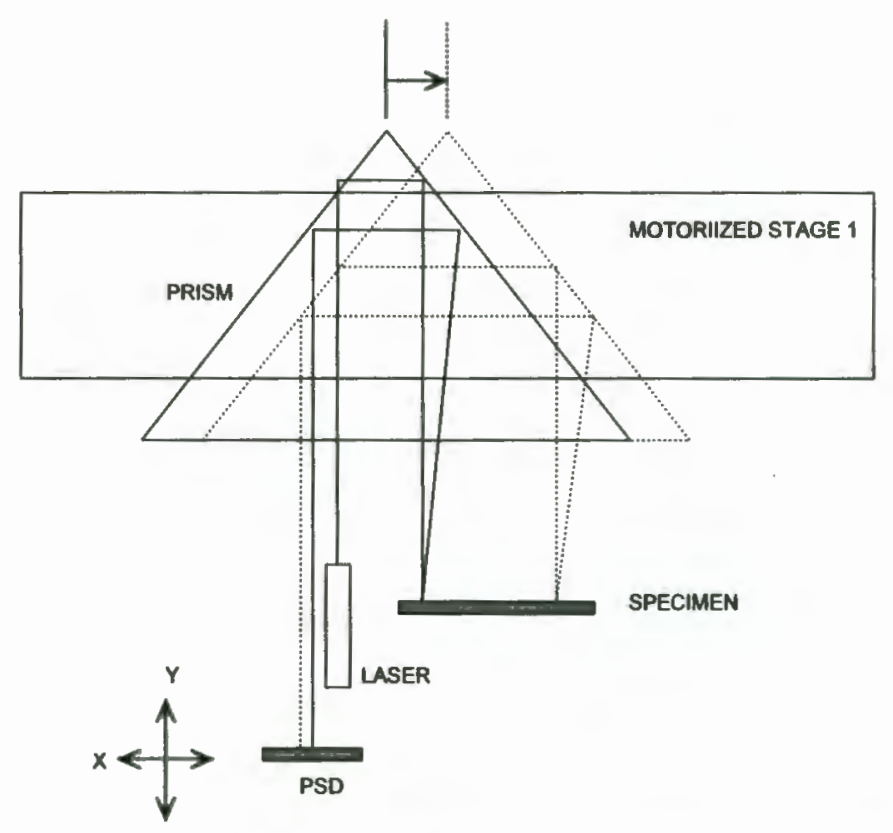

Figure 17: Schematic to illustrate the optical beam path across the specimen via the controlled movement of the prism. The resultant beam path is reflected onto the PSD which will be moved to centre itself to provide the absolute position.

and the movement of the PSD (motorized stage 2 and 3). The positional signal from quadrants $[(C+D)-(A+B)]$ and quadrants $[(B+D)-(A+C)]$ is fed back to the PC via a PC516/DAQCard ${ }^{\mathrm{TM}}$ (see Appendix B), manufactured by National Instruments.

\subsubsection{Electronics}

The positional signals are generated by the four quadrant PSD shown in Figure 18. The output from the four quadrant PSD is dependent upon the he intensity of the incident laser beam. Each

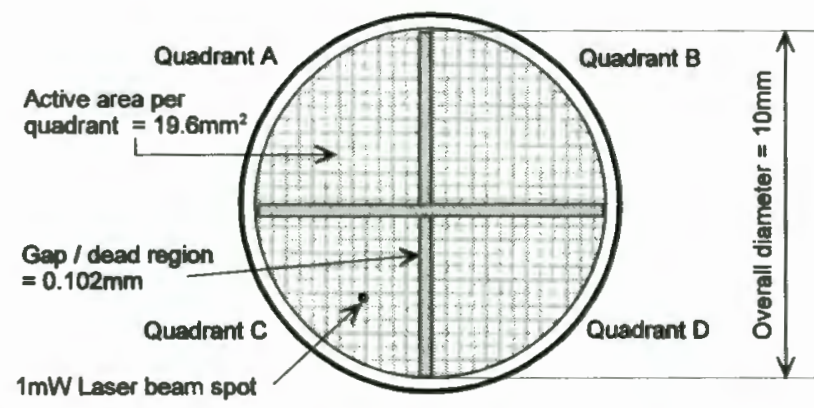

Figure 18: Schematic of the surface and dimensions of the position sensitive detector (PSD), which provides positional data to the PC. 
quadrant of the PSD acts like a single photodiode and has a simple amplifier (see Figure 19)

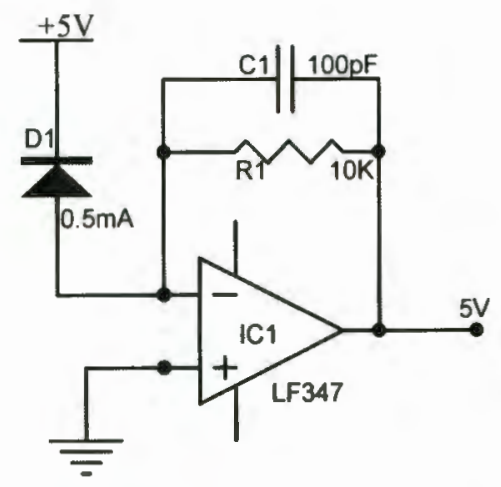

Figure 19: Amplification circuit for a PSD quadrant.

with a gain of -10000 V/A. Figure 20 shows how these outputs are coupled to the analog-todigital converter $(A D C)$ via summing amplifiers to provide the PSD motorized stages with positional data. Part of the electronics required to provide individual and difference signals to the PSD motorized stages are shown in Figure 21.

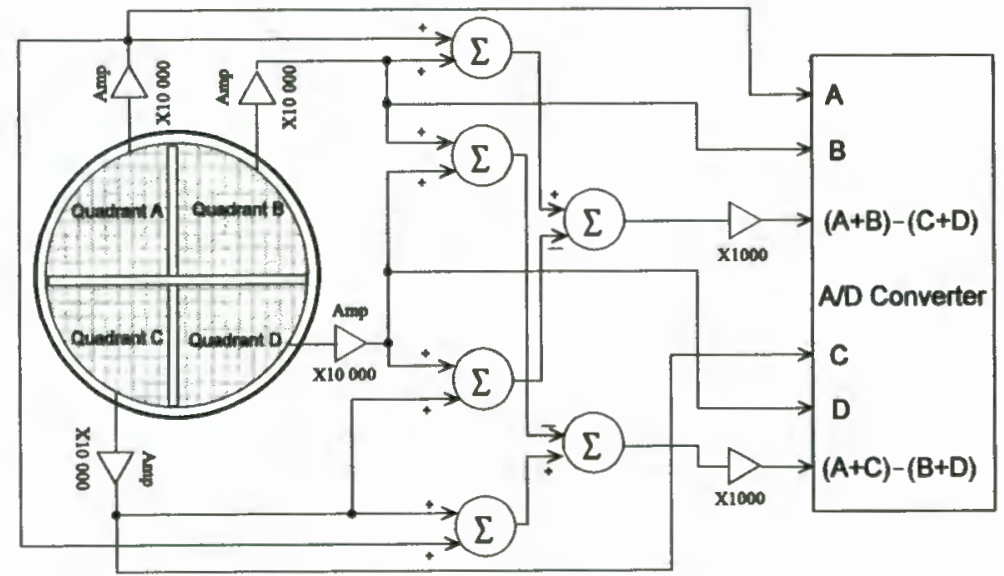

Figure 20: This diagram shows how the outputs from the PSD are coupled to the ADC via summing amplifiers, to provide the PSD motorized stages with positional data. 


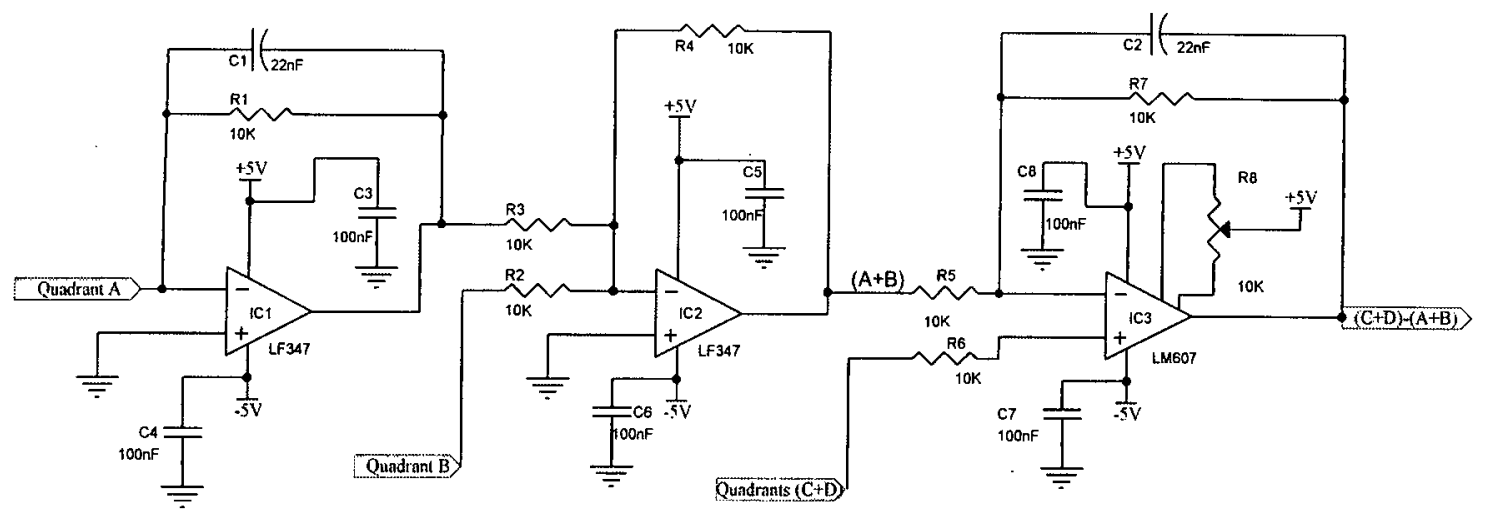

Figure 21: This circuit shows part of the circuitry required for the quadrature PSD. The signal output from quadrant $A$ is fed to $I C_{1}$ and the signal output from quadrant $B$ is fed to $I C_{2}$ to provide $A+B\left(=\right.$ top). The signal output of $I C_{2}$ and the signal outputs of quadrants $C+D$ (= bottom) is fed to $\mathrm{IC}_{3}$ to provide the difference between top and bottom. The difference between left and right is achieved in a similar fashion. These difference outputs plus the individual quadrant signal outputs are then coupled to an A/D converter.

Figure 9 and the data sheets in appendix D indicate that the responsivity of the PSD is approximately $0.5 \mathrm{~A} / \mathrm{W}$ at $693 \mathrm{~nm}$ incident wavelength (the wavelength of the He-Ne laser). If it is assumed that total maximum incident power is reflected from the substrate onto only one of the PSD quadrants, then the $1 \mathrm{~mW}$ laser beam will produce a maximum photocurrent of $0.5 \mathrm{~mA}$. This however will only be true if the total area of the laser beam is focussed onto one of the PSD quadrants. Two possible scenarios that may arise are those when the laser beam is focussed across the segment gap between any two quadrants, or where the laser beam is focussed at the intersection where all four segments meet. The latter scenario is close to the ideal case when the beam output will be nulled or centred. We will thus consider the scenario where the laser beam is located across the gap between two quadrants. We will calculate how any movement of the prism affects the output from the relevant quadrants. This will result in signal voltages being fed back to the $\mathrm{PC}$ via the DAQ card. These signal voltages will (via the LabView software) send out instructions to the MM2000 Motion Controller to move the PSD so that the output currents are nulled i.e. the laser beam is centred between the four quadrants. In order to design the electronics a rough sensitivity calculation is required.

Start with the laser beam located dead centre between two quadrants:

The gaps between the PSD quadrants are $\pm 0.102 \mathrm{~mm}$ (see appendix D), so when the laser beam 


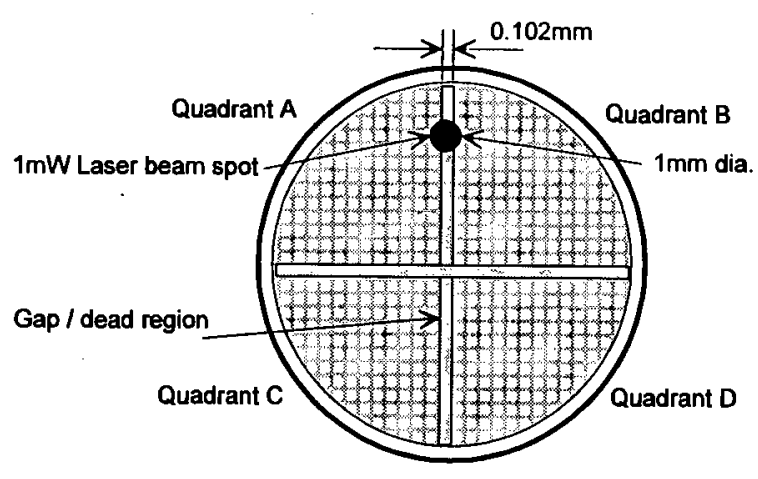

Figure 22: Diagram illustrate the scenario where the laser beam is located dead centre across the $0.102 \mathrm{~mm}$ gap between two quadrants.

is focussed to a $1 \mathrm{~mm}$ diameter beam spot the following will result, with the laser beam focussed dead centre between any two quadrants.

The area of laser beam is simply calculated:

$$
\begin{aligned}
\mathrm{A}_{\text {laser }} & =\pi r^{2} \\
& =3.14 \times\left(5 \times 10^{-4} \mathrm{~m}\right)^{2} \\
& =7.854 \times 10^{-7} \mathrm{~m}^{2}
\end{aligned}
$$

The area of the gap, on which laser beam is incident, can be assumed to be a rectangle:

$$
\begin{aligned}
A_{\text {gap }} & =1.02 \times 10^{-4} \mathrm{~m} \times 1 \times 10^{-3} \mathrm{~m} \\
& =1.02 \times 10^{-7} \mathrm{~m}^{2}
\end{aligned}
$$

If we assume uniform radiance in the beam area, the radiant incidance per unit area will be:

$$
\begin{aligned}
E_{R} & =\phi_{R} / A \\
& =1 \mathrm{~mW} / 7.854 \times 10^{-7} \mathrm{~m}^{2} \\
& =1273 \mathrm{~W} / \mathrm{m}^{2}
\end{aligned}
$$

$$
\begin{array}{cl}
\text { where } E_{R} & =\text { radiant incidance }\left(\mathrm{W} / \mathrm{m}^{2}\right) \\
\phi_{R} & =\text { radiant flux }(\mathrm{W}) \\
A & =\text { area of flux distribution }\left(\mathrm{m}^{2}\right)
\end{array}
$$

Considering the circuit in Figure 19 the voltage output from quadrant $\mathrm{A}\left(\Delta \mathrm{V}_{\mathrm{A}}\right)$ can now be calculated. The output of the PSD (see Figure 19) is taken to be $0.5 \mathrm{~A} / \mathrm{W}$ over the area of the laser beam. If the area of the opening between the quadrants is subtracted from the total area 
of the laser beam, then the current generated per quadrant will be:

$$
\begin{aligned}
I & =P \times A \times \text { efficiency } \\
& =1273 \mathrm{~W} / \mathrm{m}^{2} \times\left(6.834 \times 10^{-7} \mathrm{~m}^{2} \div 2\right) \times 0.5 \mathrm{~A} / \mathrm{W} \\
& =217 \mu \mathrm{A}
\end{aligned}
$$

If the PSD moves $1 \mu \mathrm{m}$ left or right from the centerline of the PSD then the additional area of the PSD now exposed to the laser beam will be:

$$
\begin{aligned}
\Delta A & \approx 1 \times 10^{-6} \mathrm{~m} \times 1 \times 10^{-3} \mathrm{~m} . \\
& \approx 1 \times 10^{-9} \mathrm{~m}^{2}
\end{aligned}
$$

It is assumed that the area is a rectangle because of the small diameter of the laser beam and the small distance moved. The additional area will result in an increased current in quadrant $A$, thus the increase in current is:

$$
\begin{aligned}
\Delta I_{A} & =P \times \Delta A \times \text { efficiency } \\
& =1273 \mathrm{~W} / \mathrm{m}^{2} \times 1 \times 10^{-9} \mathrm{~m}^{2} \times 0.5 \mathrm{~A} / \mathrm{W} \\
& =636 \mathrm{nA}
\end{aligned}
$$

$\Delta V_{A}$ can be calculated as:

$$
\begin{aligned}
\Delta V_{A} & =\Delta I_{A} \cdot \mathrm{R} \\
& =636 \mathrm{nA} \times 10 \mathrm{~K} \\
& =6.36 \mathrm{mV}
\end{aligned}
$$

The data acquisition card provides a 16-bit analog to digital conversion. For maximum input photocurrent i.e. $5 \mathrm{~mA}$ a total output voltage of 10 Volt above and below the horizontal axis and will be produced. The resolution of the ADC is thus one part in $2^{16}-1=65535$, which will produce an ;

$$
\begin{array}{ll}
\text { output per bit } \frac{10 \mathrm{~V}}{2^{16}-1} \quad \Rightarrow 153 \mu \mathrm{V} \\
\text { thus, } \\
\Delta V_{B}=-6.36 \mathrm{mV} \\
\Delta V_{\text {total }}=12.73 \mathrm{mV}
\end{array}
$$


So we can say,

$$
\frac{\Delta V}{\Delta x}=12.73 \mathrm{~V} / \mu \mathrm{m}
$$

It should be noted that if the beam is more intense towards its centre, which is to be expected, given a Gaussian profile, then this sensitivity will be higher when the beam is centred over the gap. This calculation also assumes that the beam is centred on the PSD gap. If it is not, then the change in area will be smaller, and can be calculated as shown below.

Figure 23 shows an enlarged view of the laser beam as it moves across the PSD surface Equation 5 provide a more accurate means of calculating the change in laser beam area if it is required. The proof of equation 5 is available in Appendix E.

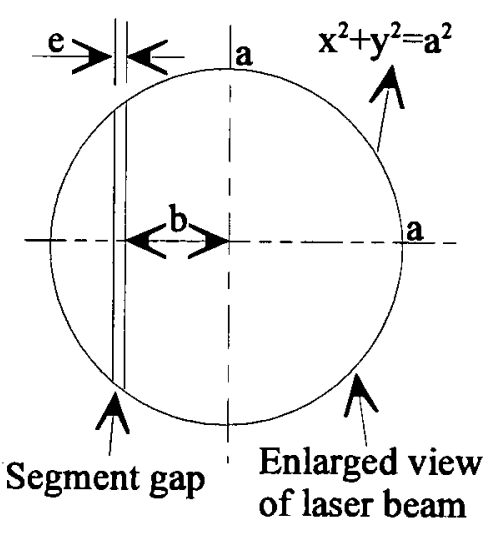

Figure 23: The schematic provides an enlarged view of the laser beam to illustrate how the area of the laser beam will change in relation to prism movement

$$
A_{s}=\pi\left\{a^{2} \arcsin \frac{b}{a}+b \sqrt{a^{2}-b^{2}}-\left[a^{2} \arcsin \frac{b+e}{a}+(b+e) \sqrt{a^{2}-(b+e)^{2}}\right]\right\}
$$


This additional accuracy is not really relevant because in practice the electronic amplifiers saturate as soon as the beam is a few microns off-centre, so the rectangular approximation is acceptable.

The data acquisition and control system is based on a PC running the LabView software. The exchange of positional information data between the LabView code and the computer takes place via the MM2000 motor controller card which control the motorized stages. The beam error from the PSD is the input to a control system which moves the PSD so as to make the error zero. The absolute position of the PSD can then be taken to be the position of the beam. 


\section{CHAPTER 3:}

\section{SYSTEM SOFTWARE AND OPERATION}

\subsection{LabView Software}

The software used for this project is the graphical programming package LabView ${ }^{13}$, which is designed for automation of instrumentation systems. LabView is similar to other programming systems, but differs in the fact that it uses a graphical programming language, called $\mathrm{G}$, to create programs in block diagram form. LabView programs are called virtual instruments (VIs) because their appearance and operation imitate actual instruments. VIs have both an interactive user interface and a source code equivalent, and accept parameters from higher-level VIs. The following are descriptions of these three VI features:

VI's contain an interactive user interface, which is called the front panel, because it simulates the front panel of a physical instrument. One can input data using a keyboard and mouse, and then view the results on the computer screen.

VI's receive instructions from a block diagram, which is constructed in G. The block diagram supplies a pictorial solution to the source code for the VI.

- VI's use a hierarchal and modular structure. They can be used as top-level programs, or as sub programs within other programs or sub programs. A VI within another VI is called a $s u b V I$.

The relationship between LabView, National Instruments driver software (NI-DAQ), the DAQ hardware and the MM2000 is shown conceptually below (see Figure 24). 


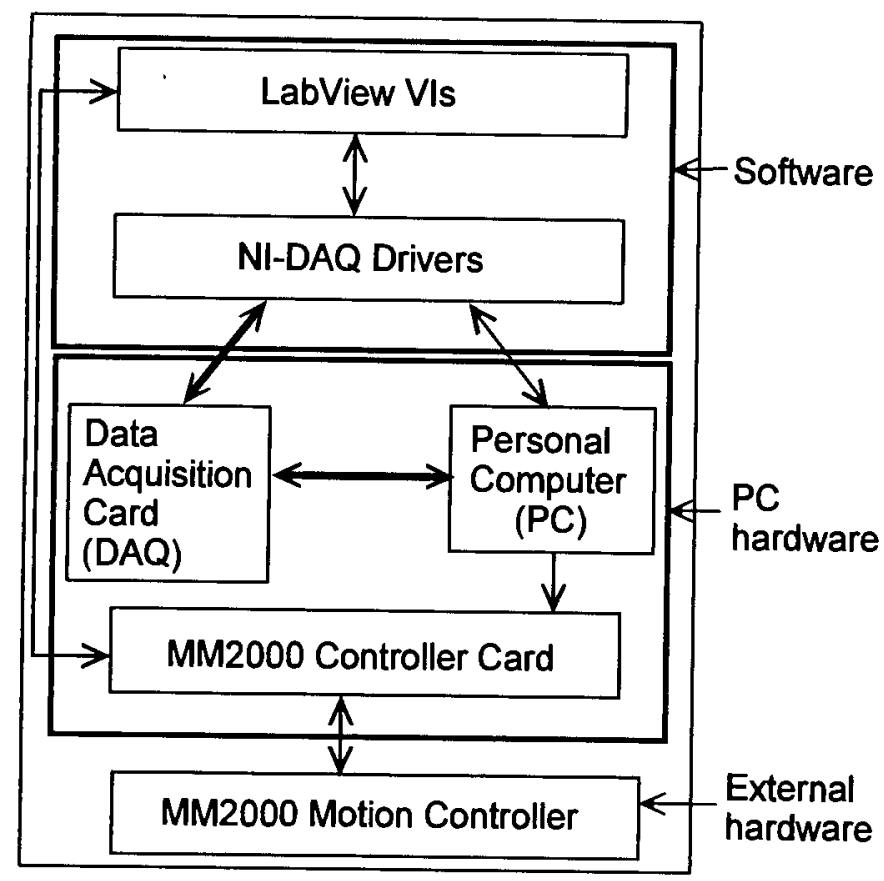

Figure 24: This block diagram shows the relationship between the LabView software, the NI-DAQ software and hardware and the MM2000 controller.

The signal from the PSD is fed to the PC 516 Data Acquisition (DAQ) card which is located inside the PC and is completely software configurable. LabView uses the software configuration information to configure the hardware to set DAQ parameters. The NI-DAQ driver software provides LabView with a high-level interface to DAQ devices and signal conditioning hardware. Each PC516 card has 8 channels of analog input with 16-bit analog-todigital (A/D) conversion. The MotionMaster 2000 is command driven(see figure 25). Commands are sent directly from LabView to the MotionMaster 2000 motion controller to carry out the operations such as the distance, the direction, the speed, and the acceleration of the stages. The MotionMaster 2000 can be directed to find a home position (" $\mathrm{dh}$ " = define home) defined by either the location of a switch (see Figure25) or the position where its internal position counter is zero. It also monitors plus and minus direction limits to protect the system from damage. System information will be fed back to LabView concerning the position as the motion progresses, whether the motion is complete or in progress, and whether an error has occurred. 

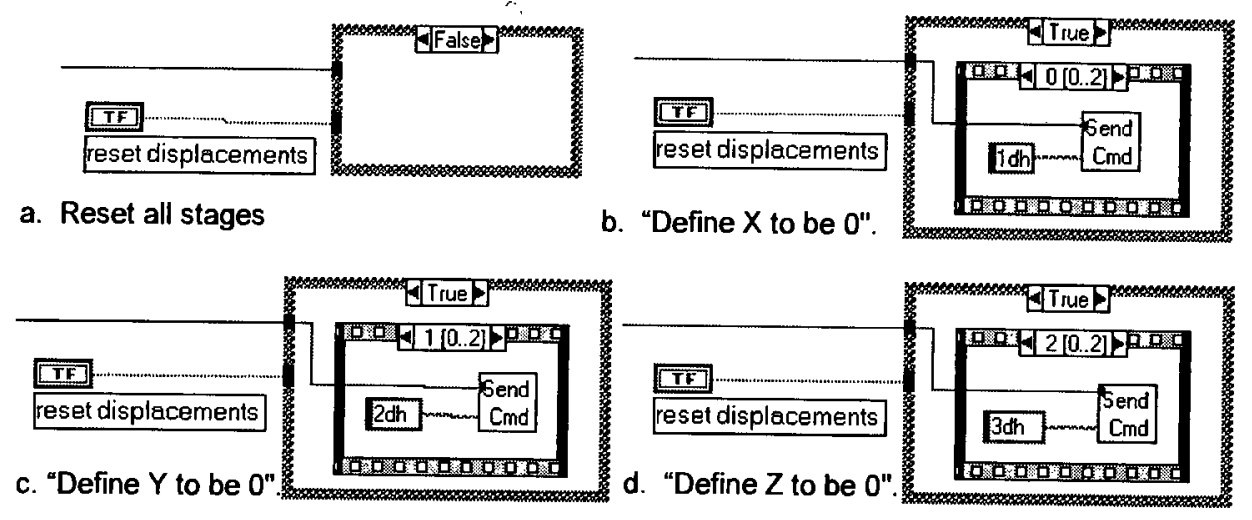

Figure 25: The diagram shows the LabView sequence of commands send to the MotionMaster 2000 motion controller to set the start position to co-ordinates $(0,0,0)$. The switch on the front panel shown in Figure 24, provides the option of defining the present co-ordinates to be defined as the origin.

\subsection{VI's for Curvature Measurement}

Three LabView VIs were created to control the prism movement, and the PSD movement. These three VIs were named:

- Autocentre VI, which is used during the set-up procedure to automatically centre the laser beam on the PSD.

- Subcurve VI, which is the main control VI that provides the routines to monitor and capture the positional data during experimentation. Figure 26 shows the front panel of this VI. The front panel makes provision for a positional readout of the prism, and an input to control the scan distance. Further provision on the panel is made for the display and recording of the vertical and horizontal positional movement of the PSD. A selection switch is available to control the step size of the stages.

- Subcurve5D VI, is the VI which captures the PSD error voltages as well as the standard data while the substrate is being scanned. 


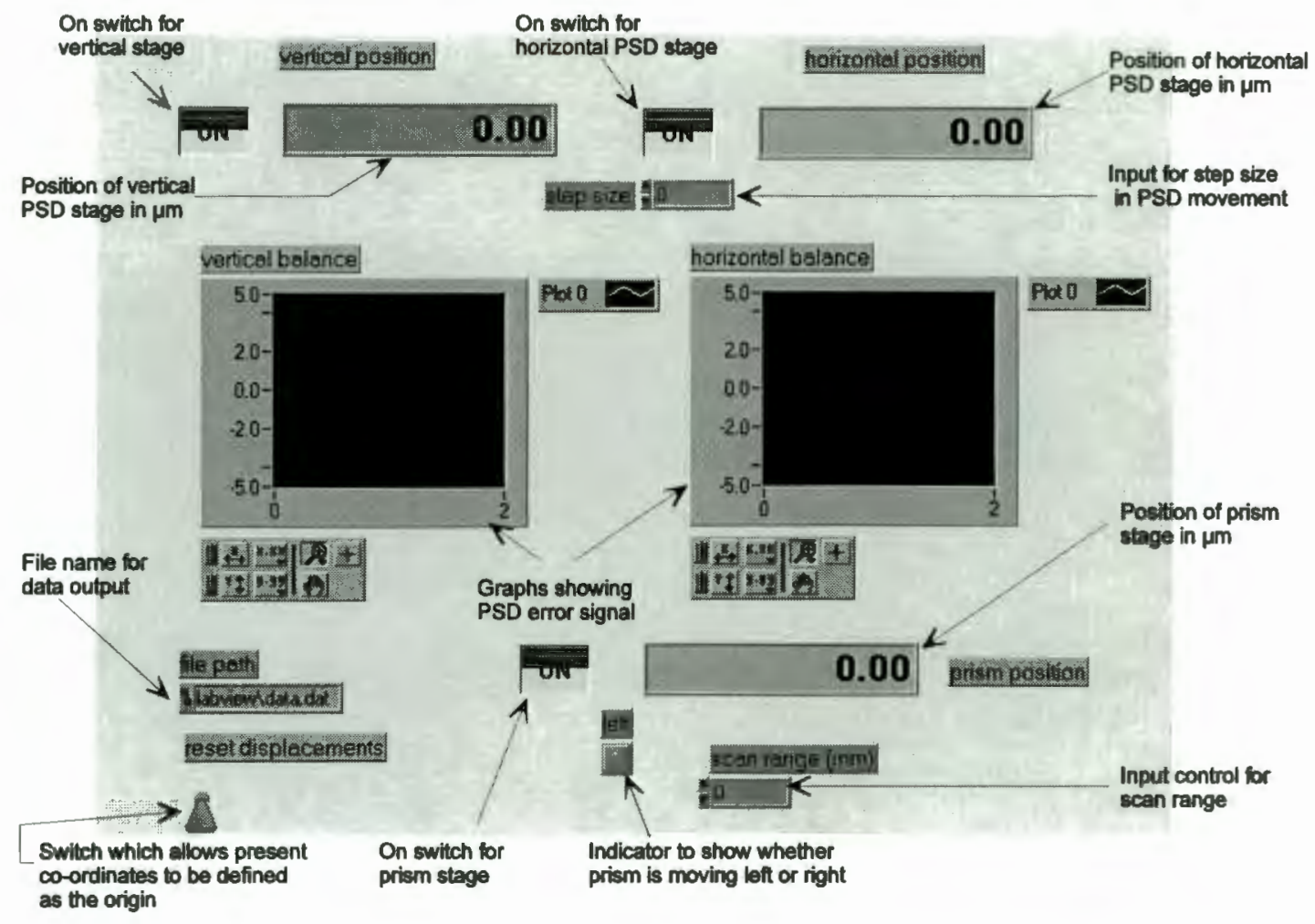

Figure 26: The front panel that was created through LabView software to monitor and record the movement of the PSD and the prism stages. This is the front panel for the Subcurve VI.

The input and output functions of the front panel are summarized in Table 1 and the flow diagrams of the VIs associated with the front panel are reflected in figures 27 to figures 31 .

\begin{tabular}{|l|l|}
\hline \multicolumn{1}{|c|}{ Inputs } & \multicolumn{1}{c|}{ Outputs } \\
\hline \multicolumn{1}{|c|}{ ON switches - vertical PSD stage } & Vertical position \\
- horizontal PSD stage & Horizontal position \\
Reset switch & Prism position \\
Step size (number) & Leftright indication \\
& Graph - vertical error \\
Scan range (number) & - horizontal error \\
File path & File data \\
\hline
\end{tabular}

Table 1. 
The flow diagrams illustrate the following sequences:

- The reset function: Once a set-up is completed all the "ON" switches can be activated to allow the present co-ordinates to be defined as the origin. If however we need to reset the co-ordinates the reset button must be activated. This means that a command will be sent to the MM2000 to define home (dh), see Figure 25, as the following coordinates $(0 ; 0 ; 0)$.

- The Main VI (loop): Which is common to all three stages, its purpose is to define the step size of the motors and the scan range of the prism in millimetres.

- The three sub VIs: Control the vertical and horizontal movement of the PSD and the prism movement.

The block diagrams of the relevant VIs and sub VIs are available in Appendix F. 


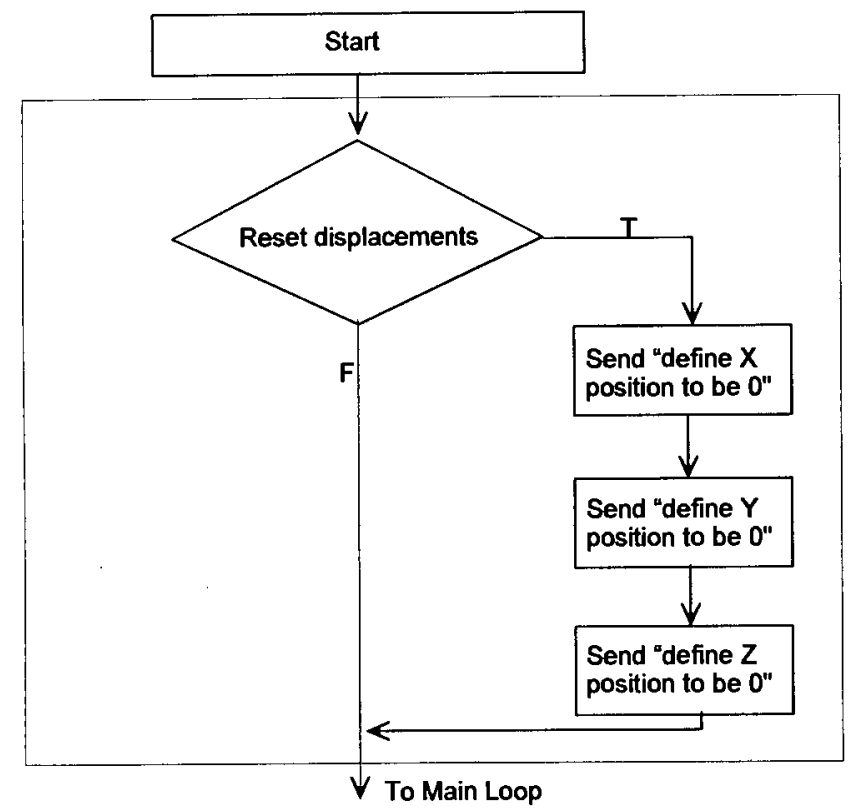

This section sets the start position to co-ordinates $(0,0,0)$. It might be avoided if we mant to maintain absolute positional accuracy.

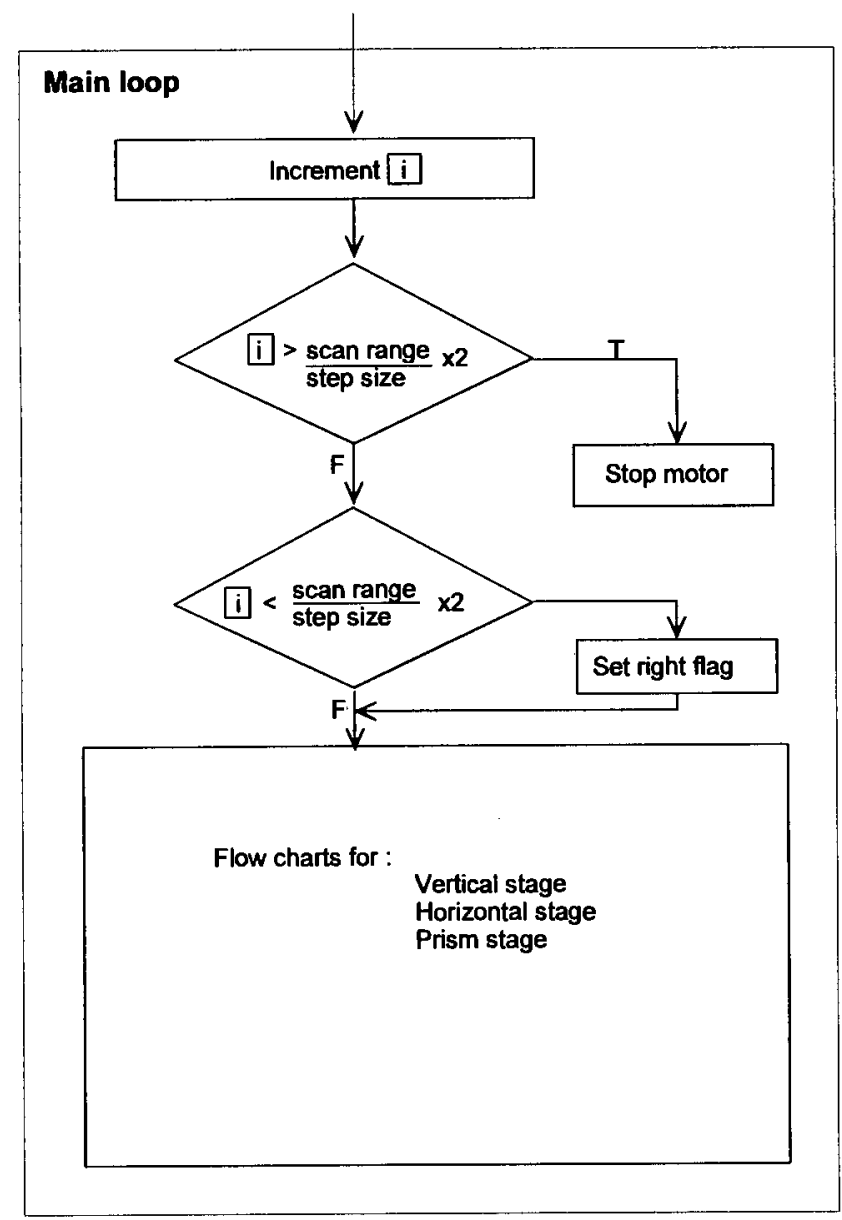

This operation detects the end of a prism scan.

This operation indicates in

which direction the prism is moving.

Figure 27: Flow diagram for the LabView Vl's that were created to control the PSD (vertical and horizontal) movement and the prism movement. The diagram describes the main loop, which is common to all the stages, and how it links to the stages 


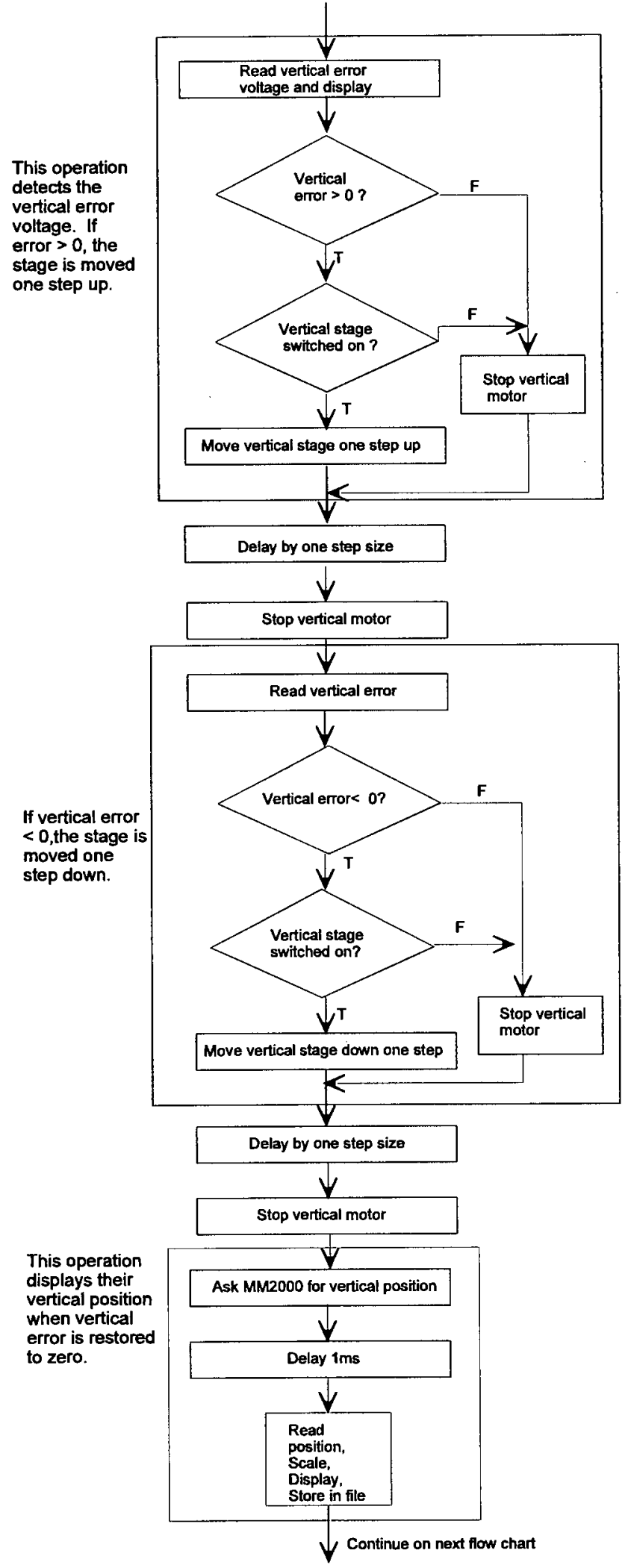

Figure 29: Flow diagram for the vertical movement of the PSD via the vertical stage and motor. 


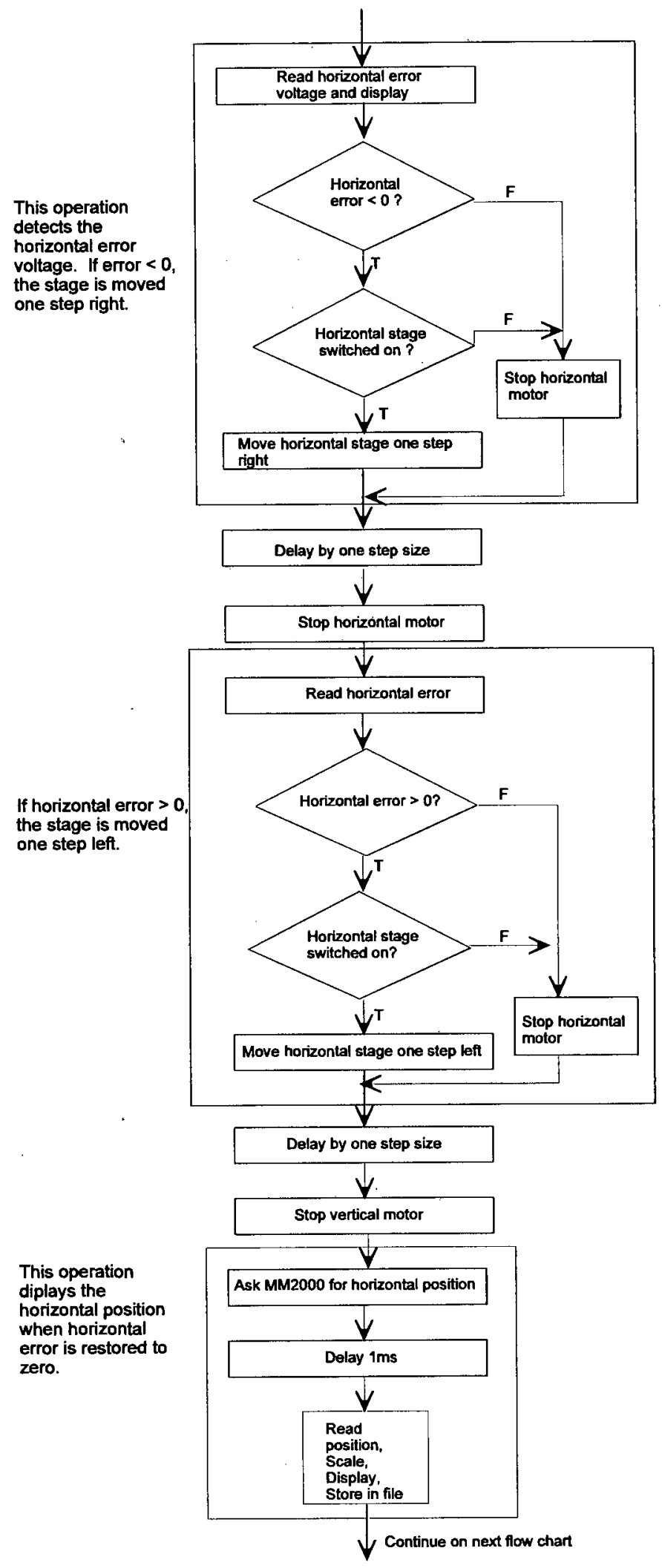

Figure 30: Flow diagram for the horizontal movement of the PSD via the horizontal stage and motor. 


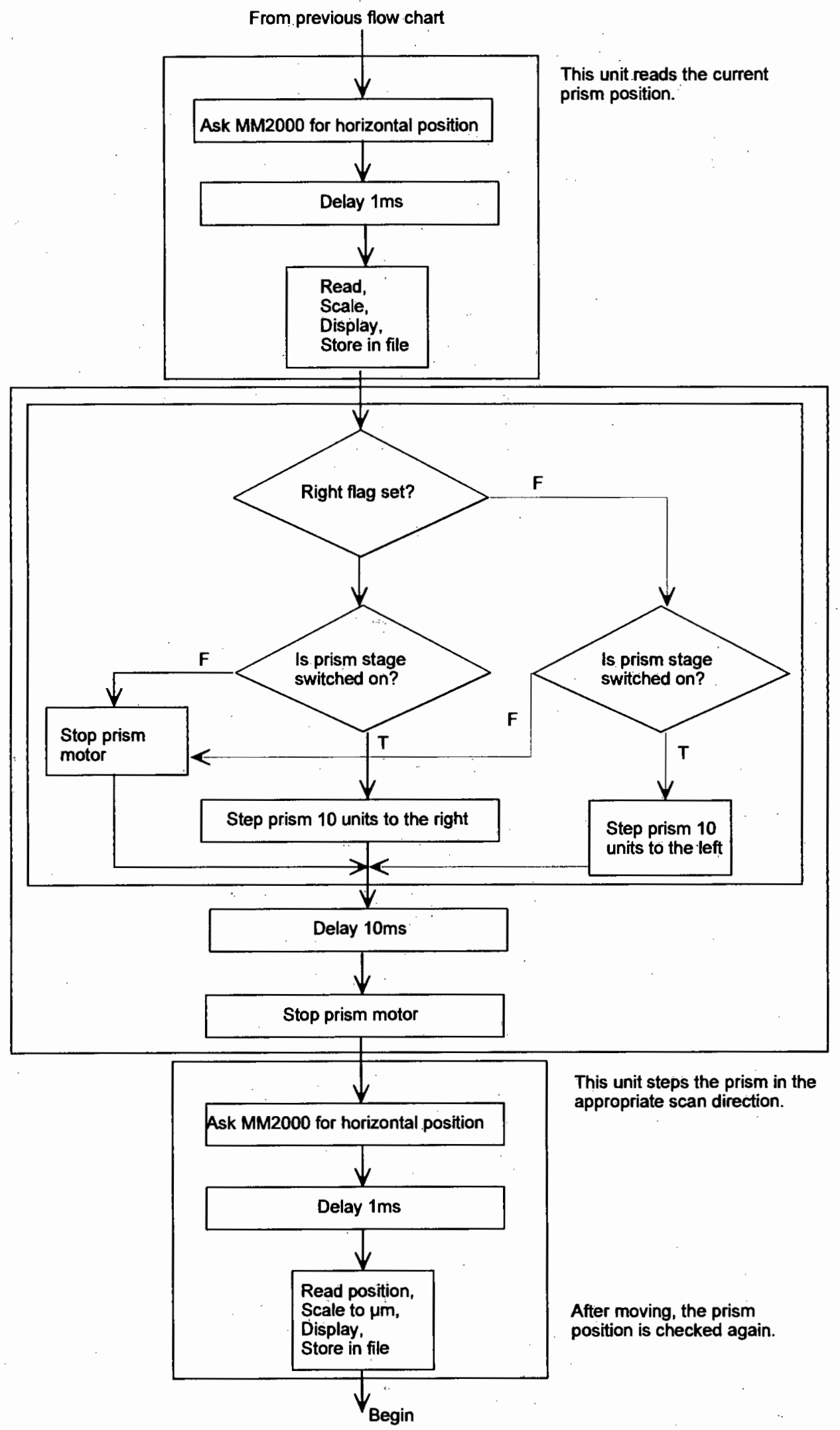

Figure 31: Flow diagram for the control of the prism stage. 
The following diagram shows the hierarchy of sub VIs used by the three LabView VIs written for this project.

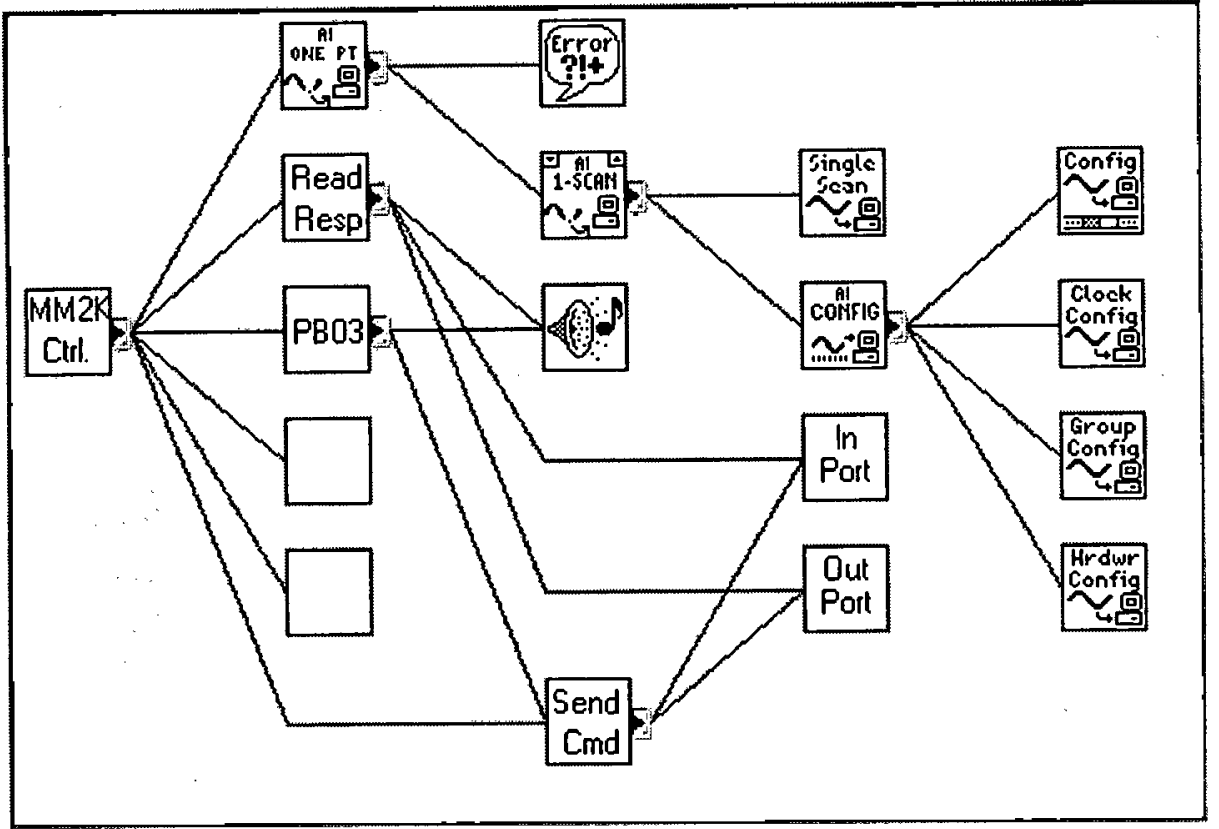

Figure 32: This hierarchy shows the relationships of the Sub VIs involved in the control of the system. Only the left two columns and the Send Cmd VI are explicitly called by the overall Subcurve VI, but the other VIs shown are used as well. 


\section{CHAPTER 4:}

\section{SYSTEM EVALUATION AND EXPERIMENTAL RESULTS}

The system as constructed gives output in the form of a file table of $(n, 5)$ dimensions, where $n$ depends on the scan length and the five variables represent the measured prism position, the horizontal position of the PSD, the vertical position of the PSD, the horizontal voltage error, and lastly the vertical voltage error. These variables are measured at approximately $0.59 \mu \mathrm{m}$ intervals, giving $n=3400$ for a $1 \mathrm{~mm}$ scan (in both directions).

The first step before we started measuring on real substrates, was to establish references in terms of which the system could be evaluated. As a reference we tested the performance of the complete system, in terms of a $1 \mathrm{~mm}$ test scan across an optically flat, front coated mirror. A factor that was also taken into account was the possible deviation which the glass of the furnace window could cause, given that the laser beam must penetrate the furnace window to reach the specimen inside the furnace. We were informed that in at least one previous system, distortion caused by the furnace window introduced errors of a size similar to the actual ROC ${ }^{14}$. The first experimental scan was thus carried out across the reference mirror, then the furnace window, and lastly directly across an actual substrate.

\subsection{Typical Results}

\subsubsection{System Evaluation}

The expected result for a perfectly flat surface would be no horizontal deviation and no vertical deviation of the beam, across the complete length of the specimen being scanned. Ideally this would be the case for all the components used in the optical path of the system. If however the ideal cannot be achieved, the introduced level of error must be small enough that the final results are not compromised in any way. It is with this aim in mind that we set out to discuss the procedures and results that were achieved during our system evaluation. 
The first step is to determine the sensitivity of the system output when scanning the mirror surface. The procedure that was followed was to minimize the error output from the PSD by centring the laser beam on the PSD, using the Autocentre VI discussed under the LabView software section. This would be the standard procedure before starting a scan. The Subcurve VI was then used to perform the actual scan. In this case, a mirror was scanned. The captured data, when plotted on a graph, should result in no movement (because it is assumed that the mirror surface is $100 \%$ flat and totally distortionless) along either axis of the PSD. The return path to the centre spot of the PSD should also result in no movement along either axis of the PSD. When displayed as a graph of PSD movement vs. prism position, we should see a straight horizontal line.

Figure 33 shows a typical system output graph of a $1 \mathrm{~mm}$ scan, representing 3390 data points, across the front coated mirror surface. A further plot (see Figure 34), shows only the forward scan portion of the graph in Figure 33. Figure 34 also shows a smoothed version of the forward scan portion. A third graph (Figure 35$)$, is based on a fraction of the recorded data ( \pm 100 data

\section{MIRROR SURFACE SCAN}

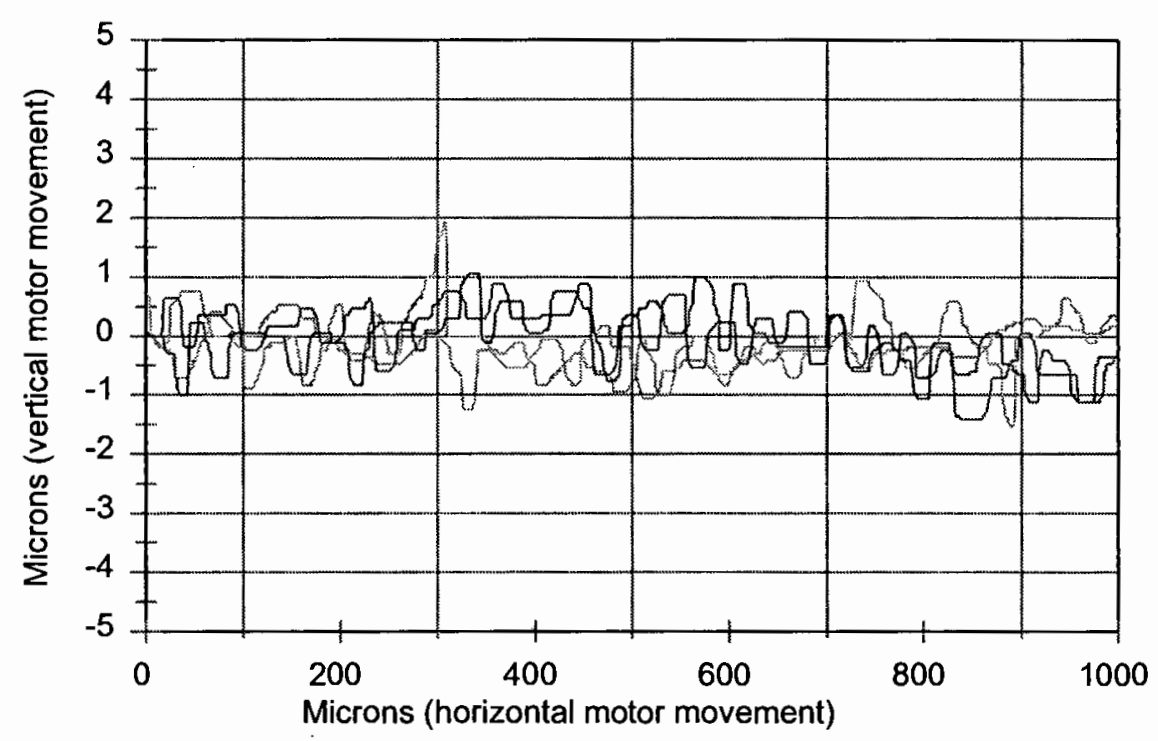

Figure 33: A $1 \mathrm{~mm}$ experimental scan across the surface of a front surface coated mirror. Two curves are shown - $X$ and $Y$ movement of the PSD - and they are shown for forward and backward prism scans. The apparent "noise" in the signals is caused by hunting of the motorized stages, which have a positioning resolution of approximately $1 \mu \mathrm{m}$. This graph is typical of the system output, and shows that the system sensitivity is well below $1 \mu \mathrm{m}$. 
points) and is exploded to clarify the result. An additional feature of this graph is that the corresponding PSD error voltage is shown.

The results shown in Figures 33, 34, and 35 shows that the forward and return paths do not result in absolutely straight lines but deviate very slightly around the horizontal axis. The PSD position tends to "dither" around the zero point owing to the use of what is effectively integral control, combined with the finite positioning ability of the stages. In spite of these deviations it can be seen from Figure 33 that the system output sensitivity is well below $1 \mu \mathrm{m}$. The apparent "noise" in the signal is caused by the hunting of the motorized stages, which have a resolution of approximately $1 \mu \mathrm{m}$. There will also be some real noise caused by minor mechanical vibrations and instabilities of the motorized stages, which result in intensity changes across the PSD quadrants. The signal error voltages (see Figure 35) that are fed back to the PC are processed, and correction instructions are then issued to the X-Y motorized stages of the PSD to keep the laser beam on the centre position. Figure 33 indicates peak overshoots of $1.8 \mu \mathrm{m}$ above the horizontal axis and $1.5 \mu \mathrm{m}$ below the horizontal axis on the forward and return paths. For a more visible analysis, a second (see Figure 34) graph was plotted. For this plot the output data was reduced to that of the forward scan only, while the same data was used to

MIRROR SURFACE SCAN

A $1 \mathrm{~mm}$ forward scan across mirror

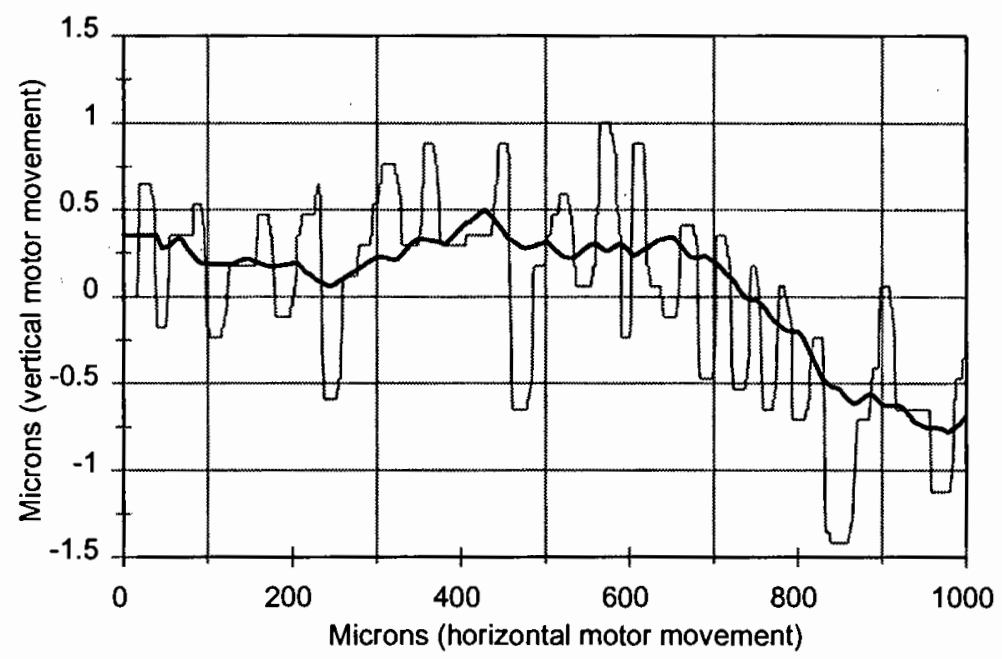

Figure 34: For clarity purposes the data from the graph in Figure 33 were truncated to provide a $1 \mathrm{~mm}$ forward scan only. This forward scan was then smoothed to show that the system sensitivity is below $1 \mu \mathrm{m}$. 
plot the average of the forward scan. Figure 34 shows clearly that the average deviation is below $1 \mu \mathrm{m}$. If it is assumed that both these lines should be straight and horizontal (assuming a perfectly flat substrate) then it can be calculated that the average and the standard deviation of $x$ and $y$ will be $x=0.158 \pm 0.439 \mu \mathrm{m}$ and $y=-0.058 \pm 0.520 \mu \mathrm{m}$. This shows that this system's sensitivity is well within the $1 \mu \mathrm{m}$ requirement.

The third graph (see Figure 35) shows an exploded view of a small section of the $1 \mathrm{~mm}$ scan. It shows the actual displacement of the $x$ - and $y$-stages of the PSD, and their corresponding error voltages. Figure 35 clearly shows the error voltages that are generated as the $\mathrm{x}$ - and $\mathrm{y}-$ stages "dither" around the zero point. When the $\mathrm{x}$-stage is followed on Figure 35 it can clearly be seen between $\pm 32 \mu \mathrm{m}$ and $\pm 47 \mu \mathrm{m}$ how the $\mathrm{x}$-stage error voltage restores the $\mathrm{x}$-stage to the zero line. The sensitivity of the system averages out to below $1 \mu \mathrm{m}$.

\section{MIRROR CALIBRATION}

Actual position and its error voltage

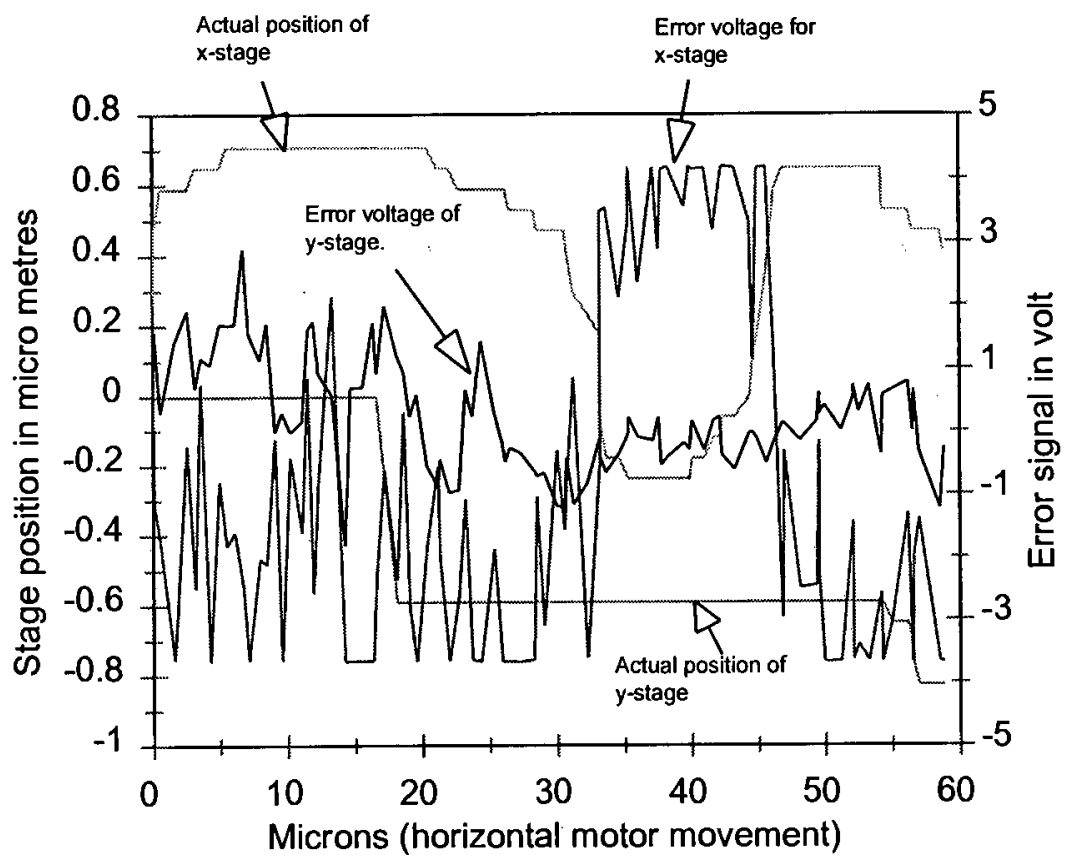

Figure 35: This graph shows the actual position of the motor, and how it hunts to find the exact position in relation to the PSD error voltage. It can be seen particularly clearly for the $x$-stage, that the motor moves to correct the error voltage. 
The second stage was to see what influence the chamber window would have on the experimental results. An absorbent material was placed under the chamber window to prevent any possible reflections from the chamber floor, and a $1 \mathrm{~mm}$ scan across the chamber window was then carried out. The results are shown in Figure 36. Here again it will be noticed that the beam spot deviated, although in this case it is not unexpected as the window is not expected to be as optically flat as the mirror. This time the results shows that there was a slight increase in deviation from the horizontal axis, which shows that the glass surface is not optically as smooth as the front coated mirror. The increase in deviation can be attributed to the composition and construction of the chamber window. An increase of $1 \mu \mathrm{m}$ above and $5.5 \mu \mathrm{m}$ below the horizontal axis was observed. It must however be noted that the hunting of the motorized stages for this scan is much less (notice how closely the forward and return scan paths are to each other) than for the mirror because the reflected laser power is less, so the error voltage from the PSD is lower. This effectively lowers the gain of the control system. This result indicates that when actual specimen evaluations are taking place compensation may have to be made to counter the influence of the chamber window on the final results. This will be more significant in cases where the substrate has a low reflectivity, and the light reflected by the

\section{CHAMBER WINDOW SCAN}

A $1 \mathrm{~mm}$ scan across the chamber window

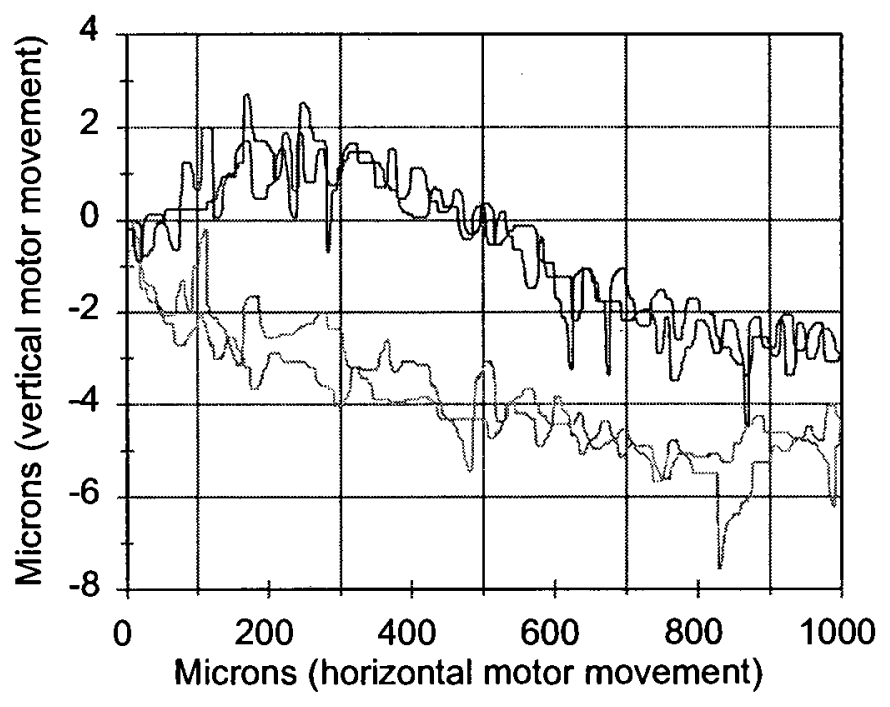

Figure 36: The stages' hunting is less in this scan because the reflected laser power is less, so the error voltage from the PSD is lower. This effectively lowers the gain of the control system. 
window makes a greater contribution to the total light reaching the PSD. It may be possible to deliberately align the window and substrate sufficiently out of parallel so that the beam reflected by the window misses the PSD altogether.

\subsubsection{Experimental Results}

During the third stage an actual coated substrate was evaluated. The substrate was scanned directly, i.e. not through the chamber window. Figure 37 shows the results that were obtained when, as in the previous stages, a $1 \mathrm{~mm}$ scan along the coated substrate was carried out. As expected it will be noticed that the beam spot deviated substantially more than was the case with the mirror or the chamber window. The reason is that the coated substrate, which was subjected to heat during coating, will not be as flat as the mirror or chamber window. Here it will be noticed that the hunting of the motorized stages is less which indicates that the reflected laser power is less, so the error voltage from the PSD is lower which effectively lowers the gain of the control system. By calculating the total $\Delta d$, using $\Delta d=\sqrt{(\Delta h)^{2}+(\Delta v)^{2}}$ and using equation (1), the ROC of this coated substrate can be calculated.

\section{SUBSTRATE SCAN}

A $1 \mathrm{~mm}$ scan on an actual substrate

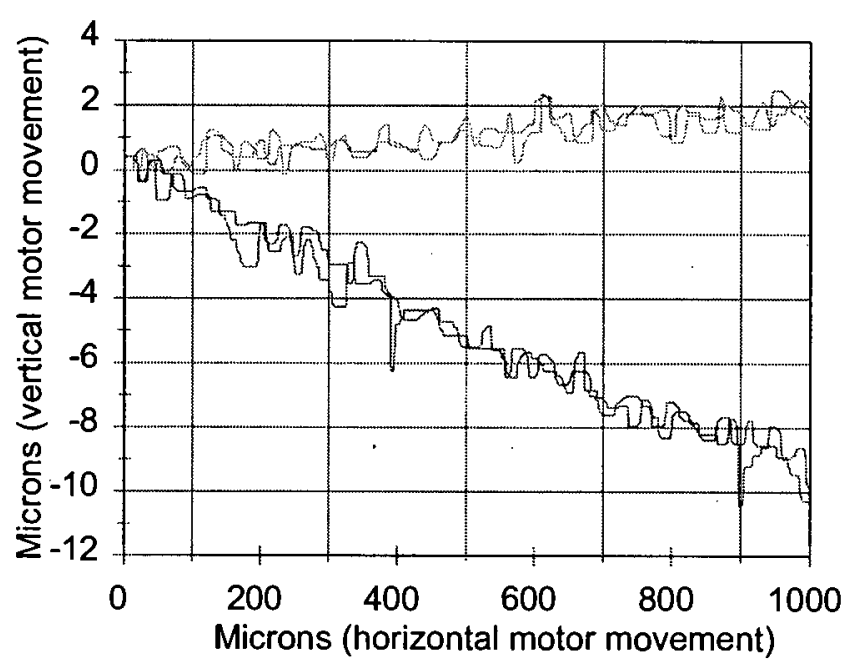

Figure 37: Results of a $1 \mathrm{~mm}$ scan across an actual substrate. The graph shows that the substrate is curved in both horizontal and vertical planes. 
Using the data from Figure 38 the substrate ROC is calculated as follows:

$$
\text { total } \begin{aligned}
\Delta d & =\sqrt{(\Delta h)^{2}+(\Delta v)^{2}} \\
& =\sqrt{(9.794)^{2}+(2.124)^{2}} \\
& =10.0217 \mu \mathrm{m}
\end{aligned}
$$

thus,

$$
\begin{aligned}
R O C & =2 L(\Delta x \div \Delta d) \\
& =2 \times 1\left(1 \times 10^{-3} \div 10.0217 \times 10^{-6}\right) \\
& =199.567 \mathrm{~m}
\end{aligned}
$$

\section{SUBSTRATE SCAN}

A $1 \mathrm{~mm}$ scan to calculate Substrate ROC

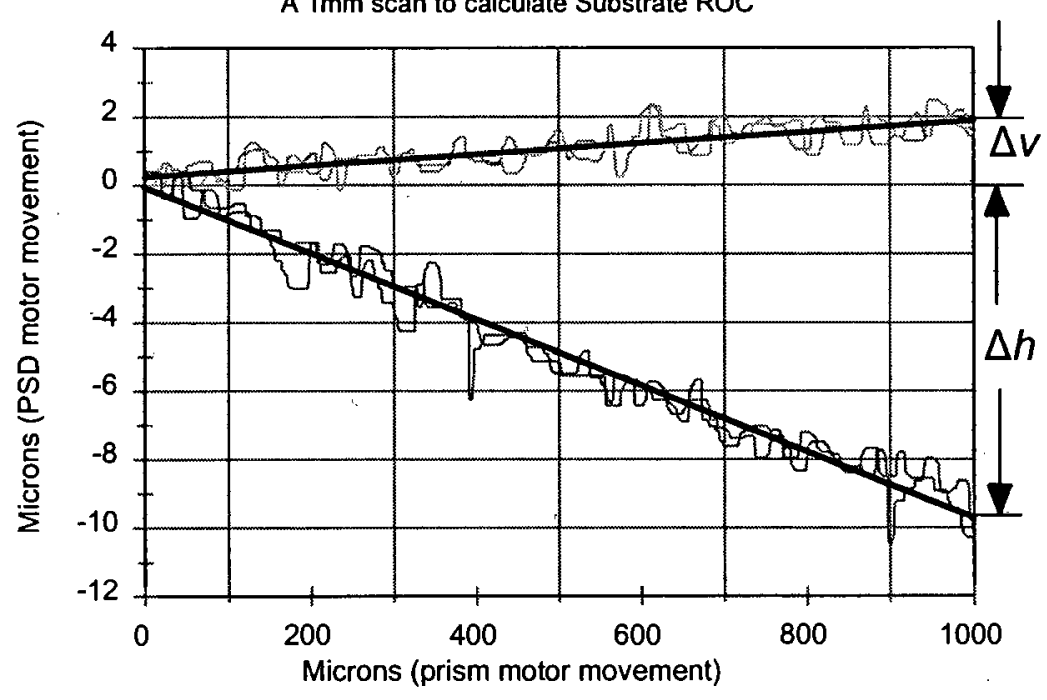

Figure 38: This graph shows the measurement of deviation that took place across the horizontal and vertical planes, while scanning an actual coated substrate. The $h$ - and $v$-deviation can now be used to calculate the substrate ROC. 


\subsection{Reduction of Position Inaccuracy using Error Voltage}

Due to the PSD "dithering" around the zero point a very slight position inaccuracy is introduced into the system. Looking at Figure 39, which represents the x-stage displacement of the PSD versus error voltage only, it can clearly be seen that the error voltage indicates how off-position the $\mathrm{x}$-stage is. To minimize this very slight position inaccuracy in the system, the corresponding error voltage gain is used to filter the $x$ - and $y$-stages of the PSD. The procedure that was followed to achieve this is described below.

MIRROR CALIBRATION

Actual position and its error voltage

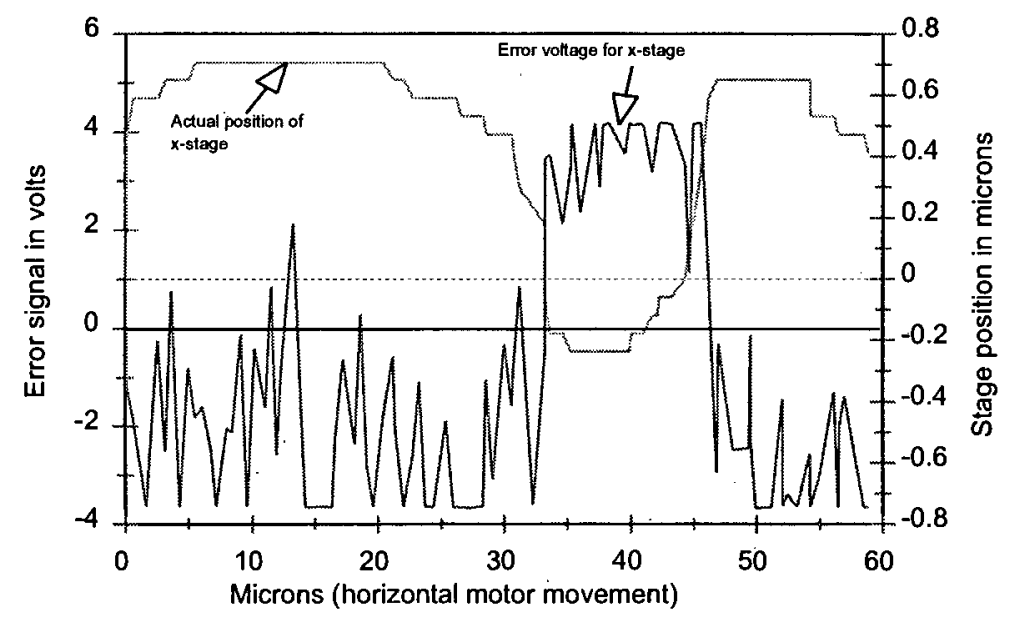

Figure 39: This graph shows the actual position of the motor, and how it hunts to find the exact position in relation to the PSD error voltage. It can be seen particularly clearly for the $x$-stage, that the motor moves to correct the error voltage.

\subsubsection{Error voltage scan procedure}

The PSD was moved relative to a stationary beam, to simulate the effect of a moving beam on a stationary PSD (see Figure 40). This was done for each type of surface (mirror, glass and substrate) for comparative purposes. The results for each type of surface will be discussed separately. 


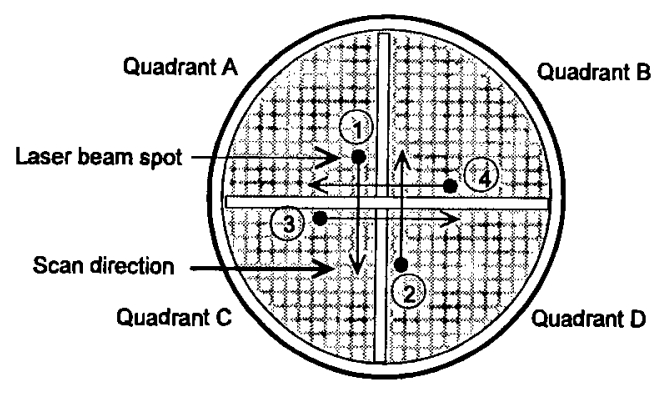

Figure 40: This diagram shows the relative movement of the laser beam along the $x$ - and $y$-axis when recording the inherent voltage error induced by the quadrant-to-quadrant transition of the PSD.

\subsubsection{Mirror Calibration Scan}

Figure 41 shows the 2-dimensional scan, of PSD displacement versus error voltage that was obtained for the mirror. When analysing this graph it will be noticed that there are two distinct

MIRROR CALIBRATION

Scanning through centre of PSD

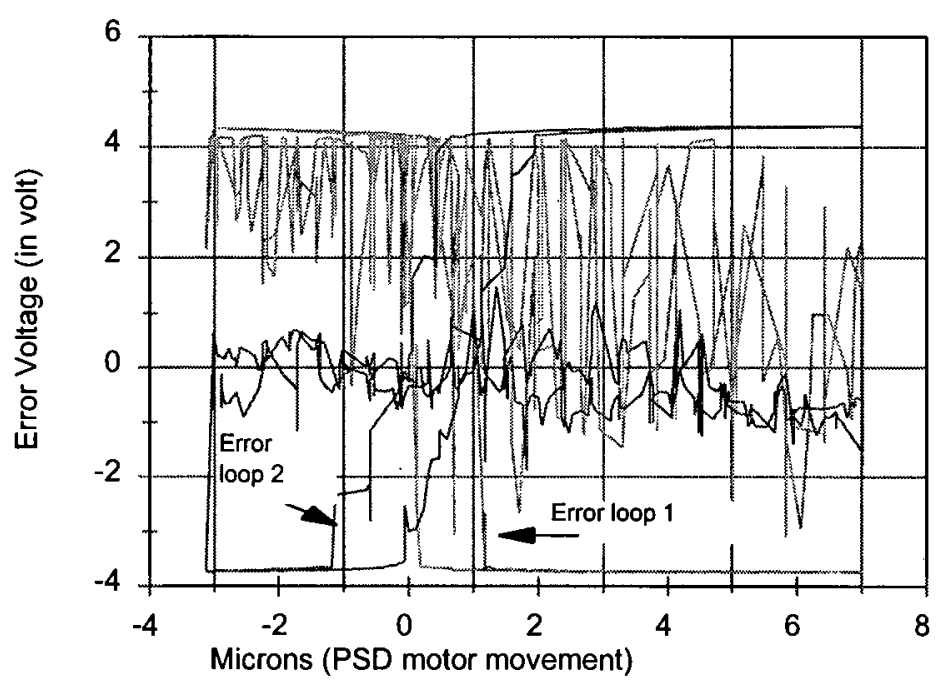

Figure 41: This graph shows the vertical and horizontal scan paths through the PSD centre. In both instances it will be noticed that the scans start from a point of saturation, move through the zero point to a further saturation point and then return to the origin. During this movement a voltage error hysteresis loop is formed. Two virtually identical error loops are formed. The slope of these loops are an indication of the amount of error induced into the system. 
plots. Each plot is related to the scan paths illustrated by Figure 40 above. Both scan paths shows a distinct voltage hysteresis loop (Figure 41, error loops 1 and 2). These loops result from the mechanical play in the stages, and represent the positioning inaccuracy due to backlash. Two further graphs (Figures 42 and 43) are used to clarify the plots in Figure 41.

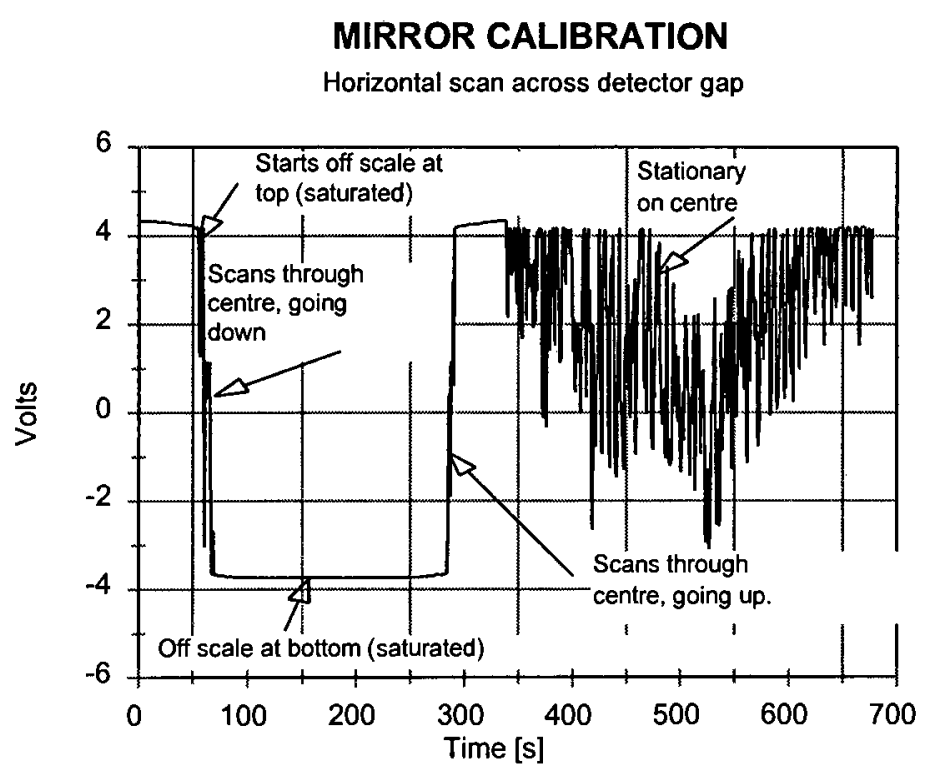

Figure 42: This graph represents error loop 1 in figure 38. It clearly shows the beam crossing the horizontal gap in the detector. Notice how the graph starts at $a \pm 4 \mathrm{~V}$ saturation point in the first quadrant, scans through the PSD centre until it reaches the next saturation point $( \pm-4 V)$ in the next quadrant. The slope of this graph between saturation points is an indication of the magnitude of the error voltage for a given displacement.

These graphs show the transitions across the horizontal and vertical axes of the detector on a time versus error voltage comparison. A further graph, which is a combination of Figures 42 and 43 will be used to show both quadrant-to-quadrant transitions and the relevant motor movement.

Looking at Figures 42 and 43, it will be noticed that Figure 42 represents error loop 1 in Figure 41 (scan across the horizontal gap of the detector), and Figure 43 represents error loop 2 (scan across the vertical gap of the detector) in the same figure. The plot in Figure 42 shows that the 
initial output from the first quadrant is at $\mathrm{a} \pm 4 \mathrm{~V}$ saturation point. This output should remain unchanged irrespective of PSD movement. The graph however shows that once the laser beam scans down through the horizontal gap of the detector, that there is actually a slight change in the output voltage before it reaches its saturation level in the next quadrant. On the return path, scanning again through the horizontal gap of the detector a similar change in output voltage is experienced. The slopes of these voltage changes between the saturation points is a clear indication of an error voltage that is induced into the system. Analysing Figure 43 shows similar results for the vertical scans through the vertical gap of the detector. The apparent "noise" that is visible around the zero lines in both graphs, is a result of the hunting of the PSD stage after returning to the centre. Determining the average gradient of these loops make it possible to calculate the amount of position inaccuracy for any measurement. Once the amount of error is determined, the system can be correctly pre-calibrated. The following section will briefly discuss the determination of the required system calibration voltage.

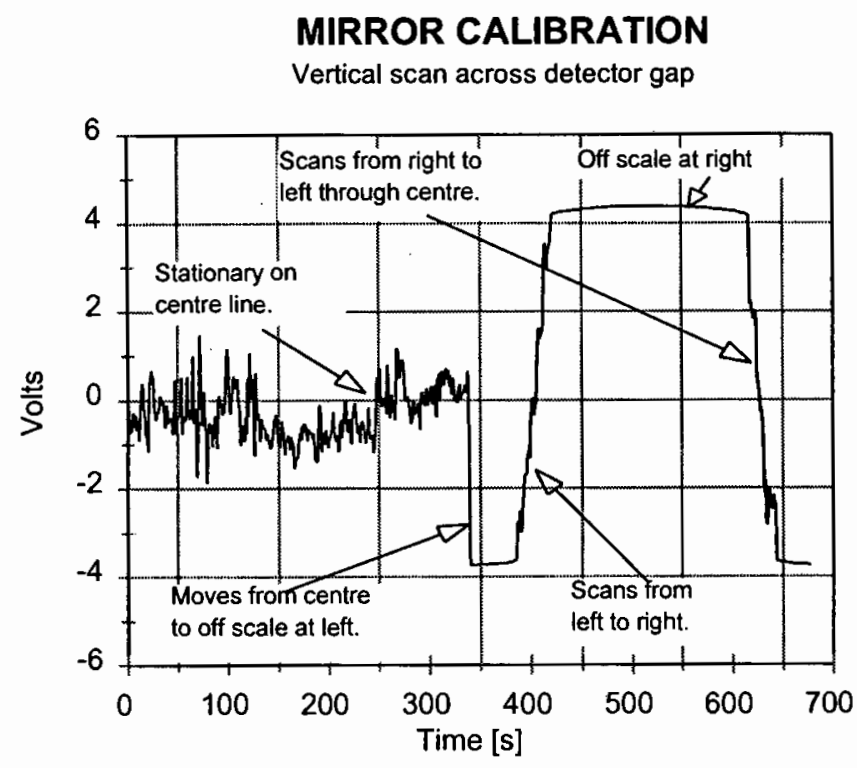

Figure 43: This graph represents error loop 2 in figure 41. In this graph the beam crossing the vertical gap in the detector is displayed. The output for this graph is similar to that displayed in Figure 42. 


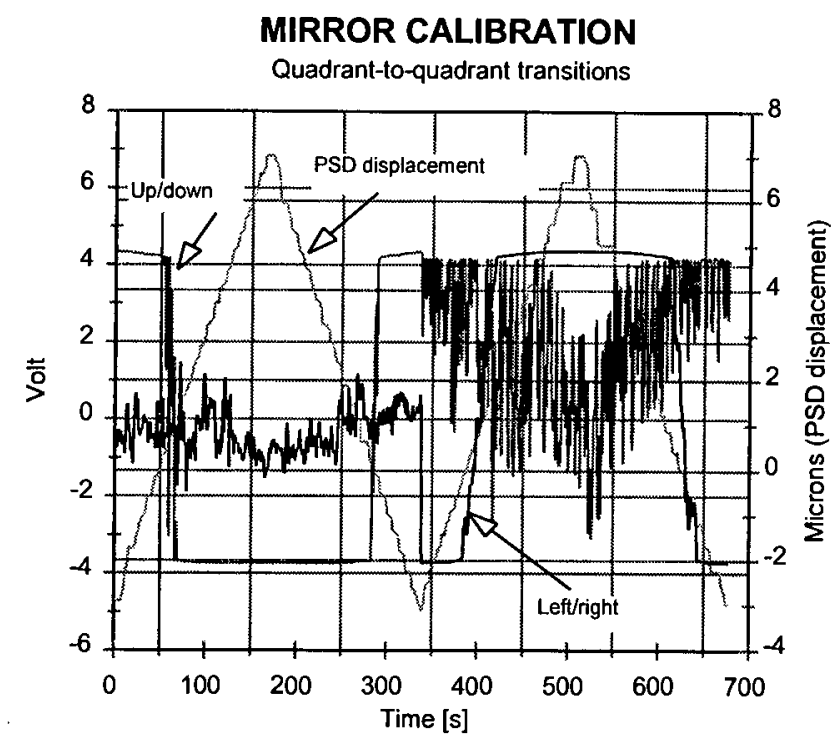

Figure 44: In this graph the combination of the horizontal and vertical scans, together with the relevant PSD displacement is shown.

\subsubsection{Calculating Error Voltage Gain}

For the sake of simplicity, a single mirror scan is used to illustrate how the error voltage gain for the system is calculated. No reduction in accuracy is caused by this simplification. From the data used to plot the graph in Figure 41 the gradients for slopes 1 and 2 were determined. From this an average slope for the up/down scan across the detector horizontal gap was established. The values from the graph for $d V_{l}$ were taken between $4.199 \mathrm{~V}$ and $-3.665 \mathrm{~V}$, and the corresponding values for $d x_{1}$ between $0.354 \mu \mathrm{m}$ and $0.649 \mu \mathrm{m}$.

The average error voltage gain $/ \mu \mathrm{m}$ can now be calculated as follows:

$$
\begin{aligned}
\text { Average error voltage gain } & =\frac{d V_{1}}{d x_{1}} \\
& =\frac{7.864 \mathrm{~V}}{0.295 \mu \mathrm{m}} \\
& =26.658 \mathrm{~V} / \mu \mathrm{m}
\end{aligned}
$$


MIRROR CALIBRATION

Error voltage gain calculation

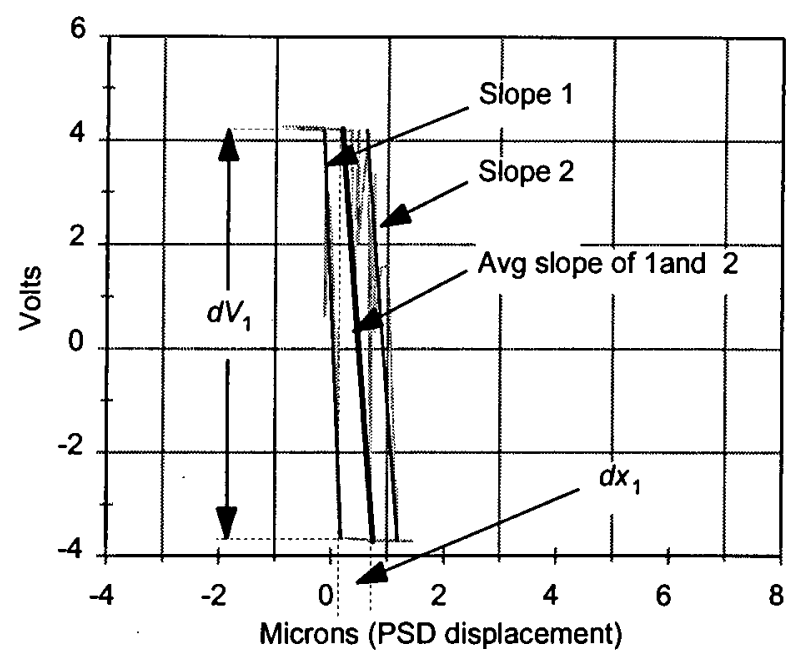

Figure 45: This graph shows the two slopes for the up/down quadrant transition of the mirror. An average curve for these two slopes was determined and the average error voltage gain per $\mu \mathrm{m}$ then calculated.

\subsubsection{Chamber Window Calibration}

Calculating the error voltage gain induced by the glass surface of the furnace chamber window, the same procedure as for the mirror was followed. The difference is that the error was calculated for both error loops, because unlike the mirror it was found (see Figure 46) that the error loops differed slightly in slope. A possible reason for this is that the beam is not radially symmetric (which is quite possible given that the source is a laser diode). This would give us different beam profiles on different axes, and hence different voltage gains.

$$
\begin{aligned}
\text { Average error voltage gain, loop } 1 & =\frac{d V_{1}}{d x_{1}} \\
& =\frac{3.919 \mathrm{~V}}{4.127 \mu \mathrm{m}} \\
& =0.9496 \mathrm{~V} / \mu \mathrm{m}
\end{aligned}
$$

Average error voltage gain, loop $2=\frac{d V_{2}}{d x_{2}}$

$$
\begin{aligned}
& =\frac{2.5245 \mathrm{~V}}{5.962 \mu \mathrm{m}} \\
& =0.4234 \mathrm{~V} / \mu \mathrm{m}
\end{aligned}
$$




\section{GLASS SURFACE CALIBRATION}

Error voltage calculation

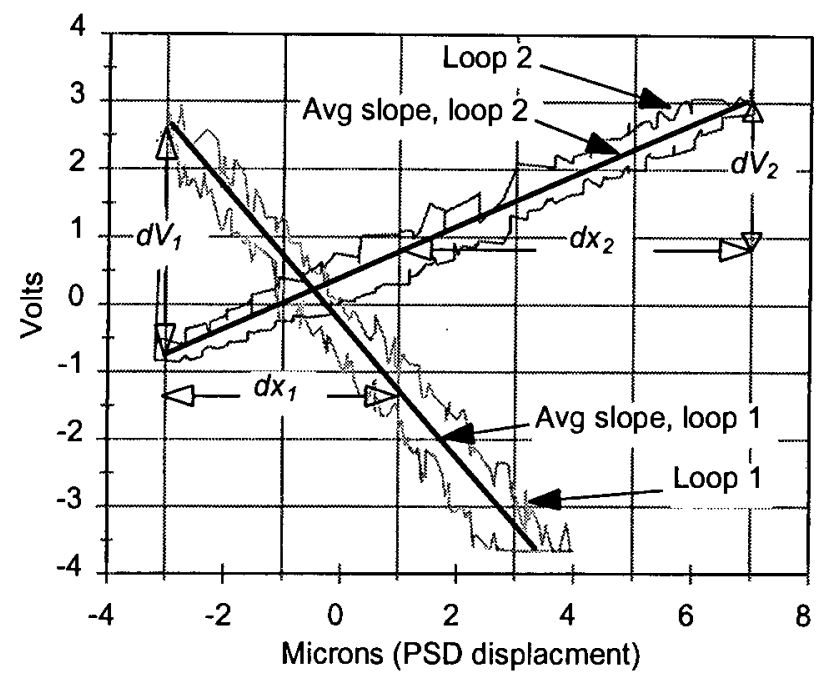

Figure 46: For clarity the data of the above graphs were rearranged to show error loops 1 and 2 . The gradients for both slopes of loops 1 and 2 were determined. An average slope for each loop was then calculated. From these averages, the average voltage gain/ $\mu \mathrm{m}$ was then calculated. Loop 1 produced an average error voltage gain of $0.9496 \mathrm{~V} / \mathrm{\mu m}$ and loop 2 an average voltage gain of $0.4234 \mathrm{~V} / \mu \mathrm{m}$.

\section{GLASS SURFACE CALIBRATION}

Quadrant-to-quadrant transition scans

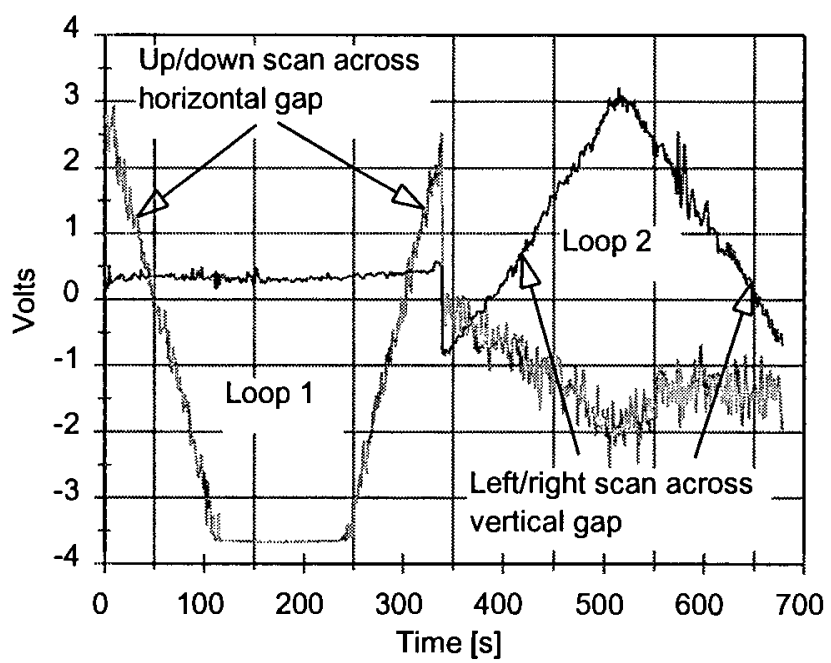

Figure 47: This graph shows the scans across the horizontal and vertical gaps of the detector respectively. 


\subsubsection{Substrate Calibration Scan}

The same procedure as for the mirror and the chamber window glass were followed during the substrate scan. As expected two similar loops ( see Figure 48) with slightly different gradients were once again produced. The slope of loop1 for the substrate is very similar to that of loop 1 for the mirror, with a slight reduction in error voltage gain. The average slope for each loop was determined and hence the average voltage gain calculated for each loop.

\section{SUBSTRATE CALIBRATION}

Error voltage gain calculation

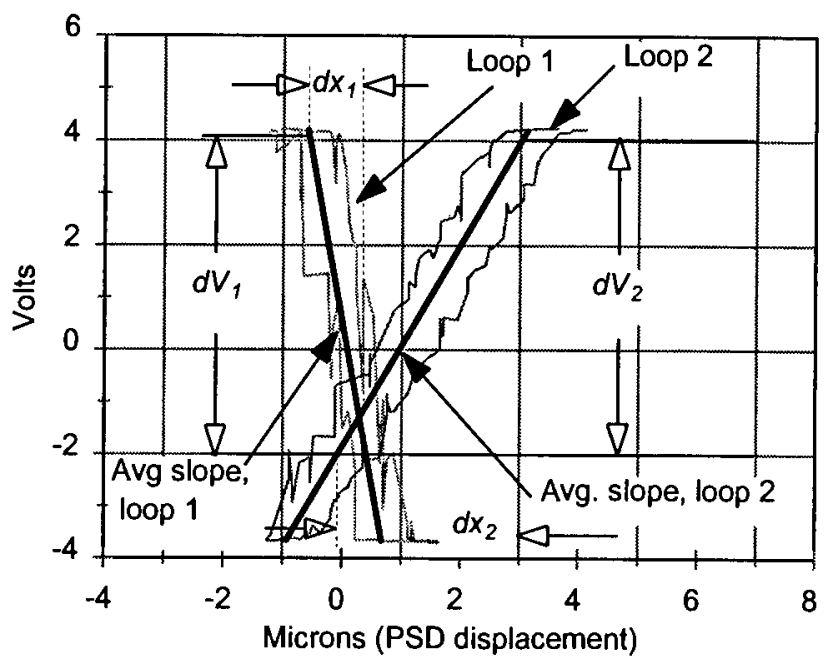

Figure 48: Two similar looking loops were produced from the data collected from the horizontal and vertical scans across the gaps of the detector. Notice how similar loop 1 looks to that of loop 1 for the mirror. An average error voltage of $8.1368 \mathrm{~V} / \mu \mathrm{m}$ for loop 1 , and an average error voltage gain of $1.9958 \mathrm{~V} / \mu \mathrm{m}$ for loop 2 was calculated.

Average error voltage gain, loop $1=\frac{d V_{1}}{d x_{1}}$

$$
\begin{aligned}
& =\frac{6.241 \mathrm{~V}}{0.767 \mu \mathrm{m}} \\
& =8.1369 \mathrm{~V} / \mu \mathrm{m}
\end{aligned}
$$

Average error voltage gain, loop $2=\frac{d V_{2}}{d x_{2}}$

$$
\begin{aligned}
& =\frac{6.241 \mathrm{~V}}{3.127 \mu \mathrm{m}} \\
& =1.9958 \mathrm{~V} / \mu \mathrm{m}
\end{aligned}
$$


A plot of error voltage vs. time shows that both scans produced similar results.

\section{SUBSTRATE CALIBRATION}

Substrate quadrant-to quadrant scans

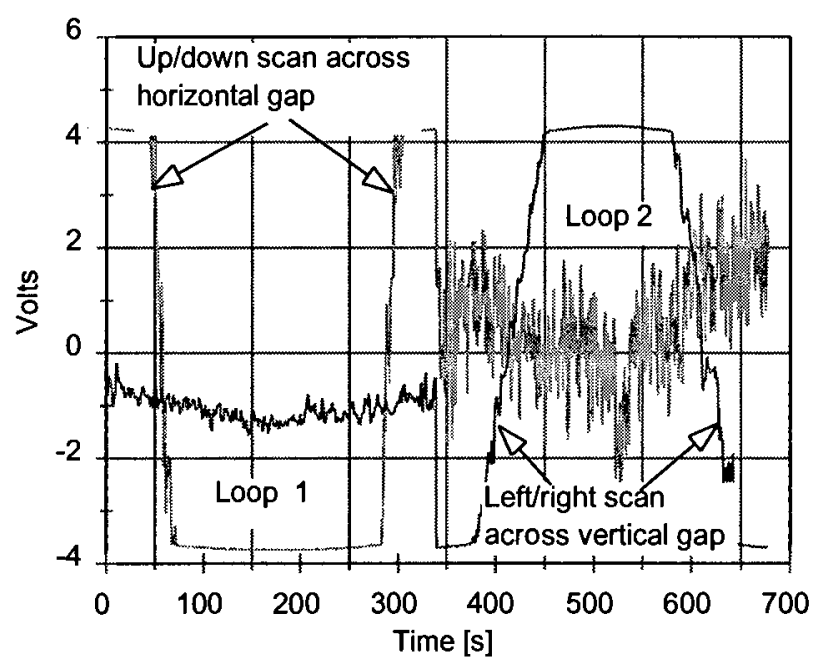

Figure 49: This graph shows clearly that similar, and relatively symmetrical results were achieved with the scans across the horizontal and vertical gaps of the detector.

\subsection{Analysis of Results using Error Voltage}

The final stage of this work is to show the effect of error calibration on the overall system operation and position accuracy. The accuracy of the system is not limited by the $1 \mu \mathrm{m}$ stage positioning resolution, as long as the sub-micron error can be determined from the PSD error voltage. Using the error voltage gain calculated in the previous section, we can calculate the

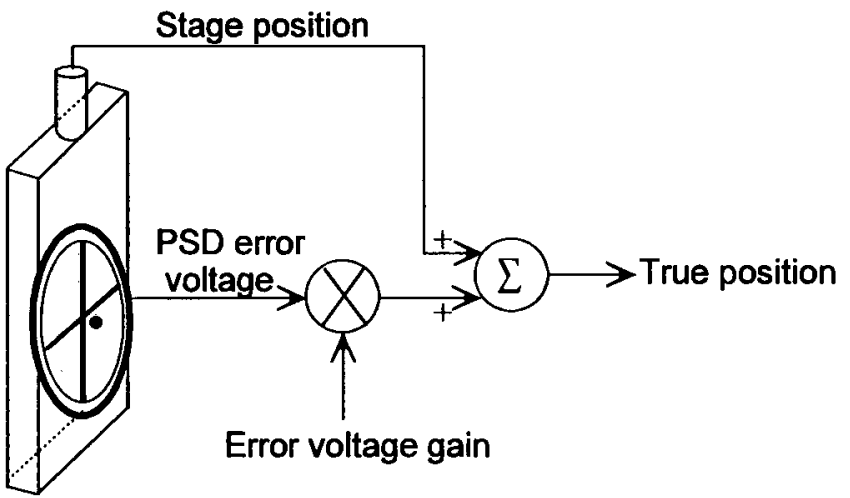

Figure 50: This diagram shows how the PSD error voltage and the error voltage gain are summed with the stage position to provide the true beam position. 
true beam position. Two graphs are used to show the outcome of the introduction of the previously calculated error voltage gains into the system. Figure 51 is an extract of the mirror scan in Figure 35. This figure shows the actual position of the $\mathrm{x}$-stage and its corresponding error voltage. The third plot in this figure shows the result obtained after the previously calculated average error voltage gain of $26.658 \mathrm{~V} / \mu \mathrm{m}$ were introduced into the system. It will be noticed that the result obtained for the mirror is virtually a straight line which would indicate a tendency towards zero positional error. The average and standard deviation was calculated as $0.0349 \mu \mathrm{m} \pm 0.0966 \mu \mathrm{m}$. Figure 52 shows the PSD y-stage of the actual coated substrate scan used during the experimental stage, and the result obtained after the average error voltage gain of $1.9958 \mathrm{~V} / \mu \mathrm{m}$ was introduced into the system. The results show that the system sensitivity is well below one micron, which is an overall improvement on previously reported systems.

\section{MIRROR SCAN}

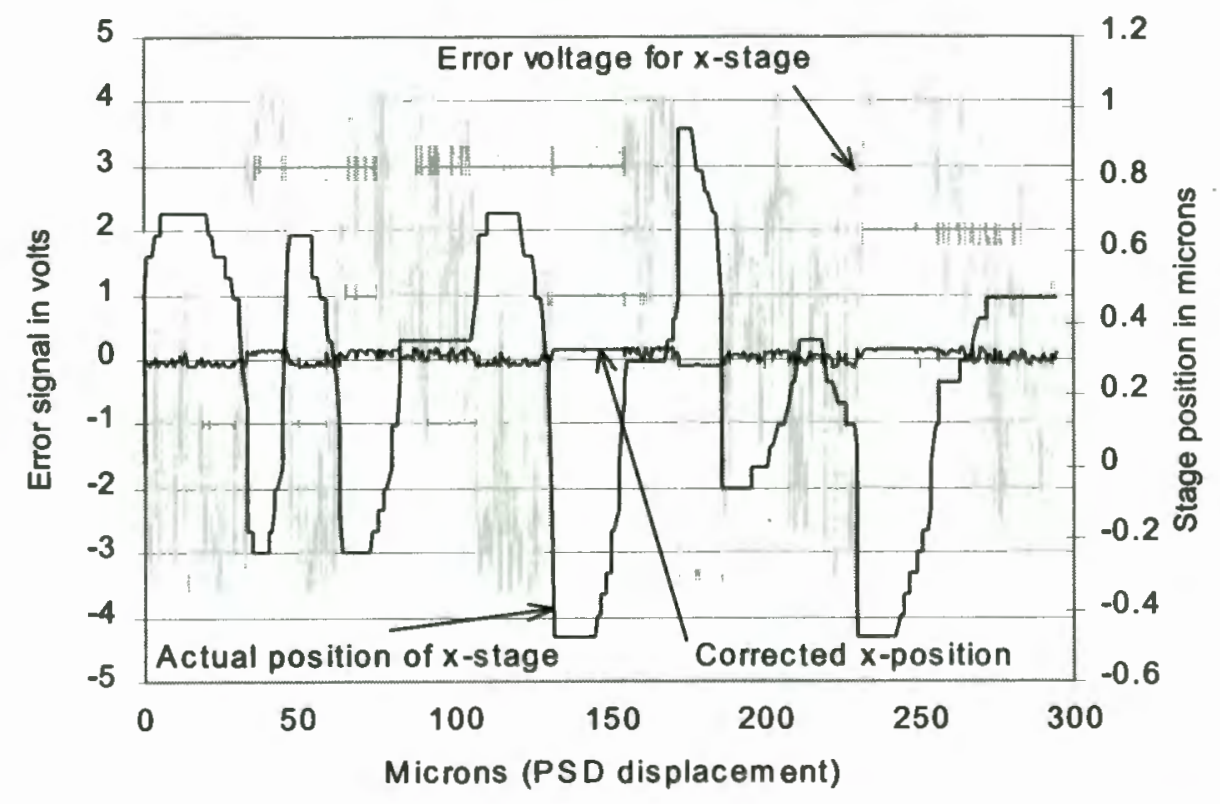

Figure 51: This graph is an extract from the graph in Figure 35. The PSD $x$-stage and its corresponding error voltage together with their stage position correction is shown. The stage position correction is achieved through the introduction of the average voltage gain previously calculated $(26.658 \mathrm{~V} / \mu \mathrm{m})$. 


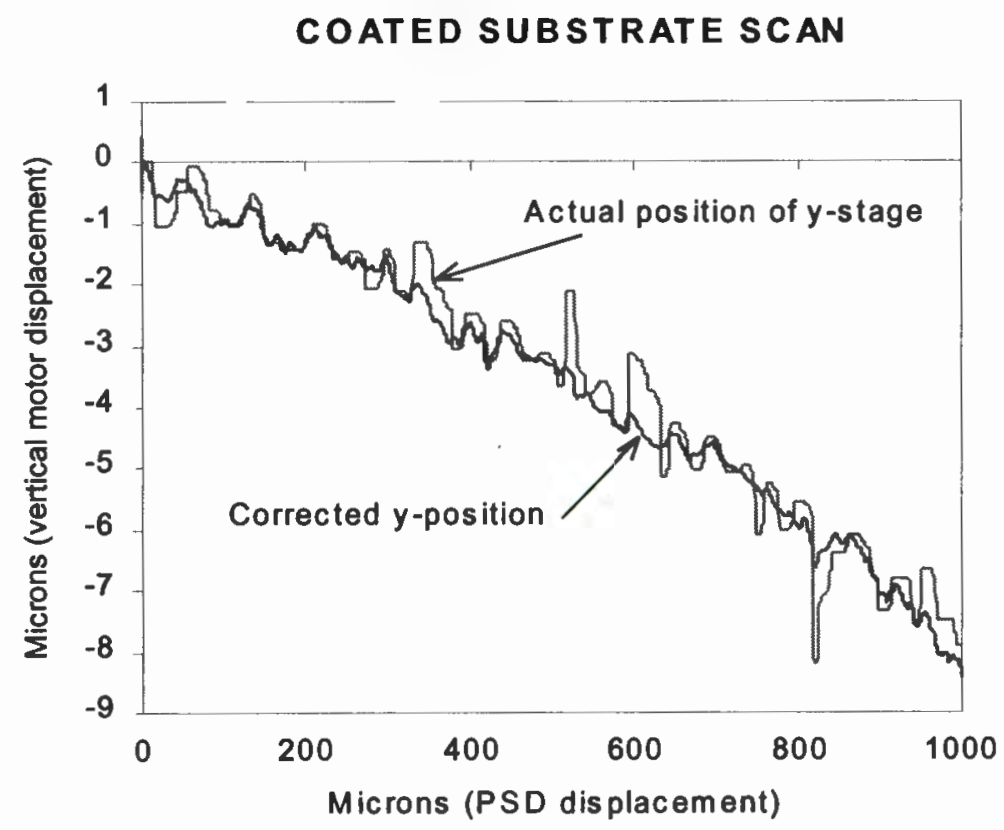

Figure 52: This graph shows the PSD y-stage and its position correction. The stage position correction was achieved through the introduction of the average error voltage gain previously calculated for this stage $(1.9958 \mathrm{~V} / \mathrm{\mu m})$. It can be seen from this graph and Figure 50 that the introduction of error voltage correction reduces the positional error to well below $1 \mu \mathrm{m}$.

It would be possible to adapt the main VI to automatically perform a substrate calibration, and then to correct the position error in real time. This is envisaged for a future iteration of this system. 


\section{CHAPTER 5:}

\section{CONCLUSIONS AND RECOMMENDATIONS}

This project has investigated the feasibility of improving on existing curvature measurement systems. The approach followed was to develop an electro-optical system embodying the successful principles of previous systems while eliminating the drawbacks. Factors affecting the design of this system and the theoretical analysis of aspects of its operation have been performed. The limitations of photodetector geometry were resolved through the use of a four quadrant position sensing detector (PSD), motorized stages, and LabView software and programs. This made it possible to achieve high data collection rates. Positioning errors were minimized through the calculation of the average error voltage for a given substrate and the use of this factor to correct the position inaccuracy. This was further enhanced by the 2dimensional scan capability of the system. The system provided a high degree of stability due to the minimal number of moving components involved in the optical path. The final results showed that system sensitivity is well below $1 \mu \mathrm{m}$, and positional accuracies in ROC in excess of $10 \mathrm{~km}$ were achieved.

Positioning and mounting of the substrates at the bottom of the furnace remains problematic and time consuming. This problem is magnified because of the small physical dimensions and material composition of substrates, when large quantities of substrates need to be tested. Future development could be done on a repeatable mounting system to allow for repeatable substrate measurements. Further future developments could possibly be done on the automation of error voltage gain calibration and correction, and the use of automatic backlash correction. 


\section{REFERENCES}

1. M.E. Thomas, "The use of profilometers for the measurement of wafer curvature", Science and Technology Vol. 6, No. 4, pp 2570-2571, Jul/Aug 1988.

2. L.I. Maissel and R. Glang, "Handbook of Thin Film Technology", $1{ }^{\text {st }}$ Edition, (McGraw -Hill, New York , 1970), Chapter 12, pp 3-47.

3. G.J. Leusink, T.G.M. Oosterlaken, G.C.A.M. Janssen, and S. Radelaar, "In situ sensitive measurement of stress in thin films", Rev. Sci. Instrum., Vol. 63, No. 5, pp 3143-3146, May 1992.

4. Joon Woe Choe, Jesus Noel Calata, and Guo-Quan Lu, "Constrained-film sintering of a gold circuit paste", J. Mater. Res., Vol. 10, No. 4, pp 982-994, April 1995.

5. Carina Kylner and Lars Mattsson, "An Optical instrument for overall stress and local stress relaxation analysis in thin metal films", Rev. Sci. Instrum. 68 (1), pp 143-149, January 1997.

6. A.K. Sinha, H.J. Levinstein, and T.E. Smith, "Thermal stresses and cracking resistance of dielectric films ( $\mathrm{SiN}, \mathrm{Si}_{3} \mathrm{~N}_{4}$, and $\mathrm{SiO}_{2}$ ) on Si substrates", J. Appl. Phys. 49(4), pp 2423-2426, April 1987.

7. J.T. Pan and Ilan Blech, "In situ stress measurement of refractory metal silicides during sintering", J. Appl. Phys. 55(8), pp 2874-2880, 15 April 1984.

8. T.F. Retajczyk, Jr., and A.K. Sinha, "Elastic stiffness and thermal expansion coefficients of various refractory silicides and silicon nitride films", Thin Solid Films, 70, pp 241-247, 15 February 1980.

9. Paul A. Flinn, Donald S. Gardner and William D. Nix, "Measurement and Interpretation of Stress in Aluminium-Based Metallization as a Function of Thermal History", IEEE Transactions on Electron Devices, Vol. Ed-34, No. 3, pp 689-699, March 1987. 
10. V.L. Teal and S.P. Murarka, "Stresses in $\mathrm{TaSi}_{x}$ films sputter deposited on polycrystalline silicon", J. Appl. Phys. 61 (11), pp 5038-5046, 1 June 1987.

11. Endel Uiga, "Optoelectronics", Chapter 4, pp 129-160, 1 st Edition, Prentice Hall Inc. New Jersey, 1995.

12. UDT Sensors, "Standard Photo Detector Component Catalogue”, pp 51-52, 1998, UDT Sensors, Inc., 12525 Chadron Avenue, Hawthorne, CA 90250.

13. National Instruments, “LabView, Graphical Programming for Instrumentation”, 1996, 6504 Bridge Point Parkway, Austin, TX 78730-5039.

14. Personal communication, D. Josell, NIST, Gaithersburg, MD, USA, July 1998. 
APPENDICES 


\section{Appendix A}

Components on which the optical system for substrate curvature measurement will be mounted.
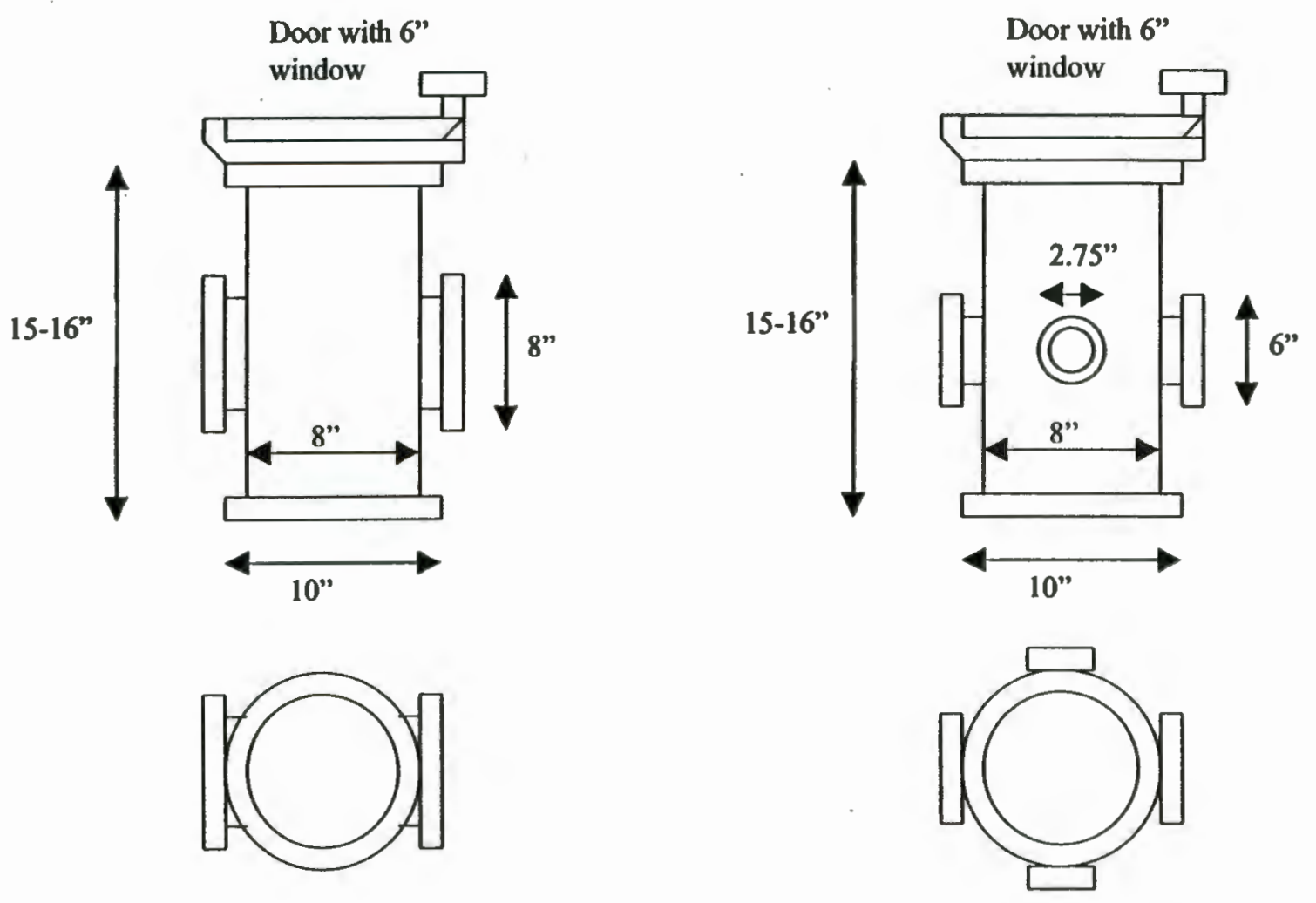

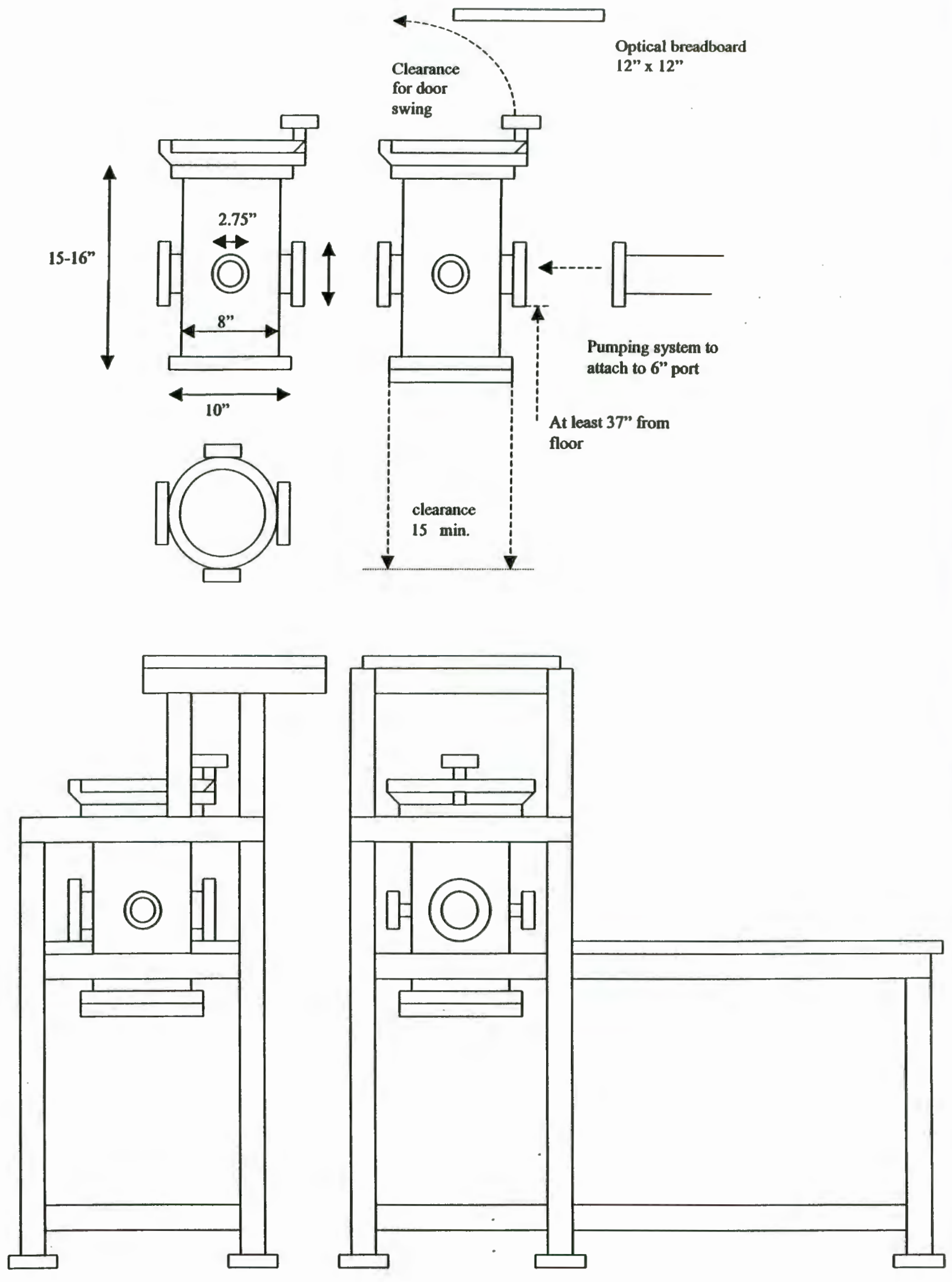
Basic chamber based on

6-way reducing cross
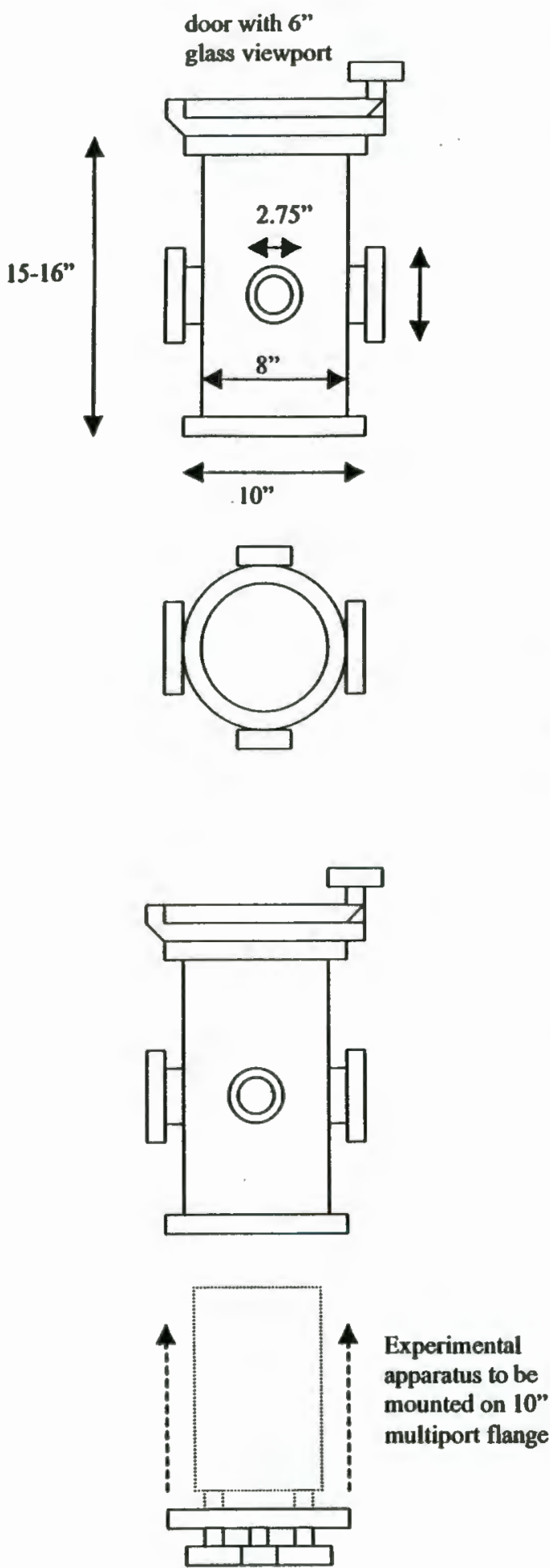
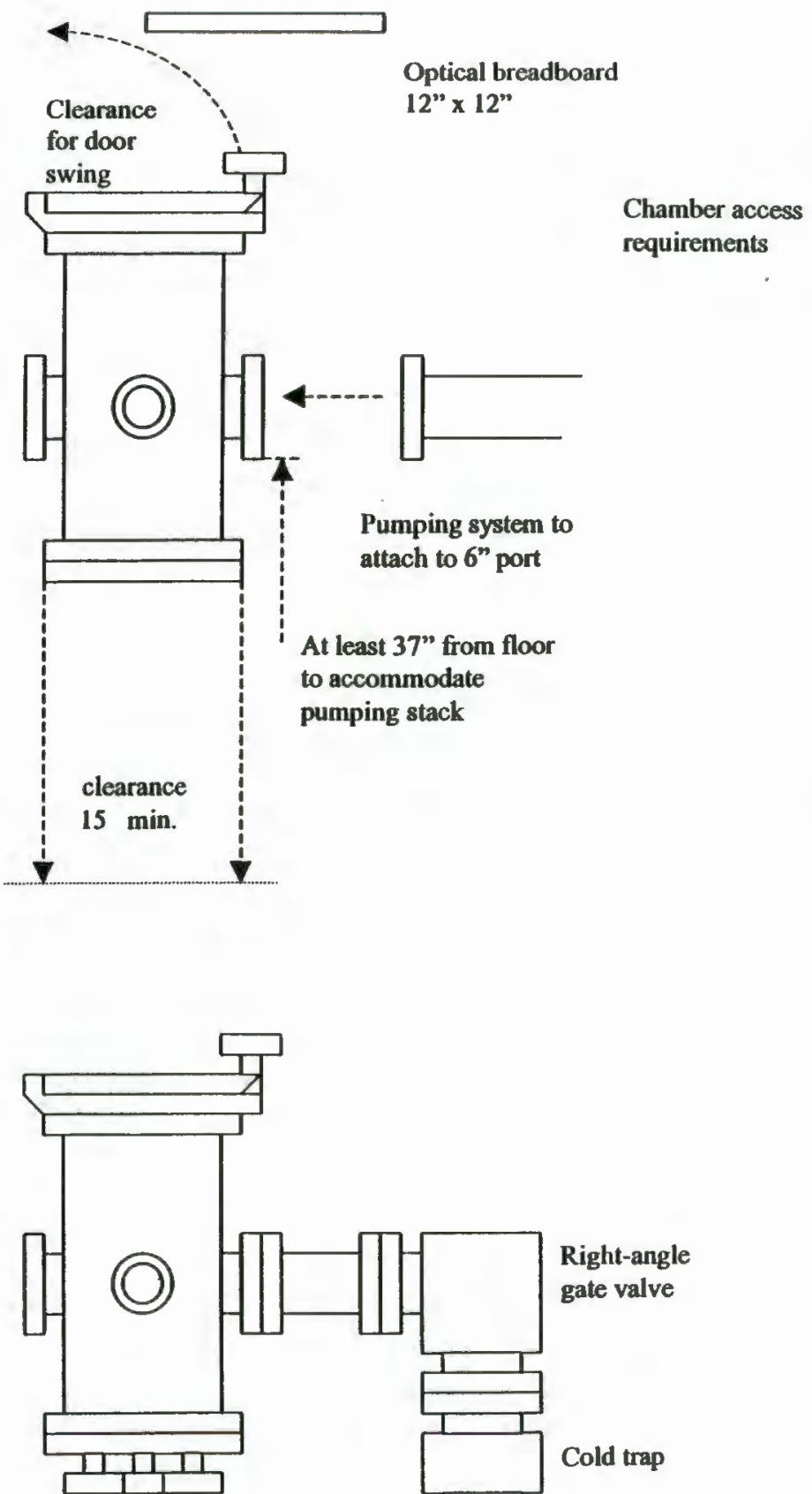

Right-angle gate valve

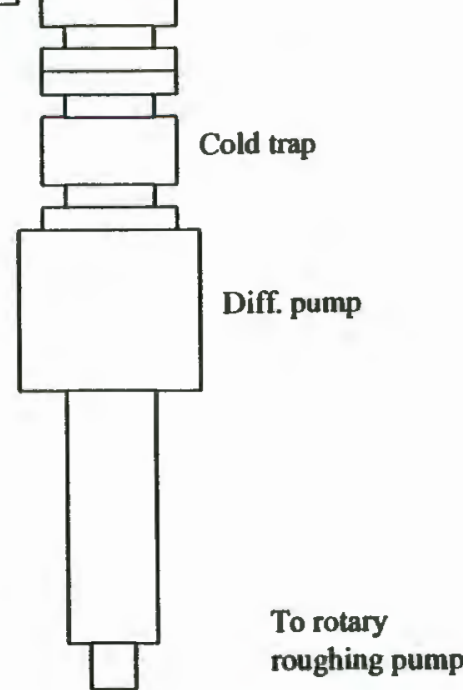




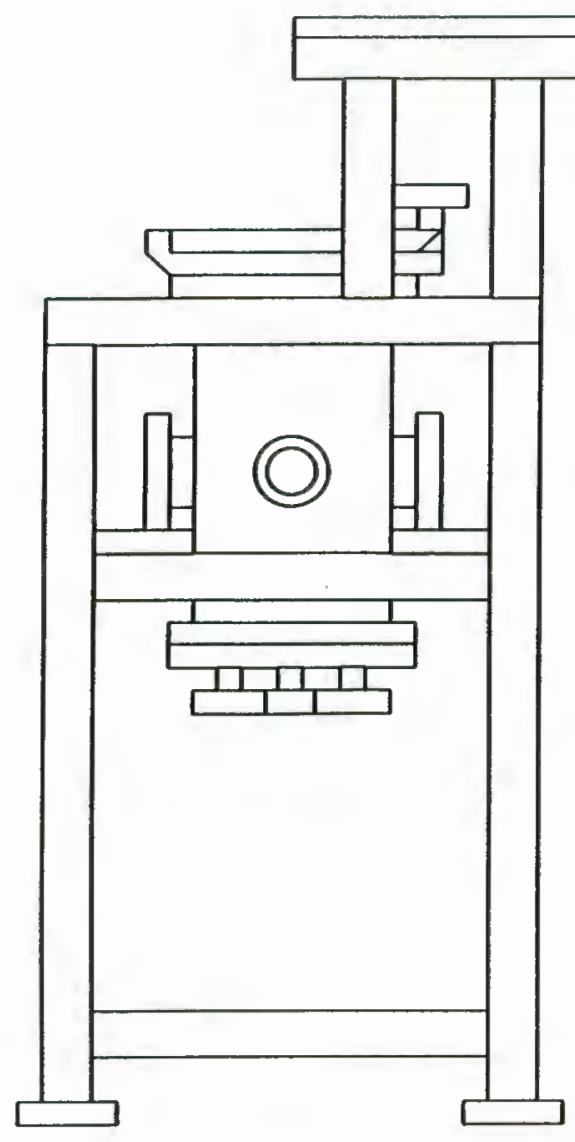

Concept sketches - not to scale

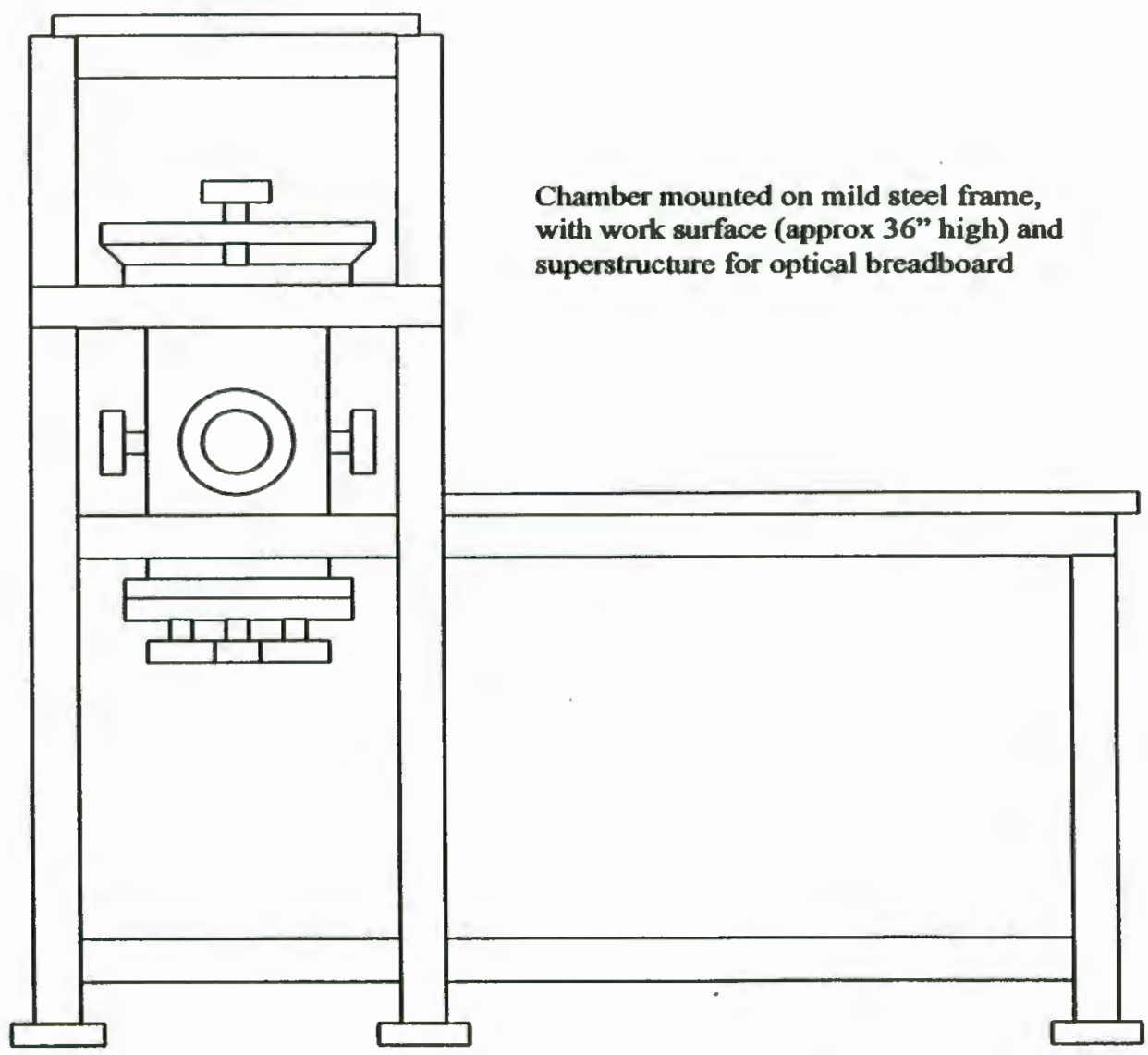




\section{Appendix B}

lllustrations of the interconnections between the DC motorized stages, the PC and the Motionmaster 2000 interface box and card.

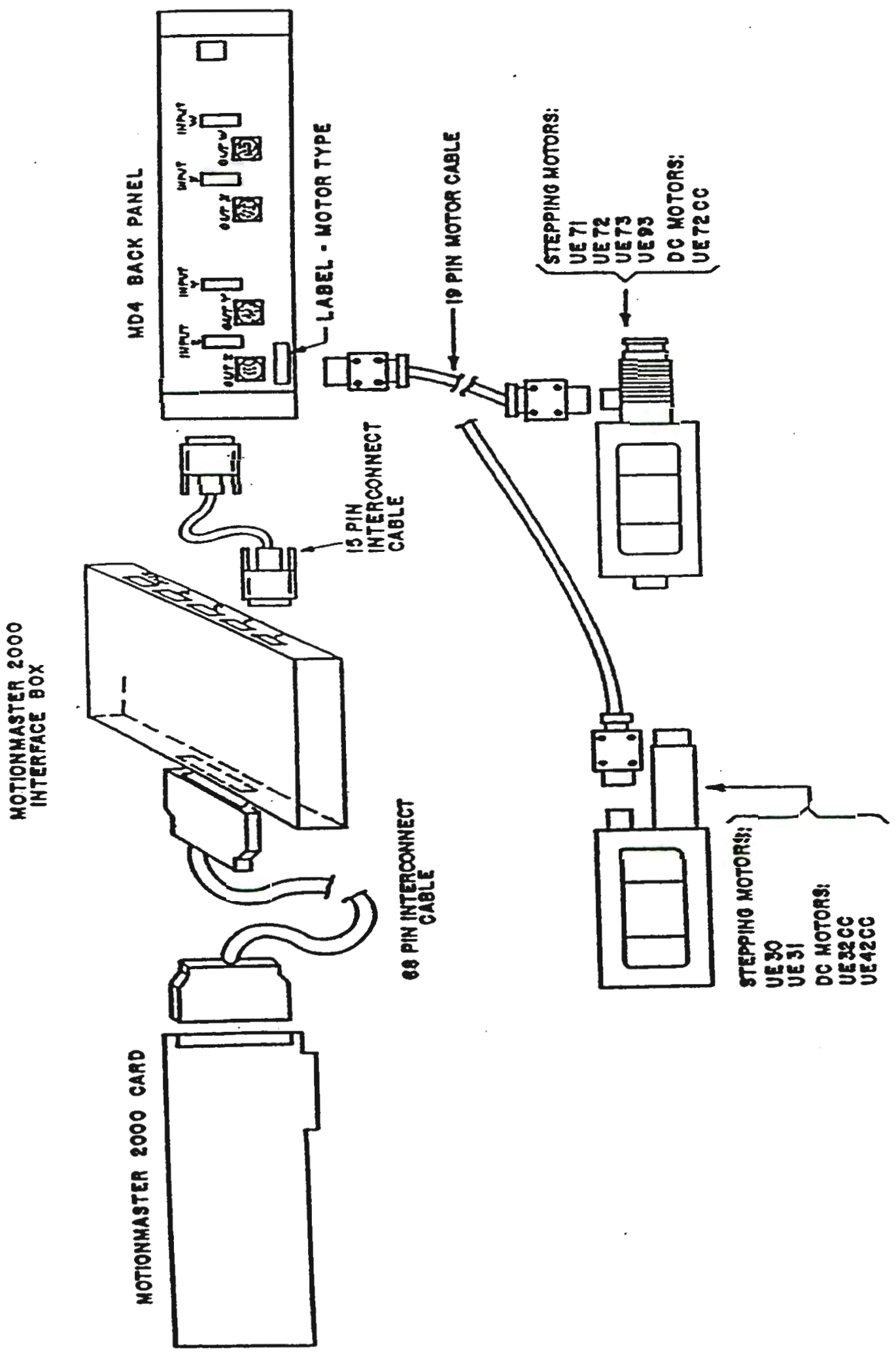




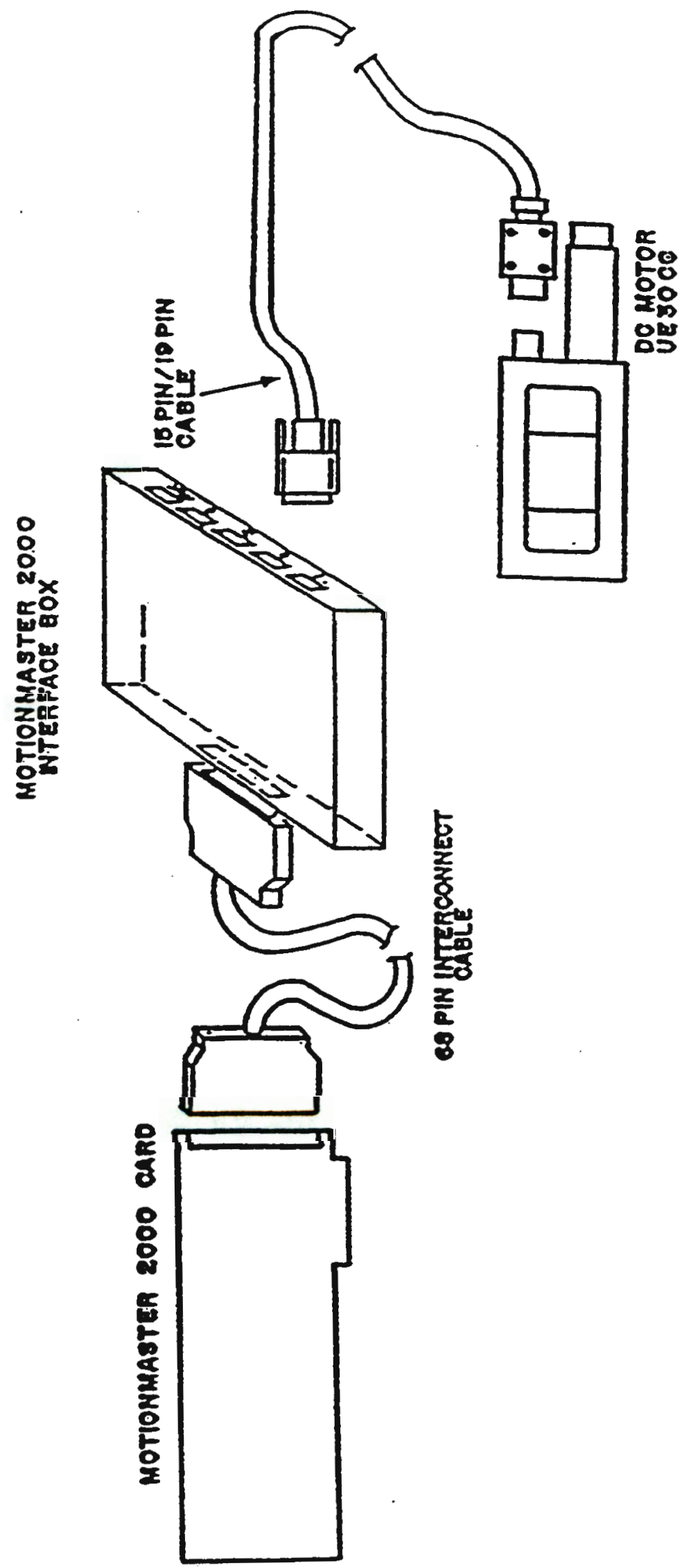

$\frac{0}{2}$ 


\section{Appendix C}

DC Motor Characteristics:

\begin{tabular}{|c|c|c|c|c|}
\hline Motor & $\begin{array}{c}\text { Mechanical } \\
\text { power }\end{array}$ & $\begin{array}{c}\text { Nominal Voltage } \\
(\mathrm{V})\end{array}$ & $\begin{array}{c}\text { Armature } \\
\text { Resistance } \\
(\Omega)\end{array}$ & $\begin{array}{c}\text { Tachometer } \\
(\mathrm{V} / \mathrm{Krpm})\end{array}$ \\
\hline UE16CC & 0,31 & 12 & 115 & - \\
\hline
\end{tabular}

Command Signals for UE16CC DC Motor:
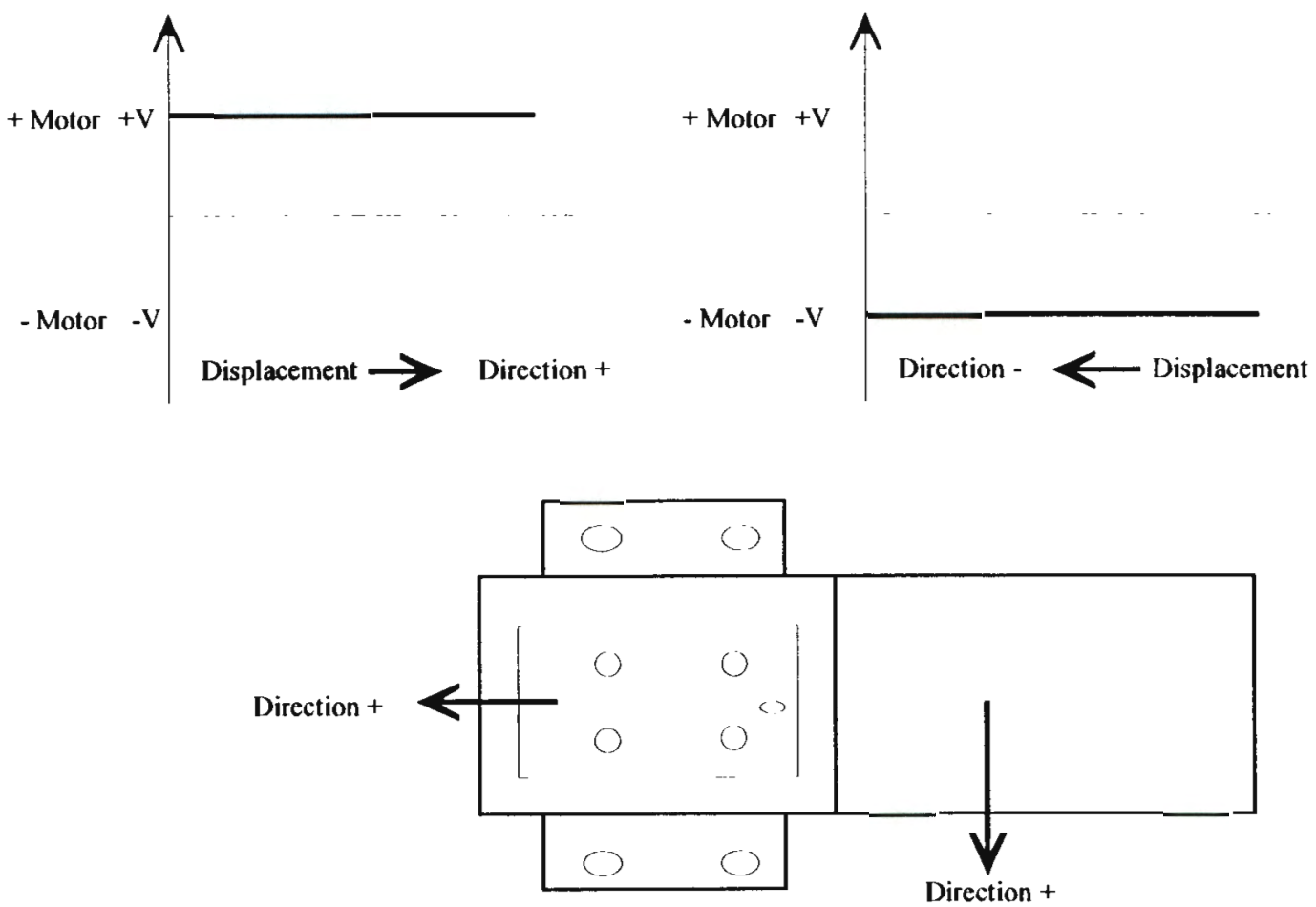
1. When the stage moves in + Direction, the + Motor voltage is higher than - Motor voltage.

2. When the stage moves in - Direction, the + Motor voltage is lower than - Motor voltage.

\section{Sensors Position:}

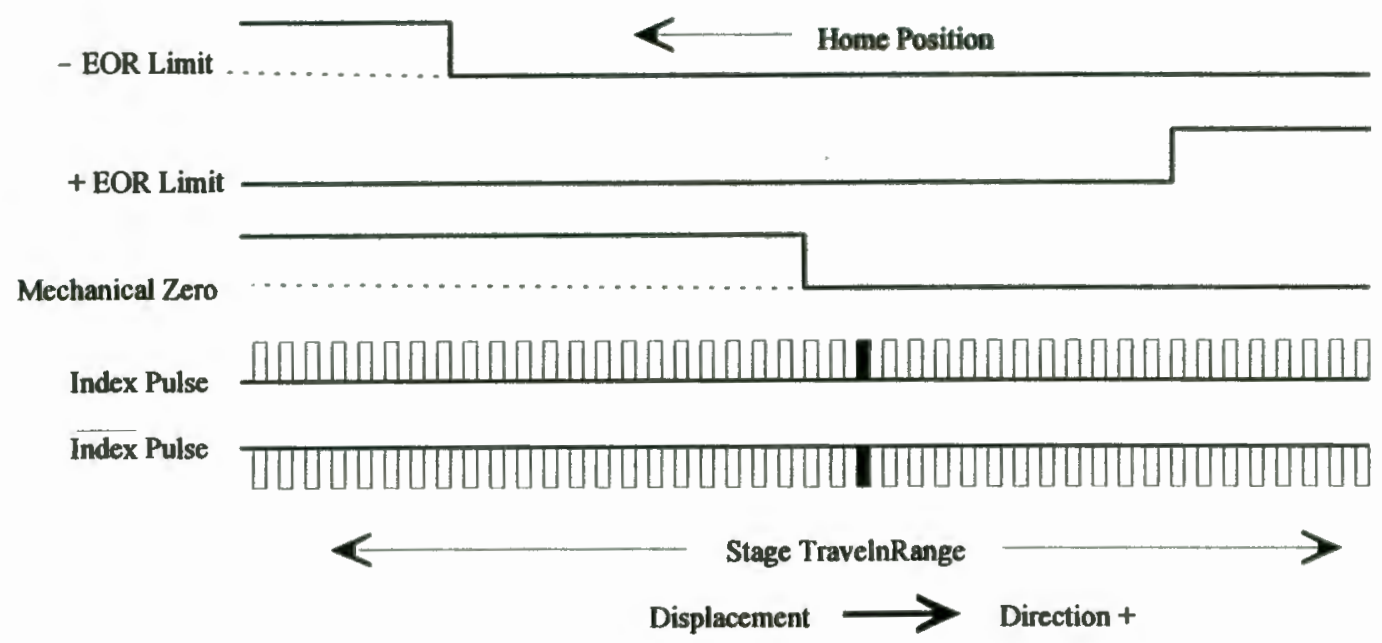

End -of-Run and Mechanical Zero are "Open Collector" type output signals. Their use needs a pull-up resistance connected to the power supply ( generally the power supply of the board where signals are sent).

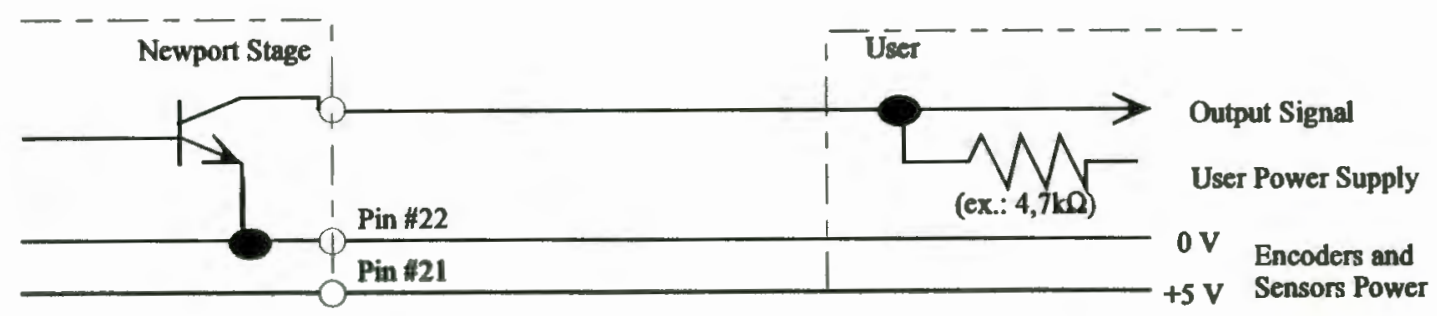

Index Pulse and Index Pulse are "differential pair" type output signals. Using these signals permits a high noise immunity. 

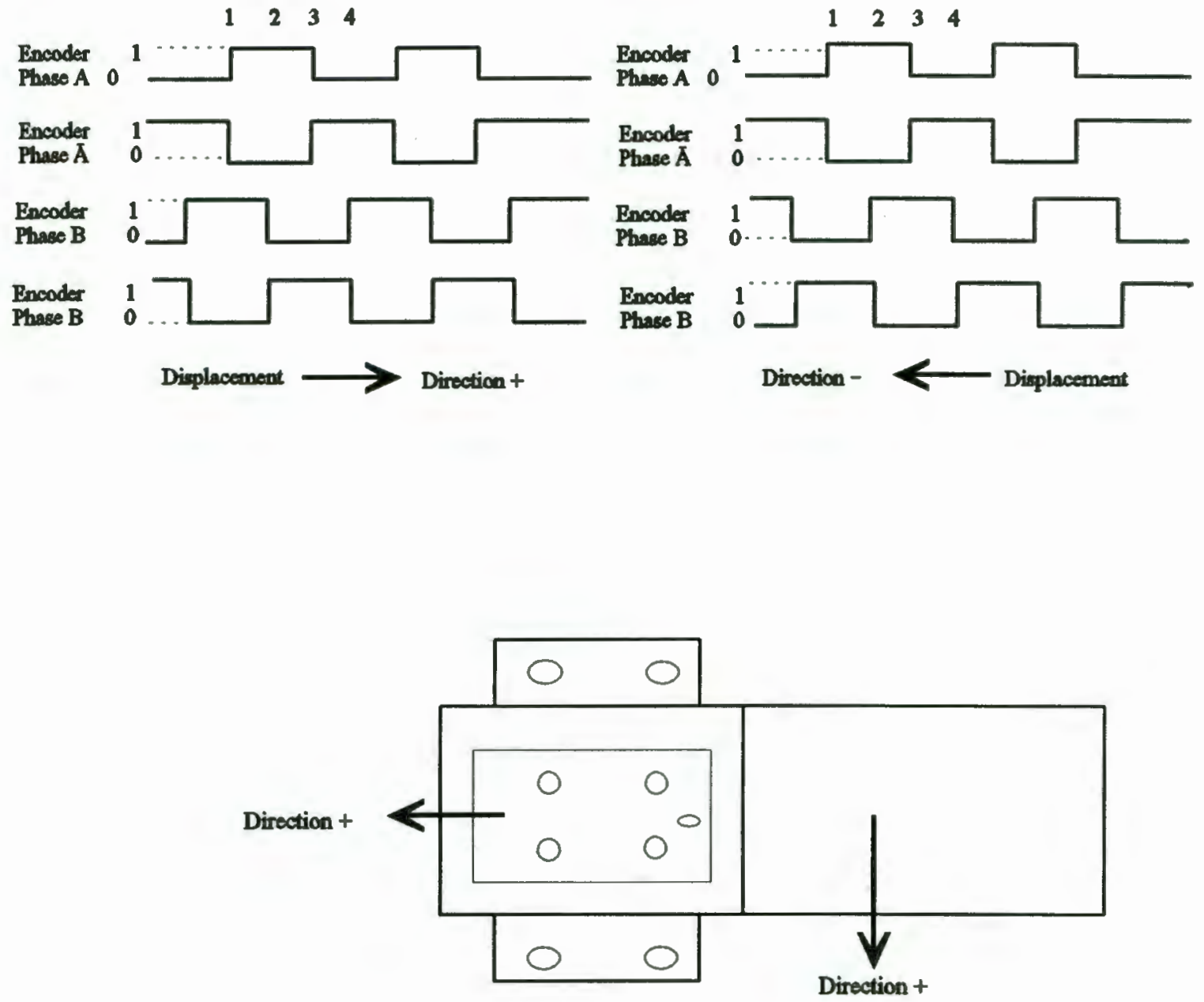

The incremental sensor operates following the photoelectric measurement principle, with a disk including slides. When the shaft turns, the sensor generates square signals in quadrature, sent to pins \#19, \#20, \#23 and \#24 of the 25-pin Sub-D connector. 


\section{Appendix D}

\section{PosItION SENSORS SEGMENTED (SPOT) SERIES}

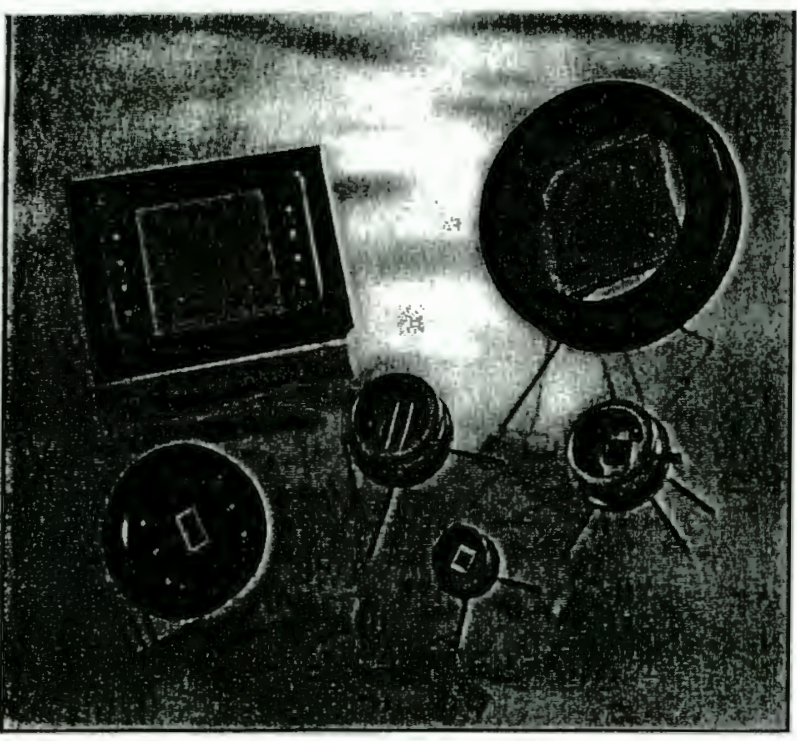

\section{DESIGNER'S NOTEBOOK}

The SPOT Series are common substrate pholodelectors segmented into cther two (2) or four (4) separate active areas. They are available with

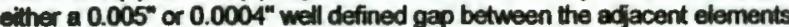
resulting in high response uniformity between the elements. The SPOT series are ideal for very accurate nulling or centering applications. Position information can be obtained when the light spot diameter is larger than the spacing between the cells.

Spectral response rango is from $350-1100 \mathrm{~nm}$. Notch or bandpass filters can be added to achieve epecific spectral responses.

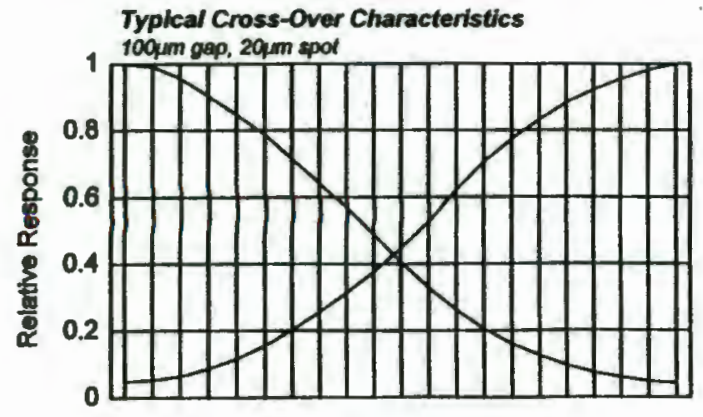

$1 \mathrm{div} .=10 \mathrm{~mm}$

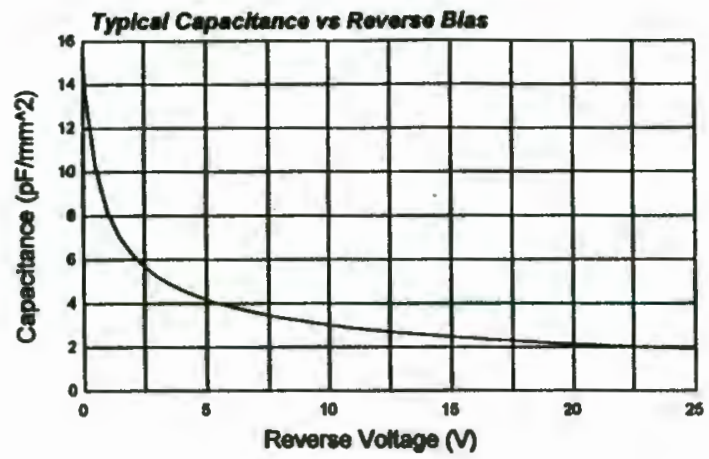

\section{APPLICATIONS \\ FEATURES}

Machine Tool Alignment

Position Measuring

Beam Centering

Surface Profiling

Targeting

Guidance Systems
High Accuracy

Excellent Resolution

High-Speed Response

Ultura Low Dark Current

Excellent Response Watch

High Stabllity over Time and

Temperature

These detectors exhbit excellent stability over time and temperature, fast response times necessary for high speed or putse operation, and position resolutions of better than $0.1 \mathrm{\mu m}$.

Maximum recommended power density is $10 \mathrm{~mW} / \mathrm{cm}^{2}$ and typical unilormity of response for a $1 \mathrm{~mm}$ diameter epot is $\pm 2 \%$.

The circuit on the opposite page represents a typical biasing and detection circuit set up for both bi and quad cells. For position calculations and further details, refer to "Photodiode Characteristics" section of the catalog.
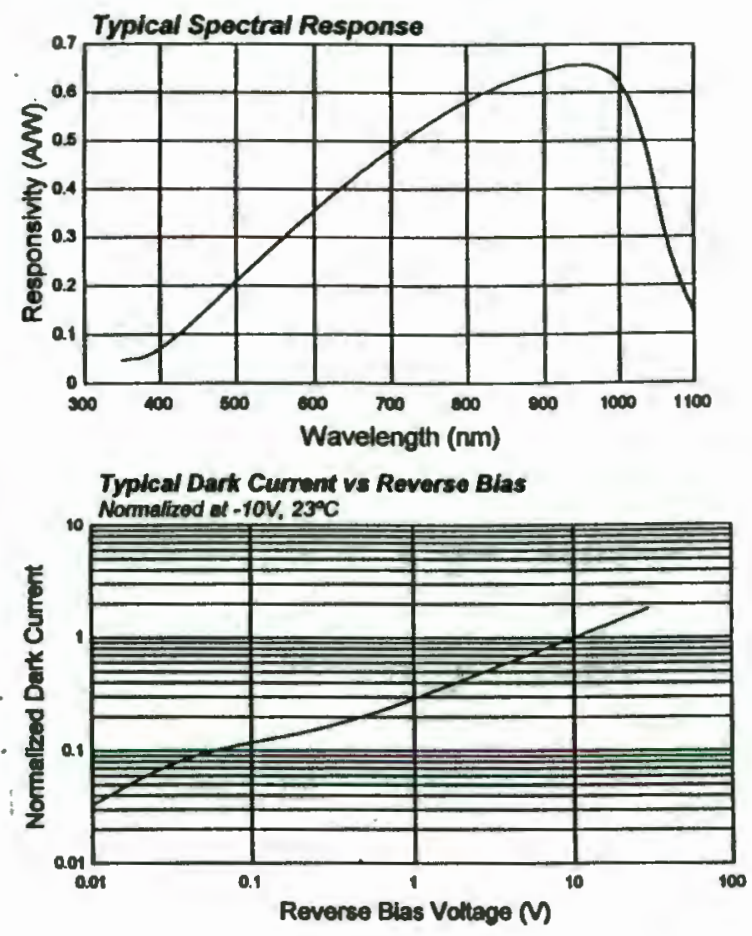
SEGMENTED PHOTODIODES

TYPICAL ELECTRO-OPTICAL SPECIFICATIONS AT $T_{A}=23^{\circ} \mathrm{C}$

\begin{tabular}{|c|c|c|c|c|c|c|c|c|c|c|c|c|c|c|}
\hline \multirow[t]{3}{*}{$\begin{array}{l}\text { Modol } \\
\text { Mo. }\end{array}$} & \multicolumn{2}{|c|}{$\begin{array}{l}\text { Active Area } \\
\text { Por Eloment }\end{array}$} & \multirow{3}{*}{ 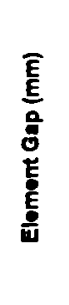 } & \multirow{2}{*}{\multicolumn{2}{|c|}{$\begin{array}{c}\begin{array}{c}\text { Rosponsivity } \\
\text { (Am) }\end{array} \\
\begin{array}{c}970 \\
\mathrm{~nm}\end{array}\end{array}$}} & \multirow{3}{*}{$\begin{array}{c}\begin{array}{c}\text { Capacltance } \\
\text { (Pf) }\end{array} \\
-10 \mathrm{~V} \\
\text { typ }\end{array}$} & \multirow{2}{*}{\multicolumn{2}{|c|}{$\begin{array}{c}\begin{array}{c}\text { Dark } \\
\text { Curront } \\
\text { (nA) }\end{array} \\
-10 \mathrm{~V}\end{array}$}} & \multirow{3}{*}{$\begin{array}{c}\begin{array}{c}\text { NEP } \\
(N / \text { (t) }\end{array} \\
\begin{array}{c}-10 \mathrm{~V} \\
970 \mathrm{~nm}\end{array} \\
\text { typ }\end{array}$} & \multirow{3}{*}{$\begin{array}{c}\text { Roverse } \\
\text { Vothage } \\
\text { (M) }\end{array}$} & \multirow{3}{*}{$\begin{array}{c}\begin{array}{c}\text { Rise Time } \\
\text { (nis) }\end{array} \\
\begin{array}{c}-10 \mathrm{~V} \\
780 \mathrm{~nm} \\
80 \Omega\end{array} \\
\text { typ }\end{array}$} & \multicolumn{2}{|c|}{$\begin{array}{l}\text { Tomp } \\
\text { Rangse } \\
\text { ("C) }\end{array}$} & \multirow[t]{3}{*}{$\begin{array}{l}\text { Package } \\
\text { Stylo T }\end{array}$} \\
\hline & \multirow{2}{*}{$\frac{\widehat{E}}{\bar{E}}$} & \multirow{2}{*}{$\begin{array}{l}\frac{E}{E} \\
\frac{\delta}{E} \\
E \\
E \\
\underline{E}\end{array}$} & & & & & & & & & & \multirow{2}{*}{ 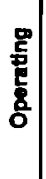 } & \multirow{2}{*}{ 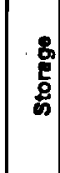 } & \\
\hline & & & & $\min$ & typ & & typ & $\max$ & & & & & & \\
\hline \multicolumn{15}{|c|}{ 'TWO-ELEMENT' SERIES, METAL PACKAGE } \\
\hline 8POT-2D & 3.3 & $1.3 \times 2.5$ & 127 & \multirow{3}{*}{0.60} & \multirow{3}{*}{0.65} & 11 & 0.15 & 2.0 & $1.1 \mathrm{e}-14$ & \multirow{3}{*}{30} & 5 & \multirow{3}{*}{$\begin{array}{l}8 \\
\frac{8}{+} \\
1 \\
\stackrel{y}{y}\end{array}$} & \multirow{3}{*}{$\begin{array}{l}\stackrel{n}{2} \\
\stackrel{+}{ \pm} \\
\vdots \\
\stackrel{p}{p}\end{array}$} & $38 /$ TO-5 \\
\hline SPOT-2019 & 0.7 & $0.6 \times 1.2$ & .013 & & & 3 & 0.05 & 1.0 & 6.2 e -15 & & 7 & & & $37 / \mathrm{TO}-18$ \\
\hline SPOT.30 & 2.8 & $0.6 \times 4.6$ & .025 & & & 7 & 0.13 & 2.0 & $9.9 e-15$ & & 4 & & & 38 / TO- 5 \\
\hline \multicolumn{15}{|c|}{ 'FOUR-ELEMENT' SERIES, METAL PACKAGE } \\
\hline SPOT-4D & 1.61 & 1.389 & .127 & \multirow{4}{*}{0.60} & \multirow{4}{*}{0.65} & 5 & 0.10 & 1.0 & 8.7 e -15 & \multirow{4}{*}{30} & \multirow{4}{*}{3} & \multirow{4}{*}{ 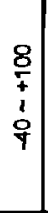 } & \multirow{4}{*}{ 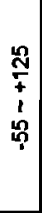 } & \multirow{2}{*}{$38 /$ TO-5 } \\
\hline 8POT-40लm & 0.25 & 0.589 & .013 & & & 1 & 0.01 & 0.5 & $2.8 \mathrm{e}-15$ & & & & & \\
\hline SPOT-O & \multirow{2}{*}{19.6} & \multirow{2}{*}{10,7} & .102 & & & 60 & 0.50 & 100 & $19 \mathrm{e}-14$ & & & & & \multirow{2}{*}{$40 /$ LoProf } \\
\hline SPOT-EOv & & & .010 & & & . & 0.00 & 8.0 & 1.008 & & & & & \\
\hline \multicolumn{15}{|c|}{ PLASTIC PACKAGE $\$$} \\
\hline FuL-S200 & 3.3 & $1.3 \times 2.5$ & .127 & & & 11 & 0.15 & 2.0 & $1.1 \mathrm{e}-14$ & & 5 & 8 & $?$ & \\
\hline FL-SADG & 1.6 & $1.3 \mathrm{sq}$ & .127 & $0 \times 0$ & 065 & 5 & 0.10 & 1.0 & 8.7 e -15 & a & & $i$ & í & \\
\hline FLLSS9DG & 19.6 & $10 \downarrow \ddagger$ & .102 & & & 60 & 0.50 & 10.0 & $1.9 e-14$ & & - & & & 15/Plastic \\
\hline
\end{tabular}

5 The photodiode chips in "FIL" series are isolated in a low profile plastic package. The have a large field of view as well as "in fine" pins. FiL-S2DG has the same photodiode as SPOT-2D, FIL-S4DG has the same photodiode as SPOT-4D and FIL-S9DG has the same photodiode chip as SPOT-9D.

f Overall Diameter (All four Quads)

I For mechanical drawings please refer to pages 57 thru 67.

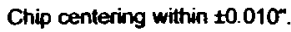

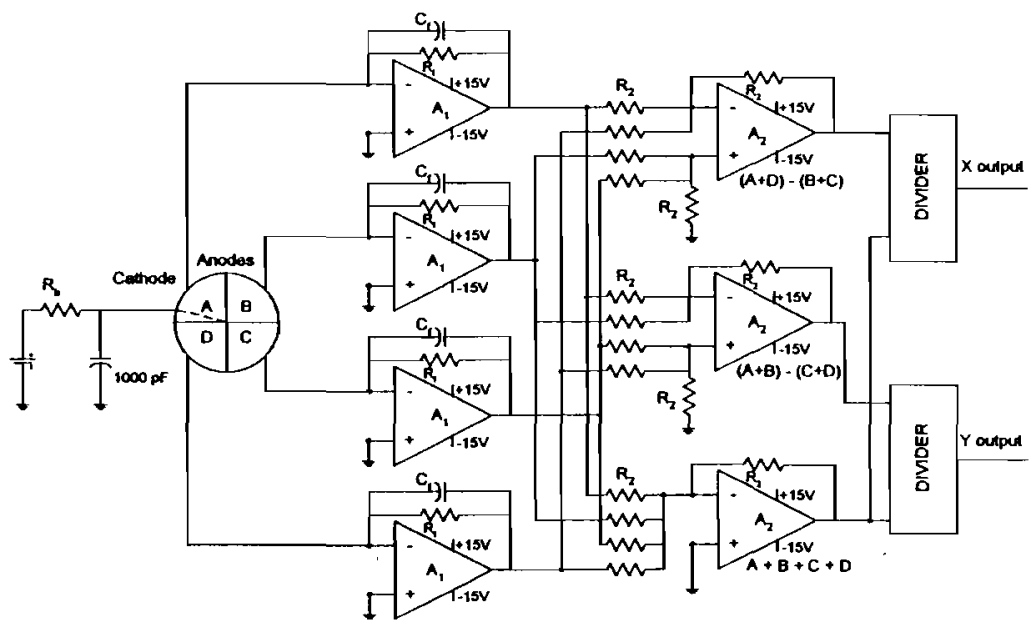

For further details refer to the Photodiode Characteristic section of the catalog. 


\section{Appendix E}

When the PSD moves left or right from centre the change in radiant incidance on the relevant quadrant will change according to the area of the relevant quadrant exposed to the incident laser beam. The proof for the variation in the area of flux distribution $\left(\mathrm{m}^{2}\right)$ follows below.

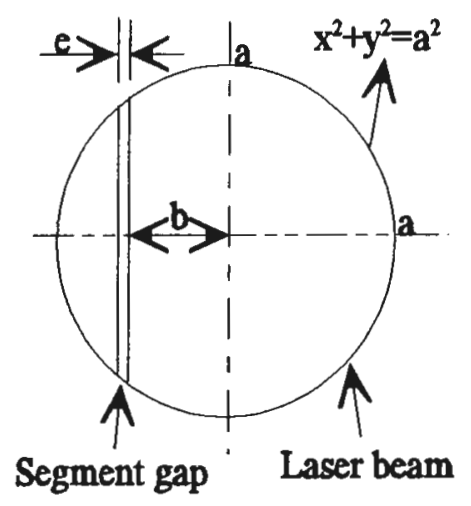

Proof:

Segment area $A_{s}$

$$
\begin{aligned}
A_{S} & =2 \pi \int_{e+b}^{b} y d x \\
& =2 \pi \int_{e+b}^{b} \sqrt{a^{2}-x^{2}} d x \\
& =2 \pi \int \sqrt{a^{2}\left(1-\sin ^{2} \theta\right)} \cdot a \cos \theta d \theta \\
& =2 \pi a^{2} \int \cos ^{2} \theta d \theta \\
& =2 \pi \mathrm{a}^{2} \int \frac{1}{2}(1+\cos 2 \theta) d \theta \\
& =\pi \mathrm{a}^{2}\left[\theta+\frac{1}{2} \sin 2 \theta\right] \\
& =\pi \mathrm{a}^{2}[\theta+\sin \theta \cdot \cos \theta] \\
& =\pi \mathrm{a}^{2}\left[\sin ^{-1} \frac{x}{a}+\frac{x}{a} \cdot \frac{\sqrt{a^{2}-x^{2}}}{a}\right]_{a+b}^{b} \\
& =\pi\left[\mathrm{a}^{2} \sin ^{-1} \frac{x}{a}+x \sqrt{a^{2}-x^{2}}\right]_{a+b}^{b} \\
& =\pi\left\{\mathrm{a}^{2} \sin ^{-1} \frac{b}{a}+b \sqrt{a^{2}-b^{2}}-\left[a^{2} \sin ^{-1} \frac{b+e}{a}+(b+e) \cdot \sqrt{a^{2}-(b+e)^{2}}\right]\right\}
\end{aligned}
$$




\section{Appendix F}

\section{Subcurve VI - Frontpanel}

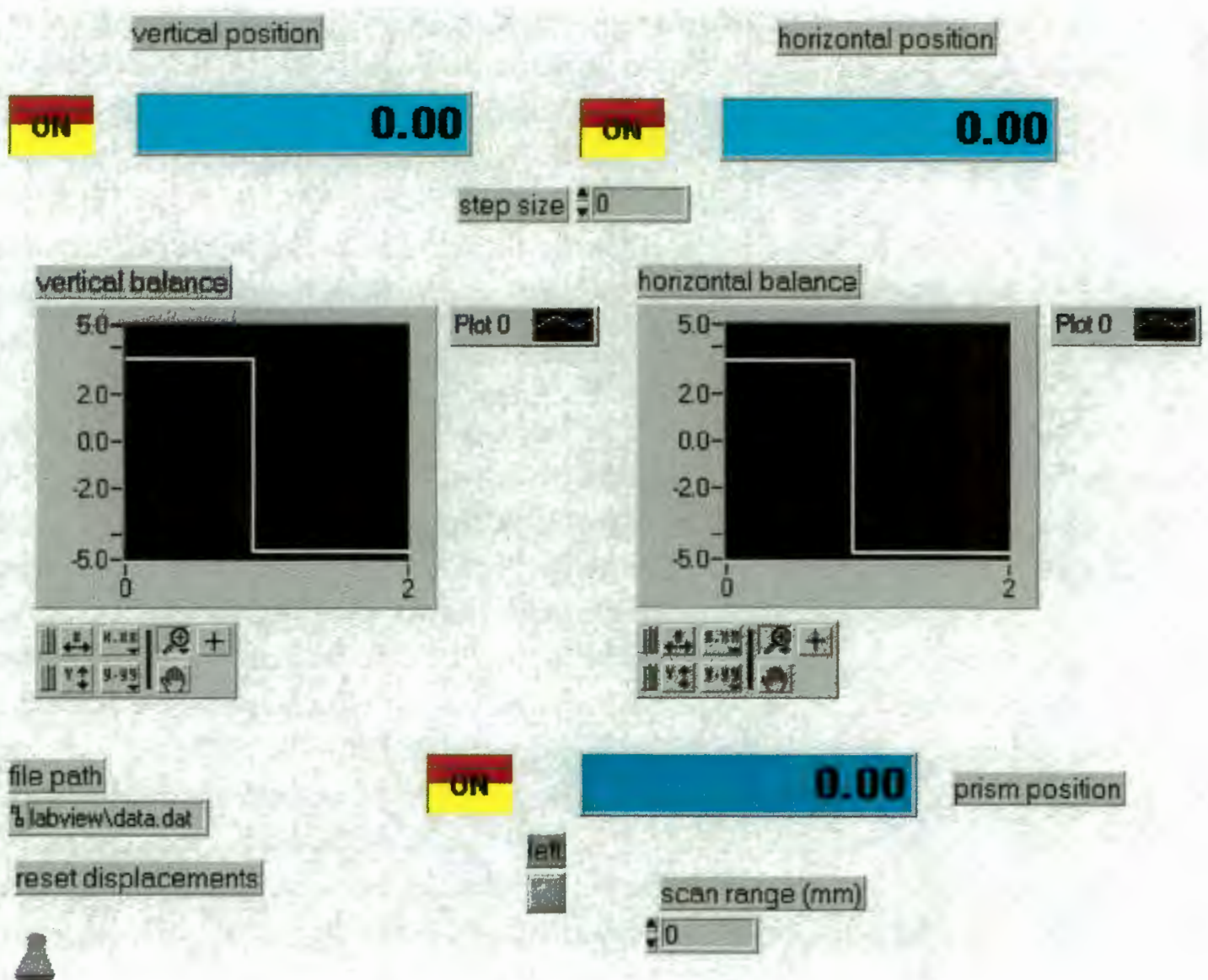




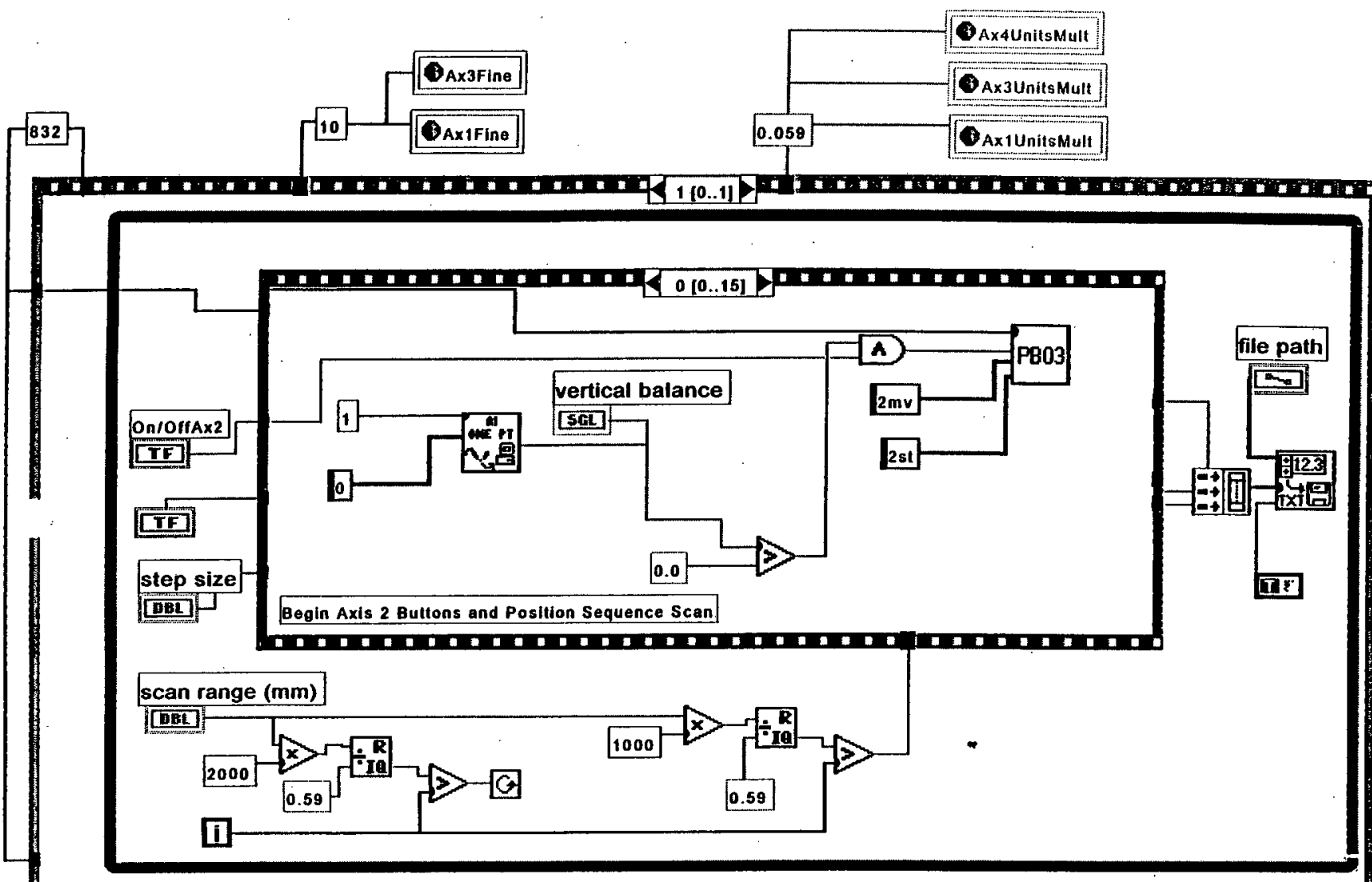

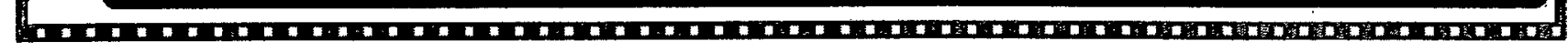

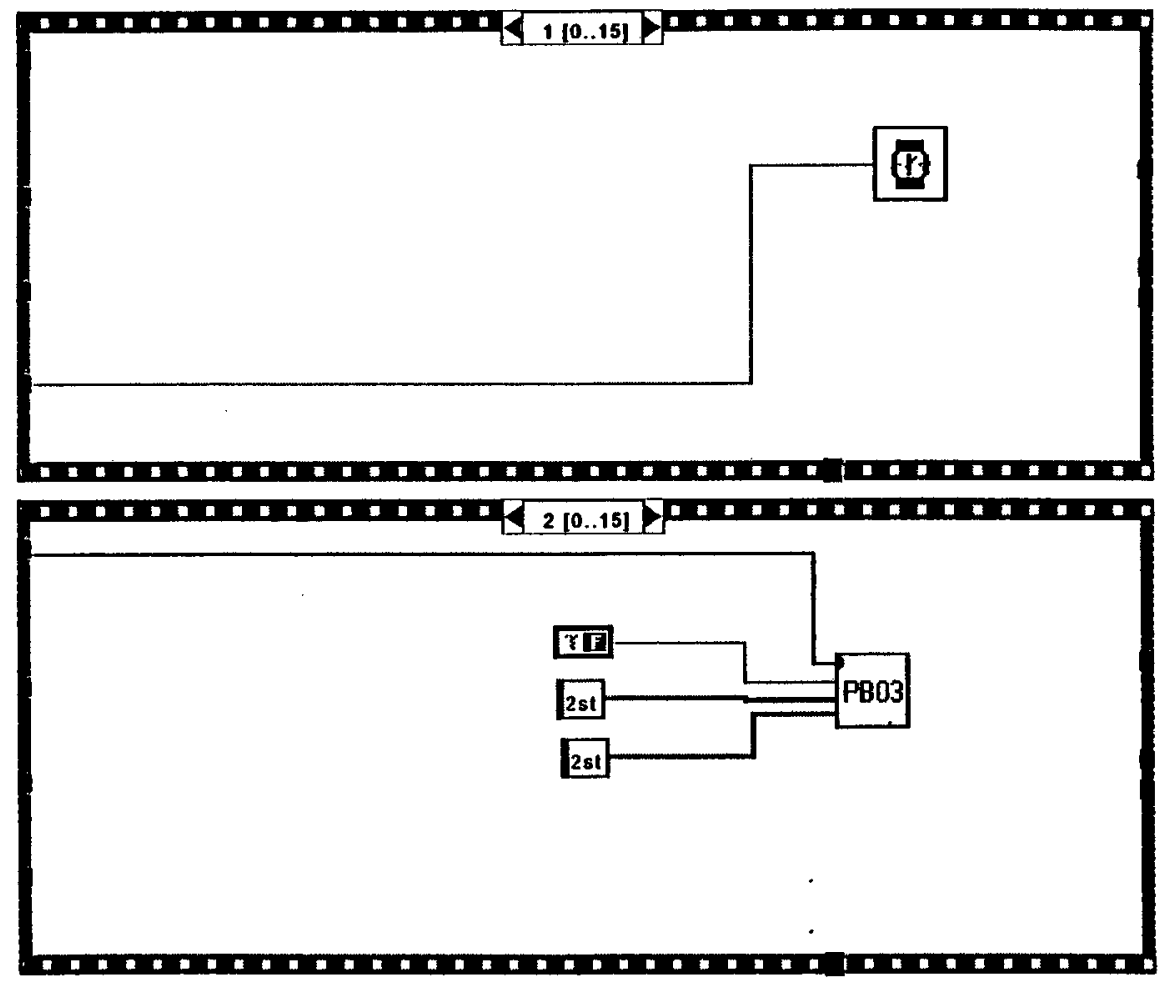




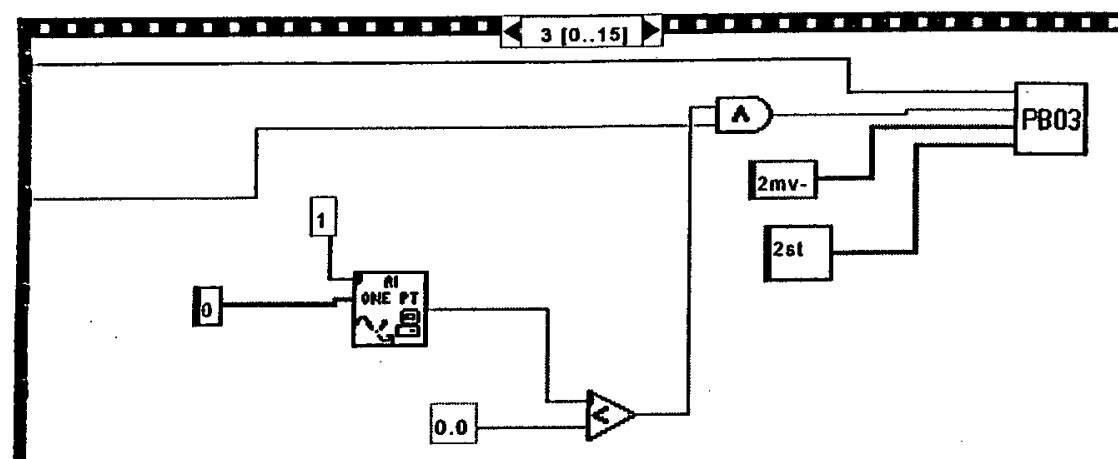

قy

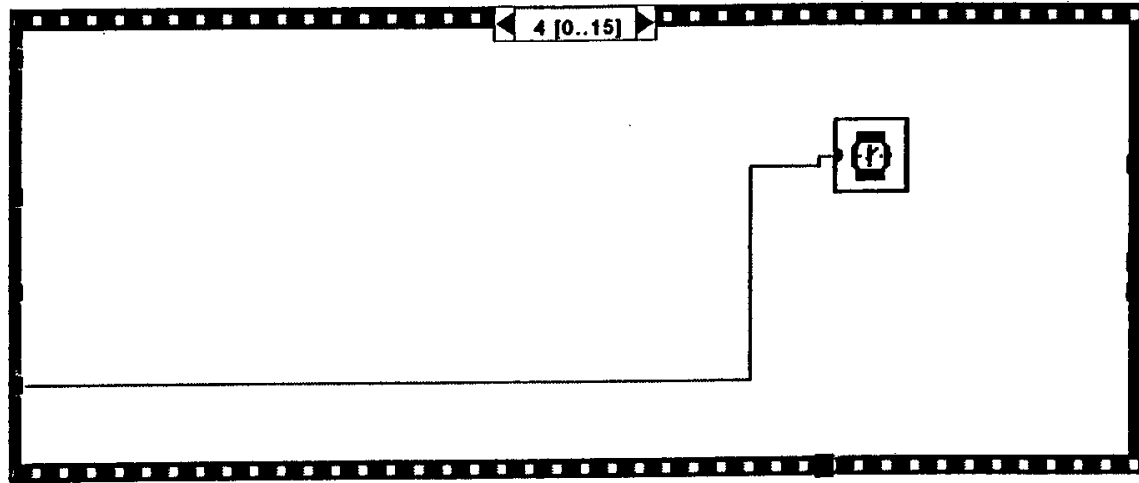
(10.15]

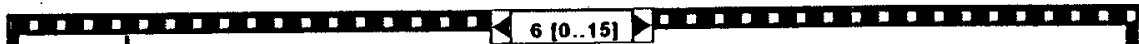

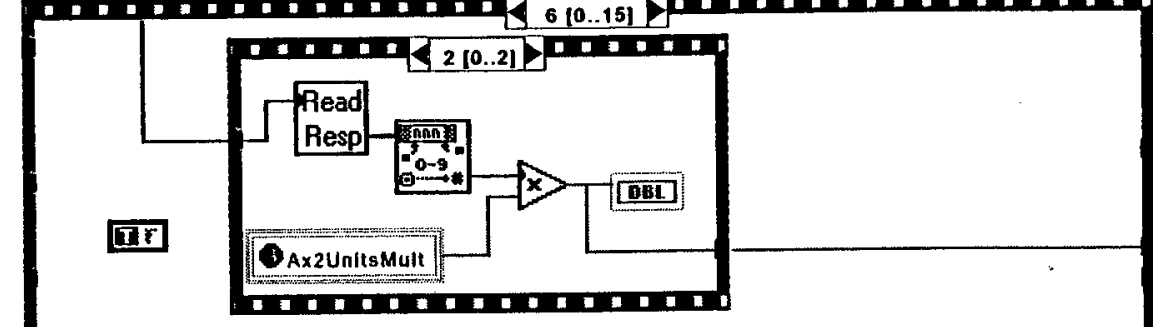

|

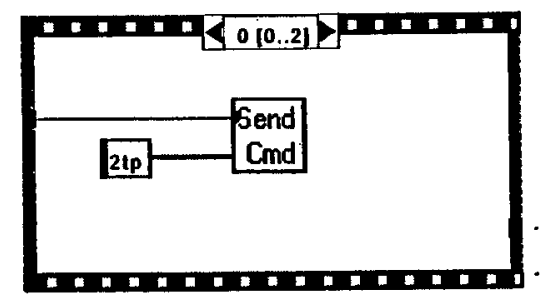




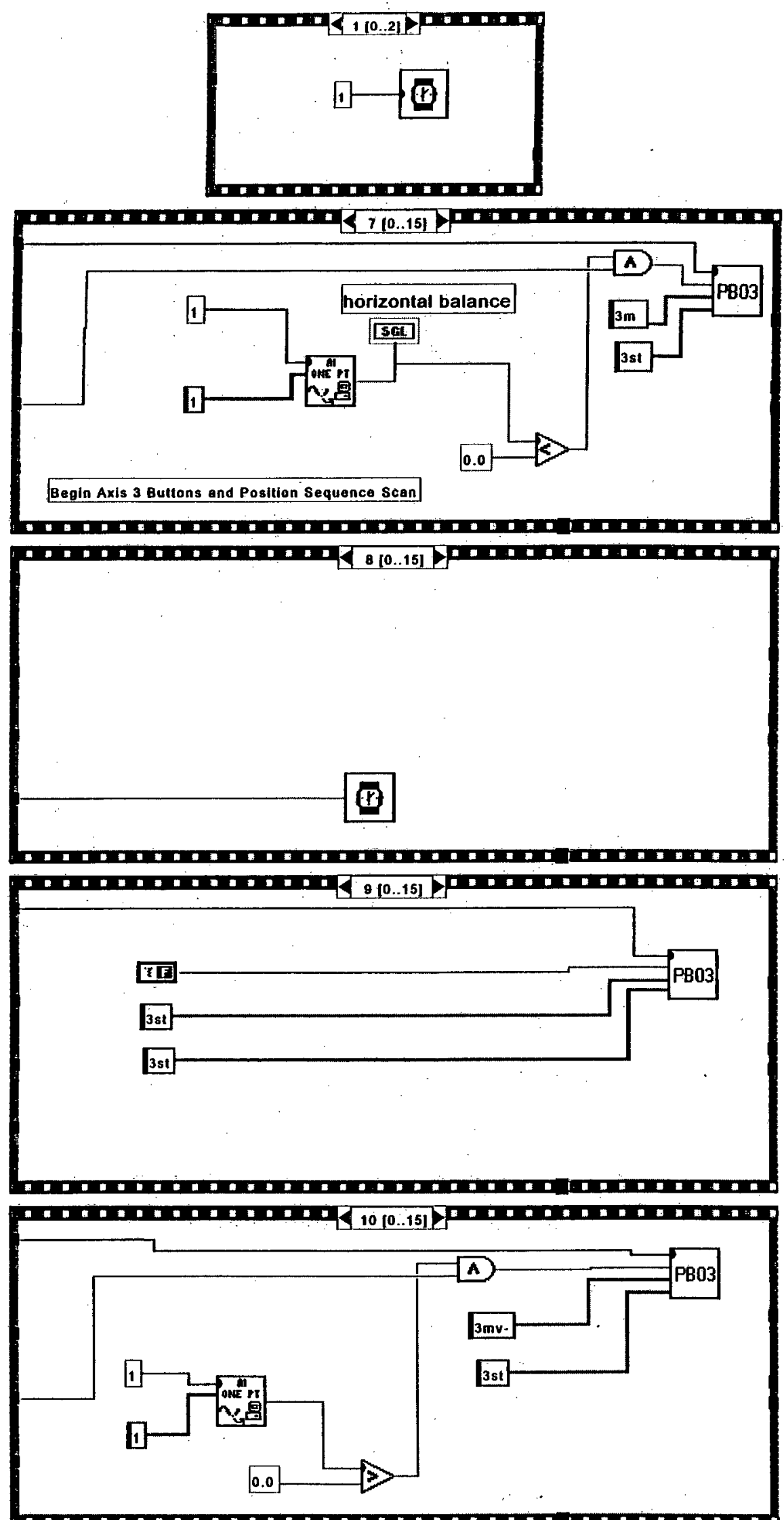




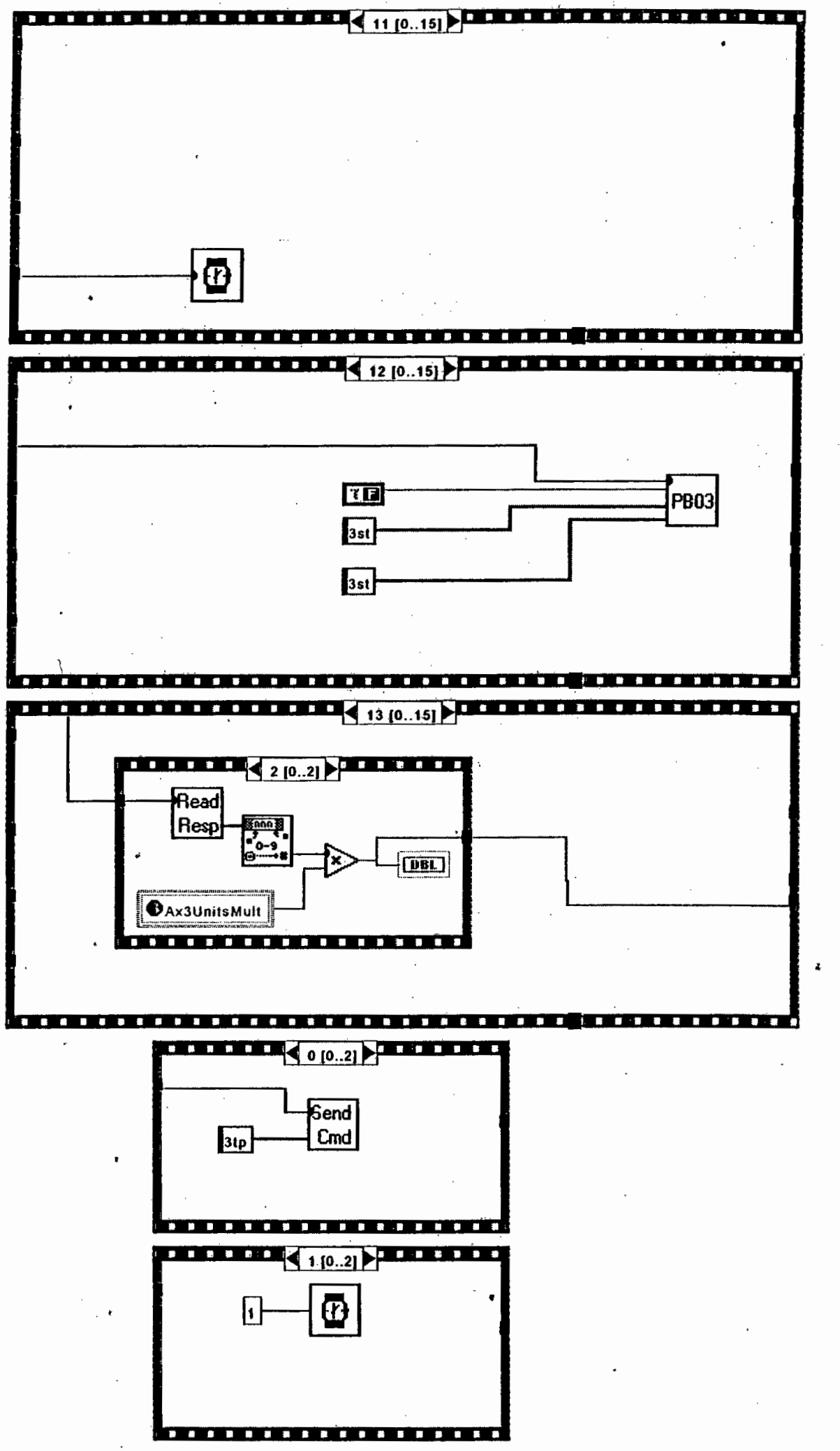




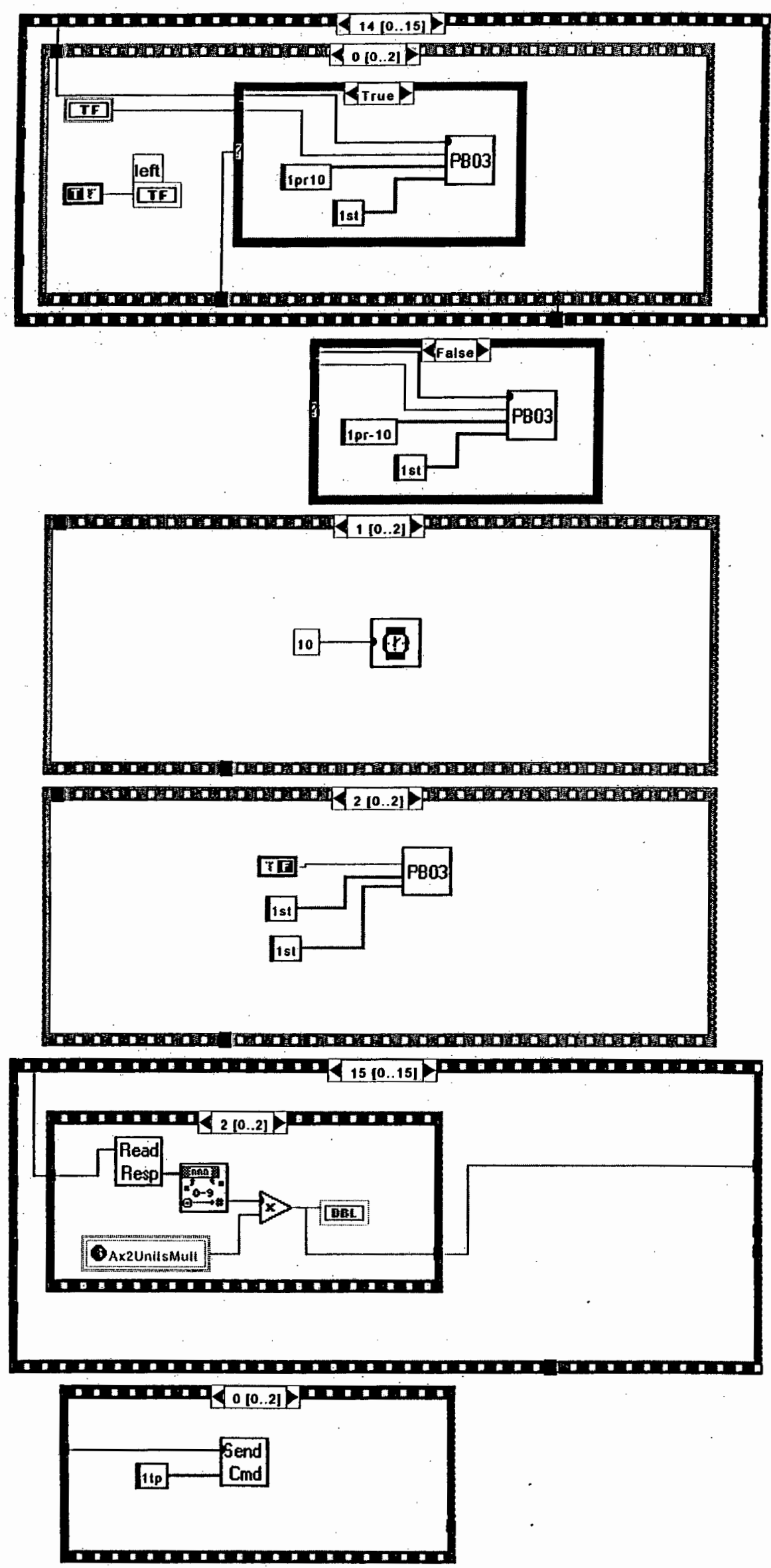




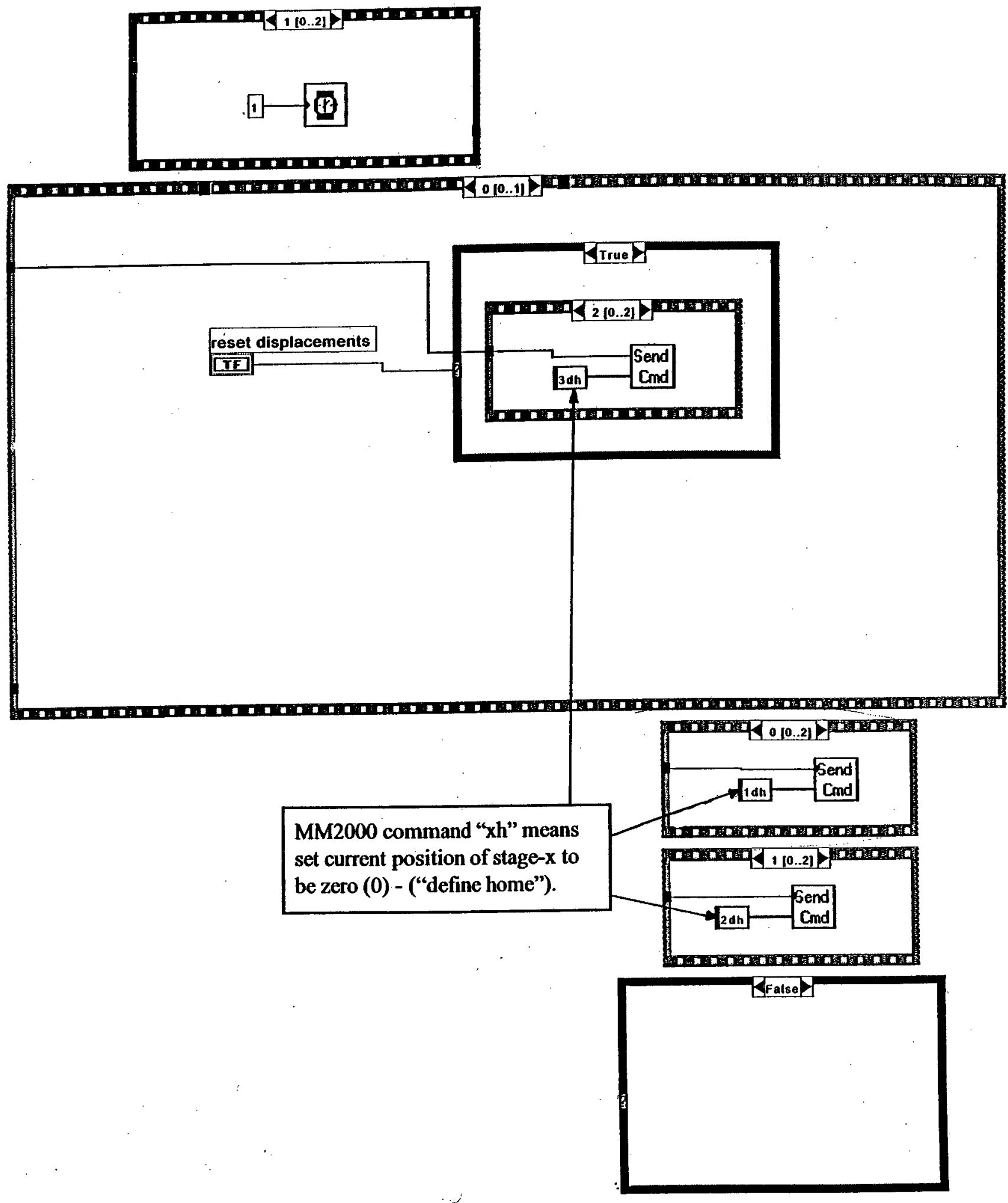

